NISTIR 89-3925

\title{
DEVELOPMENT OF A \\ COMPUTER-CONTROLLED \\ HOT-DEFORMATION APPARATUS AT NIST
}

Yi-Wen Cheng

Yair Rosenthal

Harry I. McHenry

National Institute of Standards and Technology

U.S. Department of Commerce

Boulder, Colorado 80303-3328

October 1989 

NISTIR 89-3925

\section{DEVELOPMENT OF A \\ COMPUTER-CONTROLLED \\ HOT-DEFORMATION APPARATUS \\ AT NIST}

Yi-Wen Cheng

Yair Rosenthal ${ }^{\dagger}$

Harry I. McHenry

Materials Reliability Division

Materials Science and Engineering Laboratory

National Institute of Standards and Technology

Boulder, Colorado 80303-3328

October 1989

${ }^{\dagger}$ Guest worker, on leave from Nuclear Research Center-Negev, Beer Sheva, Israel

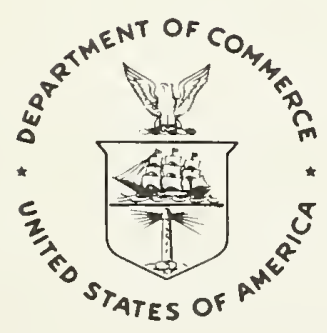

DEPARTMENT OF COMMERCE, Robert A. Mosbacher, Secretary

NATIONAL INSTITUTE OF STANDARDS AND TECHNOLOGY, Raymond G. Kammer, Acting Director 

LIST OF FIGURES . . . . . . . . . . . . . . . . . . . . . . . . . . V v

ABSTRACT . . . . . . . . . . . . . . . . . . . . . . . vii

I. INTRODUCTION . . . . . . . . . . . . . . . . . . . . . . . . 1

II. DESCRIPTION OF THE HOT-DEFORMATION APPARATUS . . . . . . . . . 3

Loading System . . . . . . . . . . . . . . . . 3

Heating and Control System . . . . . . . . . . . . . 5

Cooling and Control System . . . . . . . . . . . . . 6

Vacuum System . . . . . . . . . . . . . . . . 6

Assembly for Dilation Measurement After Deformation . . . . . . 7

Computer and Peripherals . . . . . . . . . . . . . . 8

Computer Programs for System Control, Data Acquisition, and Data Analysis . . . . . . . . . . . . . . . . 9 9

III. EXAMPLES OF USING THE APPARATUS . . . . . . . . . . . . . . . . 13

Direct-Quenching Simulation of ASTM A710 Steel . . . . . . . . 13

Studies of Directly Cooled Forging Steels . . . . . . . . . . 17

IV. CONCLUSIONS AND SUMMARY . . . . . . . . . . . . . . . . . . . 21

V. ACKNOWLEDGMENTS . . . . . . . . . . . . . . . . . . . . . . . . 23

VI. REFERENCES . . . . . . . . . . . . . . . . . . . . . . . . . . . 24

APPENDIX 1. Computer Program Listing for System Control and

Data Acquisition . . . . . . . . . . . . . . 52

APPENDIX 2. Computer Program Listing for

Post-Test Data Analysis . . . . . . . . . . . 72 
Page

1. Thermal and mechanical treatments in a thermomechanical processing (TMP) simulation. . . . . . . . . . . . . .

2. Hot-deformation apparatus. (a) overall view; (b) interior of the vacuum chamber.

3. The basic components of the hot-deformation apparatus. . . . .

4. Drawing of the load train and the device for measurement of length change during cooling and phase transformation.

5. The responses of the servohydraulic actuator to commands of various strain rates $(\dot{\epsilon}) ;$ (a) $\dot{\epsilon}=0.97 \mathrm{~s}^{-1}$; (b) $\dot{\epsilon}=4.8 \mathrm{~s}^{-1}$; (c) $\dot{\epsilon}=9.5 \mathrm{~s}^{-1} ;$ (d) $\dot{\epsilon}=13.5 \mathrm{~s}^{-1} ;$ (e) $\dot{\epsilon}=17 \mathrm{~s}^{-1}$; (f) $\dot{\epsilon}=19.2 \mathrm{~s}^{-1}$; (g) $\dot{\epsilon}=24 \mathrm{~s}^{-1}$.

6. Example of length change (dilation) vs. temperature during continuous cooling and phase transformation of a steel specimen.

7. The detailed flow chart of the program for system control and data acquisition.

8. Computer command signals and the corresponding servohydraulic stroke responses at a strain rate of $10 \mathrm{~s}^{-1}$.

9. The flow diagram of the post-test analysis program.

10. Pictures of the specimen used in the direct-quenching simulation study; before and after deformation.

11. Results of double-deformation test on ASTM A710 steel. (a) no softening in the second compression indicating no recrystallization occurred; (b) softening in the second compression indicating some degree of recrystallization occurred.

12. Microstructures of ASTM A710 steel specimens with different thermomechanical treatments; (a) and (b): reaustenitized at $910^{\circ} \mathrm{C}$ then cooled slowly and gas quenched, respectively, without deformation; (c) through (e): treatments a through c described in table 1. Etch: 38 nital. . . . . . . . . . . . . . .

13. Continuous-cooling-transformation (CCT) diagram for ASTM A710 steel; from Ref. 23.

14. Schematic illustration of increasing acicular ferrite (granular bainite) hardenability by shifting the polygonal ferrite nose to the right (shaded area).

15. Variation of microstructures from (a) near the surface and (b) at the middle of the CR-DQ specimen. 
16. True $\sigma-\epsilon$ curves obtained in simulated CR-DQ experiments (see table 1); (a) treatment a in Table 1; (b) treatment $c$ in table 1 .

17. Correlation of yield strengths in tension and yield strengths in compression. Results of tension and compression at one strength level were obtained from the same steel plate. . . . . . . . . 44

18. Correlation of tensile strengths with Knoop hardness numbers (numerical data taken from Ref. 27). . . . . . . . . . . . 45

19. The CCT diagram of microalloyed 1522 forging steel. . . . . . . 46

20. Microstructures of 1522 microalloyed steel; (a) martensite after fast cooling; (b) bainite after slow cooling. . . . . . . . . .

21. Determination of phase-transformation temperatures using the seven-point incremental polynomial technique.

$\mathrm{B}_{\mathrm{S}}$ : bainite starts; $\mathrm{B}_{\mathrm{f}}$ : bainite finishes; $\mathrm{M}_{\mathrm{S}}$ : martensite starts;

$\mathrm{M}_{\mathrm{f}}$ : martensite finishes. . . . . . . . . . . . . . . . . . .

22. True $\sigma-\epsilon$ characteristic of 1522 microalloyed steel at $1093^{\circ} \mathrm{C}$

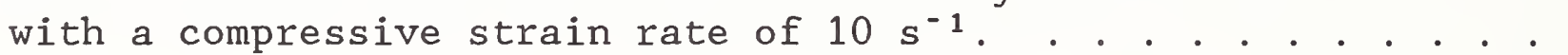

23. The CCT diagram of the 1141 microalloyed forging steel.

Dashed line is the typical cooling rate found in a forging

without forced cooling (Ref. 31).

24. Microstructures of the microalloyed 1141 steel with

different cooling rates. (a) ferrite plus pearlite;

(b) pearlite-ferrite (Widmanstatten) plus small portion of bainite;

(c) bainite plus small portion of martensite;

(d) martensite plus small portion of bainite. 
DEVELOPMENT OF A COMPUTER-CONTROLLED

HOT-DEFORMATION APPARATUS AT NIST

\author{
Yi-Wen Cheng \\ Yair Rosenthal* \\ Harry I. McHenry
}

\begin{abstract}
Materials Reliability Division
National Institute of Standards and Technology

Boulder, CO 80303
\end{abstract}

This report describes a computer-controlled hot-deformation apparatus suitable for thermomechanical-processing (TMP) simulation of forging and steel plates. The apparatus was designed and built at the National Institute of Standards and Technology, and has the following main features: a servohydraulic load frame with a $250 \mathrm{kN}$ capacity in tension or compression; a variable-actuator traveling speed up to $55 \mathrm{~mm} \cdot \mathrm{s}^{-1}$; a multiple-strike capability with controllable displacements and strain rates; a maximum heating rate of $150^{\circ} \mathrm{C} \cdot \mathrm{s}^{-1}$ with a $10 \mathrm{~kW}$ induction heater (for a cylindrical steel specimen $9 \mathrm{~mm}$ in diameter and $18 \mathrm{~mm}$ in height); a maximum cooling rate of $25^{\circ} \mathrm{C} \cdot \mathrm{s}^{-1}$ with helium-gas cooling; and vacuum to $1.33 \times 10^{-3} \mathrm{~Pa}\left(1 \times 10^{-5}\right.$ Torr $)$ within $25 \mathrm{~min}$. Source codes of the computer programs that perform system control, data acquisition, and data analysis are included in this report. The apparatus has been used to perform the direct-quenching simulation of the ASTM A710 plate steel, and forging simulation of the directly cooled microalloyed AISI 1522 and 1141 steels. Results of these studies are presented.

Key words: computer control; continuous-cooling transformation; controlled rolling; direct quenching; forging; high-strength low-alloy steels; hotdeformation apparatus; microalloyed steels; physical simulation; thermomechanical processing.

* Guest worker, on leave from Nuclear Research Center-Negev, Beer Sheva, Israel. 



\section{INTRODUCTION}

Over the last twenty years, one of the most significant advances in the steel industry has been the development and production of thermomechanically processed (TMP) high-strength low-alloy (HSLA) steel plates, which offer an excellent combination of strength, toughness, and weldability. Production schedules for TMP plates require careful control over each step including slab reheating, number of rolling passes, deformation and temperature for each pass, and cooling conditions throughout rolling. Numerous experiments are required to optimize these parameters for a new process or a new alloy system. Experiments in a pilot-scale rolling mill, as has been typically done in the past, are time consuming and costly, and measurements of rolling parameters are sometimes difficult. As a result, several small-scale laboratory simulation techniques, such as cam plastometry [1], torsion [2], and planestrain [3] or axisymmetrical [4] hot compression have been developed to alleviate the problem. Small-scale laboratory simulations offer the obvious advantages of economy, versatility, and reproducibility.

Small-scale laboratory apparatuses have been used for the following studies:

To study the static recrystallization of austenite between intervals of hot working [5];

To estimate the hot-deformation strength of austenite during controlled rolling in a plate mill [6];

To study dynamic recrystallization [7];

To determine the nonrecrystallization temperature of austenite in microalloyed steels [8];

To simulate the direct quenching after controlled rolling of a HSLA steel [9].

In the past, the laboratory-scale apparatuses have been mainly applied to study plate steels. Such apparatuses, however, are also being used to study microalloyed steel wire [10] and seamless steel tube [11]. With the increased use of directly cooled forging steels, the apparatus can be used as an instrumented forging press for detailed study of these steels. This report 
describes the development, at the National Institute of Standards and Technology (NIST), of a hot-deformation apparatus, which is suitable for TMP simulation of steel plates and forging. Examples of studies which have been done using the apparatus are presented. 


\section{DESCRIPTION OF THE HOT-DEFORMATION APPARATUS}

The actual operations of a rolling mill for plate rolling and of a forging shop are very complex. The apparatus developed and described here is by no means capable of duplicating the actual operations. Instead, the apparatus has been designed only to simulate the idealized thermal and mechanical treatments a metal (in the present case, a steel) receives during a rolling or forging operation. The TMP sequences can be simplified and depicted as those shown in figure 1. The important parameters in TMP simulations include the reheating rate, the soaking temperature and time, the compression temperature $(T)$, the time interval $(\Delta t)$ between compressions, the amount of strain $(\epsilon)$ in each compression, and the strain rate $(\dot{\epsilon})$. The apparatus to be described here has the versatility to simulate a wide range of TMP sequences typically encountered in plate rolling or forging.

The hot-deformation apparatus is shown in figure 2 and the interconnection among various components of the apparatus is given in figure 3 . The apparatus can be loosely broken down and described by individual components according to their functions: loading system, heating and control system, cooling and control system, vacuum system, assembly for dilation measurement after deformation, computer and peripherals, and computer programs for system control, data acquisition, and data analysis.

Loading System: The load frame is a servohydraulic machine with a load capacity of $250 \mathrm{kN}$. The machine has been upgraded in terms of actuator travel speed. The upgrade includes the installation of a $5.7 \times 10^{-3} \mathrm{~m}^{3} \cdot \mathrm{s}^{-1}$ servovalve with a $3.8 \times 10^{-3} \mathrm{~m}^{3}$ pilot manifold, which is set up for a $9.5 \times 10^{-3} \mathrm{~m}^{3}$ accumulator mounted on the pressure side and a $1.9 \times 10^{-3} \mathrm{~m}^{3}$ accumulator on the return side. This enables actuator control at speeds up to $500 \mathrm{~mm} \cdot \mathrm{s}^{-1}$, which is adequate for plate-rolling or forging simulations.

The design of the load train is detailed in figure 4. Taking the specimen as a cutoff line, we can treat the vertical load train as two separate portions. The top portion is the hydraulic actuator, which contains a loading ram (steel), a suspended piston (Ti alloy), a plug (Ti alloy), and a quartz platen. The upper end of the loading ram is connected to a load cell 
and the hydraulic system, which controls the movement of the loading ram. The bottom of the loading ram is connected to the Ti piston with a spring. The separation of the top portion of the load train into a loading ram and a piston facilitates the measurement of the length change of a steel specimen during cooling and phase transformation. The measurement will be further discussed later in this report.

The use of fused quartz as a loading platen at elevated temperature was suggested by Ouchi [12] and has been proved to be satisfactory. Silicon nitride has also been used for the same purpose [13]. The advantages of fused quartz are low thermal conductivity, low thermal expansion coefficient, relatively high strength and toughness at elevated temperatures, ease of machining, and low cost. To ensure smooth surfaces, the contact surface of the platens are polished with $1 \mu \mathrm{m}$ diamond powder before an experiment. The quartz platen is glued (with high-temperature epoxy) and physically clamped onto the Ti plug, which is in turn threaded into the piston. The bottom portion of the load train is stationary and contains the specimen. The load train is rigid and well aligned. The maximum diameter of a cylindrical steel specimen to be tested at $800^{\circ} \mathrm{C}$ is about $10 \mathrm{~mm}$. Larger specimens often break the quartz platen during compression. This limits the load that can be applied to the platen to about $50 \mathrm{kN}$.

The most desirable deformation mode for plate-rolling or forging simulations is a constant true-strain-rate compression, which not only closely simulates the actual plate rolling but also eases data analysis and interpretation. The constant true-strain-rate compression is accomplished through interactive control of the load train by a personal computer (PC) using the equation

$$
H(t)=H(0) \exp [-t \dot{\epsilon}]
$$

Here $H(t)$ is the specimen's instantaneous height at time $t, H(0)$ is the initial height, and $\dot{\epsilon}$ is the desired constant true strain rate. Equation (1) is derived from the total strain equation with a constant $\dot{\epsilon}$ :

$$
\epsilon=\ln [\mathrm{H}(0) / \mathrm{H}(\mathrm{t})]=\dot{\epsilon} t
$$


The implementation of eq (1) using a PC and its peripherals will be described later in this report.

Theoretically, there is no limit to the value of $\dot{\epsilon}$ that can be used according to eq (1). In practice, however, there are limitations on the value of $\dot{\epsilon}$ that can be obtained in an experiment. The limitations are not with the throughput of a PC or its peripherals; that is, the computation of eq (1) and the rate of digital-to-analog conversion, but with the responses of a servohydraulic system to its commands. Figure 5 shows examples of the responses of the servohydraulic actuator in the current apparatus to various $\dot{\epsilon}$ inputs. Ideally, the time-vs.-total true strain relation is a linear line, which is evident in the cases of $\dot{\epsilon}$ equal to $0.97 \mathrm{~s}^{-1}$ (fig. 5a) and $4.8 \mathrm{~s}^{-1}$ (fig. 5b). However, at higher $\dot{\epsilon}$, the actuator responds too slowly at the beginning, then too fast, and finally overshoots at the end of the stroke movement. This phenomenon has been observed at $\dot{\epsilon}>9.5 \mathrm{~s}^{-1}$, particularly those of $19.2 \mathrm{~s}^{-1}$ (fig. 5f) and $24 \mathrm{~s}^{-1}$ (fig. 5g).

Going too slowly at the beginning, then too fast, and finally overshooting at the end is typical of and inherent in the servohydraulic system at high $\dot{\epsilon}$. To overcome the problem in a compressive experiment, we retract the actuator at the beginning of a test so that the specimen is compressed using only the lower half of the total true strain. Then, the value of $\dot{\epsilon}$ is calculated using the actual signal from actuator responses, such as those shown in figure 5 .

Heating and Control System: Major components of the system are a 10-kW, 450$\mathrm{kHz}$ induction generator ( $r f$ frequency) and a programmable temperature controller. The heating is provided by the generator and controlled by the temperature controller, which has ramp-and-soak and multiple-set-point capabilities. Temperature is monitored with a type-S thermocouple (Pt-10\%Rh) welded directly onto the specimen. Thermal cycles in an experiment are preprogrammed into the controller. The heating coil is a 4.76-mm-diameter Cu tube. The ON/OFF switch of the generator is connected to a PC through a relay for the ON/OFF control, which is important for a controlled cooling experiment. 
Cooling and Control System: Cooling of a specimen is controlled with a PC by regulating gas flow onto the specimen through a 6.35-mm-diameter $\mathrm{Cu}$ coil concentric with the heating coil. The side of the cooling coil facing the specimen is perforated to provide a gas flow that cools the specimen uniformly. Either helium or nitrogen gas is used for cooling. Because of its higher specific heat ( $5230 \mathrm{vs} .1030 \mathrm{~J} \cdot \mathrm{kg}^{-1} \cdot \mathrm{K}^{-1}$ at $25^{\circ} \mathrm{C}$ ) and greater mobility, helium gas is more efficient than nitrogen in rapid cooling. For a cylindrical steel specimen $10 \mathrm{~mm}$ in diameter by $18 \mathrm{~mm}$ in height, the cooling rate is controllable to a maximum rate of $25^{\circ} \mathrm{C} \cdot \mathrm{s}^{-1}$.

In the initial design for cooling control, a process controller was used to control the gas flow rate. After a few trials, we found that the time needed for the process controller to interact with a flow-rate meter, and then to control a gas regulating valve was too long. Therefore, the controlling function of the process controller could not be properly realized. The current practice has been to use a PC to open the gas regulating valve at a predetermined value. Cooling rates were calibrated from experiments with various settings in the gas regulating valve. To date, the system can set only one flow rate for one experiment. This means that the system cannot perform constant cooling-rate experiments because cooling is faster at higher temperatures than at lower temperatures due to larger thermal differentials between a specimen and its surrounding (constant ambient temperature) at higher temperatures. This cooling profile, however, closely resembles that of forging parts which are force-cooled while being transported through a conveyer.

Vacuum System: A vacuum is provided mainly to prevent specimen oxidation at high temperatures. The vacuum also provides additional stability in temperature control. The vacuum system consists of a stainless-steel chamber, and a $100-\mathrm{mm}$ diffusion pump with associated equipment such as a mechanical pump, pressure gages, and a valve controller. The system can achieve a vacuum of $1.33 \times 10^{-3} \mathrm{~Pa}\left(1 \times 10^{-5}\right.$ Torr) within $25 \mathrm{~min}$. The chamber is $381 \mathrm{~mm}$ long, $381 \mathrm{~mm}$ wide, and $432 \mathrm{~mm}$ high, and is made of a 9.5-mm-thick stainless-steel plate. The bottom of the chamber is fastened to a stationary steel plate (see figs. 2 and 4 ). The outside of the chamber is reinforced with welded 
stainless-steel webs to provide rigidity, which is essential for precision in dilation measurements.

View ports and various feedthroughs, such as those for instrumentations, thermocouples, rf frequency power, and liquids, were provided with the chamber. O-rings were used to seal the top and bottom portions of the load train. It should be mentioned here that at a pressure of about $1.33 \times 10^{-1} \mathrm{~Pa}$ $\left(10^{-3}\right.$ Torr), gases will be ionized between the specimen and the heating coils. At this pressure, it is impossible to heat the specimen because the rf field arcs and shuts off the rf generator.

Assembly for Dilation Measurement After Deformation: The temperature and time at which the transformation of austenite occurs during continuous cooling plays an important role in determining the microstructure and, therefore, the properties of a steel. A knowledge of transformation temperature and time can be valuable in understanding the effects of composition, processing, and cooling rate on the microstructure and properties, and can thus aid the development of new and improved steels.

The methods available [14] to determine transformation and time include thermal analyses, metallographic techniques, electrical-resistivity measurements, magnetic-properties measurements, X-ray diffraction analyses, and dilatometry. Among these methods, thermal analyses and dilatometry are the most commonly used techniques for the detection of austenite transformation during continuous cooling. For the application described in this report, our experience shows that dilatometric measurements give more definite and precise transformation temperatures than thermal analyses. In this section, a dilatometric-measurement device capable of detecting the decomposition of austenite in steels cooled directly from the finish deformation operation is described.

The principles of dilatometry are associated with the dimensional changes accompanying the decomposition of austenite. An acceleration or reversal of dimensional changes during cooling indicates the occurrence of a solid-tosolid phase transformation, which may be correlated subsequently with the temperature and time at which it occurs. 
As noted in the Loading System section, to facilitate the measurement of length change of a steel specimen during cooling and phase transformation, the top portion of the load train was separated into a loading ram and a piston, which were connected by a spring (fig. 4). In an experiment, the loading ram is retracted after the end of a compressive deformation so that a gap of approximately $5 \mathrm{~mm}$ is maintained between the loading ram and the piston. This leaves a force of about $40 \mathrm{~N}$ resting on the specimen during dilatometric measurements. The force, which is required to maintain a constant contact between the upper platen and the specimen, includes the spring loading plus the weights of the piston, the plug, and the quartz platen.

Any changes in specimen's length during cooling and phase transformation will result in axial movements of the piston, which are monitored by a displacement gage. In order for the displacement gage to monitor the piston movement, the displacement gage has to be placed before an experiment, at the precise position at which the bottom end of the piston is anticipated to rest after the end of a compressive deformation. The displacement gage has a resolution of $0.9 \mu \mathrm{m}$ and a travel range of $3.5 \mathrm{~mm}$. From the measured length change-vs.-temperature data, such as that shown in figure 6, phasetransformation temperatures are determined using statistical techniques.

Computer and Peripherals: The computer used is a $20-\mathrm{MHz} 80386$ personal computer, equipped with a board-level analog-to-digital (A/D) plug-in board having a $45 \mathrm{kHz}$ throughput and with an IEEE GPIB board. The A/D board contains eight differential A/D channels (for input) and two digital-toanalog (D/A) channels (for output). The peripherals of the computer include a $20-\mathrm{MHz} 80387$ math coprocessor, a line printer, a 60-MByte hard disk, a 1.2-MByte floppy disk drive, and a 360-kByte floppy disk drive.

The hot-deformation apparatus is also equipped with a programmable digital storage oscilloscope and a programmable waveform generator. The oscilloscope includes four 15-bit $100 \mathrm{k} \mathrm{kz}$ digitizers and is used for highspeed data acquisition (each channel can store up to 4000 data points when all four channels are operating simultaneously); the waveform generator is used to provide $5 \mathrm{~V}$ for opening a gas valve in controlled cooling experiments. 
Computer Programs for System Control, Data Acquisition, and Data Analysis: Computer programs were written in a scientific, stack-oriented, incrementally compiled programming language [15,16]. Two programs, (1) System Control and Data Acquisition program, and (2) Data Analysis and Summarizing Report Production program, were written to perform system control, data acquisition, and post-test data analysis. The source codes of the computer programs are attached in Appendixes 1 and 2 .

The program for system control dictates the sequence of operations of the various components of the hot-deformation apparatus. A detailed flow chart of the System Control and Data Acquisition program is given in figure 7 . With reference to the figure, the thermal cycle from heat-to-soak temperature to the last compression is controlled by an autonomous programmable temperature controller, as described in the section on Heating and Control System. During an experiment, the computer continuously reads the thermocouple signals through an $A / D$ channel, because temperatures determine when a compression is to take place. (Alternatively, time can be used as the controlling parameter). As soon as the predetermined testing temperature is reached, the computer triggers the oscilloscope for data acquisition through the GPIB bus and then sends a string of signals through a D/A channel for controlling the movement of the stroke, which performs the actual compression. The same sequence is repeated until the completion of the last compression; then the computer commands the oscilloscope for transferring the data onto floppy disks, turns off the induction heating generator, and opens a pneumatic valve for controlled cooling. To turn off the induction-heating generator, the computer sends a $5-\mathrm{V}$ signal, through a programmable waveform generator on the GPIB bus, to break the heating circuit.

In an experiment, a compression is specified by the original height, $H(0)$, and the final height, $H(f)$, of the specimen and by the deformation mode, such as constant $\dot{\epsilon}$. For a constant $\dot{\epsilon}$ compression, the total true strain is

$$
\epsilon=\ln [\mathrm{H}(0) / \mathrm{H}(\mathrm{f})]=\dot{\epsilon} t_{t}
$$

and the total compression time, $t_{t}$, is 


$$
t_{t}=\epsilon / \dot{\epsilon}=\ln [\mathrm{H}(0) / \mathrm{H}(\mathrm{f})] / \dot{\epsilon}
$$

Using eqs (1) and (4), the computer computes a string of exponentially decreasing numbers, which are converted to voltages and calibrated to represent displacement in millimeters, and sends the numbers to the stroke controller through a D/A channel. Figure 8 shows a typical output of the D/A channel and the stroke response of the hydraulic testing machine. With reference to the computer output signals, the stroke response has a delay and a small overshoot at the end of the curve. These are due to the inherent characteristics of the servohydraulic system at high $\dot{\epsilon}$. The response delay and the overshoot diminish at lower $\dot{\epsilon}$.

Because of the discrete nature of digital signals, such as the inputs to the D/A channel from the computer, it is desirable to have as many points as possible for a compression test in order to obtain a continuous, smooth output from the D/A channel. However, the number of data points that can be used in a compression test is limited by the computation time needed by the computer and the execution time needed by the D/A channel. For the present computer system at a $\dot{\epsilon}$ of $15 \mathrm{~s}^{-1}$, the maximum number of data points that can be processed while maintaining a satisfactory result is about 200 . This number of data points can be used with $\dot{\epsilon}$ as low as $1 \mathrm{~s}^{-1}$. At lower $\dot{\epsilon}$, more points are required to maintain a continuous, smooth signal.

The communication between the PC and the various devices is through eight A/D channels, two D/A channels, and the IEEE GPIB bus. The desired direct measurements from an experiment typically include load, stroke movement, temperature, and the specimen's length change with respect to temperature. The apparatus was originally designed to use three of the eight A/D channels to acquire these measurements. After a few trials, we found that simultaneously one PC alone could not satisfactorily control the stroke movement through one D/A channel and acquire the data of load, stroke movement, and temperature through three A/D channels. When one PC performs these functions simultaneously, a maximum of only 50 data points can be executed for stroke control at a $\dot{\epsilon}$ of $10 \mathrm{~s}^{-1}$; this produces discontinuous signals with discrete steps. The problem lies in the fact that after the 
computer sends one stroke-controlling signal through a D/A channel, it has to open three A/D channels to receive data of load, stroke movement, and temperature. The time needed to complete a set of this sequence is too long to be satisfactory.

Therefore, in high $\dot{\epsilon}$ experiments the functions of stroke control and data acquisition must be performed by separate, autonomous devices. This can be done with a second PC equipped with high-speed A/D boards or other dataacquisition devices. In the present apparatus, we used a programmable digital storage oscilloscope, which equips with two floppy-disk drives for instant data storage. For a multiple-strike experiment, the signals of load, stroke movement, and temperature are captured with the oscilloscope and saved onto the floppy disks. This sequence is repeated for every compression. The time required for saving the signals from the oscilloscope onto the floppy disks is about $6 \mathrm{~s}$, which is the minimum time required between two consecutive compressions.

Because of the high-speed nature of a plate-rolling or forging simulation (one compression is typically completed within $0.1 \mathrm{~s}$ ), synchronization of the stroke-control subprogram and the data-acquisition subprogram is crucial. Without proper timing in triggering the oscilloscope for data acquisition and storage, the information needed from an experiment would be lost. The synchronization is complicated by the different command execution times required by different devices. In our case, the time required to activate the stroke-control sequence through the D/A channel is much shorter than that required to trigger the oscilloscope through the GPIB bus. Thus, the activation of the stroke-control sequence must be delayed after the triggering commands have been sent to the oscilloscope. The optimum delay times between different devices were obtained by trial and error.

The raw data saved on the oscilloscope's disks are load vs. time, stroke movement vs. time, temperature vs. time, and the specimen's length change vs. time. These data on floppy disks can not be retrieved directly by a PC because of differences in disk formats. A specially programmed digitalprocessing software [17] must be used to enable the PC to read the data from the disks. Depending on the purpose of a simulation experiment, the program 
for post-test analysis can calculate the various material properties from load-vs.-stroke movement data. The properties include Young's modulus, proportional limit, yield strength, engineering $\sigma-\epsilon$ curve, true $\sigma-\epsilon$ curve, and strain-hardening characteristics. From the specimen's length change-vs.temperature data, the program can produce dilation-vs.-temperature curves (fig. 6), from which continuous-cooling transformation (CCT) diagrams can be generated. The operation of the analysis program is interactive and is summarized in figure 9. 


\section{EXAMPLES OF USING THE APPARATUS}

The hot-deformation apparatus described in the previous section is being used to perform the following studies: the direct-quenching simulation of ASTM A710 steel, and forging simulation of the directly cooled microalloyed AISI 1522MV and 1141 forging steels.

\section{Direct-Quenching Simulation of ASTM A710 Steel: Controlled rolling followed} by direct quenching ( $C R-D Q$ ) eliminates the reaustenitizing-and-quenching step required in the conventional quenched-and-tempered ( $Q-T$ ) heat treatment; thus, it saves energy and reduces manufacturing costs. The CR-DQ process also increases strength and improves the notch toughness of microalloyed steels, when compared to the conventional rolling and direct-quenching process [18].

The conventional process of producing Q-T steel plates is summarized as follows:

1. A slab is reheated to and held at a reheating temperature for a predetermined soaking time.

2. The slab is subjected to several passes of rough rolling.

3. The slab then receives several passes of finish rolling to become a finished plate.

4. The plate is air-cooled to ambient temperature.

5. The plate is reheated to an austenitizing temperature for a predetermined length of time.

6. The plate is quenched and then tempered.

In a CR-DQ process, the slab reheating temperature is lower than that of conventional processes. Step 3 is done at temperatures below the austenite recrystallization temperature. Step 3 is followed by step 6; thus, steps 4 and 5 are eliminated. The objective of the study is to understand the general response of the ASTM A710 steel to the CR-DQ treatments. 
Material: The material used for this simulation study was a copper precipitation-strengthened steel: ASTM designation A710 [19]. The chemical composition of the steel in weight percent is

$\frac{C}{0.03} \frac{\mathrm{Mn}}{0.54} \frac{\mathrm{S}}{0.002} \frac{\mathrm{Si}}{0.33} \frac{\mathrm{P}}{0.009} \frac{\mathrm{Nb}}{0.052} \frac{\mathrm{V}}{0.005} \frac{\mathrm{Ni}}{0.96} \frac{\mathrm{Cr}}{0.93} \frac{\mathrm{Mo}}{0.217} \frac{\mathrm{Cu}}{1.04}$

The steel was received in a 19 -mm-thick plate form and was conventionally processed, that is, hot-rolled to a thickness of $19 \mathrm{~mm}$, air-cooled, reaustenitized, quenched, and aged. Cylindrical specimens, $10 \mathrm{~mm}$ in diameter by $18 \mathrm{~mm}$ in height, were taken from the plate; the cylindrical axis coincided with the long transverse direction. A specimen before and after deformation is shown in figure 10 .

Experimental Details: In this study, the sequence of CR-DQ was simplified and simulated by two compressions. The simplified temperature-deformation sequences are described in table 1. The first compression simulates the rough rolling and the second compression represents a heavy reduction in the nonrecrystallized austenite region. All specimens were quenched with gas (either helium or nitrogen) immediately after the second compression.

The selection of 900 and $850^{\circ} \mathrm{C}$ for the second compression, as described in table 1 , was based on the results obtained using a double-deformation test $[5,8]$. As shown in figure 11a, there is no softening in the second compression, indicating no recrystallization at $950^{\circ} \mathrm{C}$. Softening is observed in figure $11 \mathrm{~b}$, which shows the results tested at $1000^{\circ} \mathrm{C}$. Based on figure 11 , we conclude that recrystallization occurred between 950 and $1000^{\circ} \mathrm{C}$.

Results and Discussion: Figure 12 shows the microstructures and diamondpyramid microhardness (DPH) measurements of different thermomechanically treated specimens in the as-cooled condition (without aging). Figures 12a and $12 \mathrm{~b}$ are microstructures of specimens reheated to $910^{\circ} \mathrm{C}$, held for $10 \mathrm{~min}$, and then cooled slowly in vacuum with heater power off (fig. 12a) and helium-gas quenching (fig. 12b), respectively. These specimens were not deformed. 
Table 1. Temperature-deformation sequences for simplified CR-DQ simulations.

\begin{tabular}{ll}
\hline reheat temperature: & $\begin{array}{l}1150^{\circ} \mathrm{C} \text { for } 5 \text { min followed by slow cooling at a rate } \\
\text { between } 0.5 \text { and } 1.1^{\circ} \mathrm{C} \cdot \mathrm{s}^{-1}\end{array}$ \\
*irst compression: & $30 \%$ reduction at $1050^{\circ} \mathrm{C}$ \\
second compression: & \\
treatment (a): & $30 \%$ reduction at $900^{\circ} \mathrm{C}$ followed by helium-gas \\
& quenching at a rate of $16^{\circ} \mathrm{C} \cdot \mathrm{s}^{-1}$ between 800 and $500^{\circ} \mathrm{C}$ \\
treatment (b): & $30 \%$ reduction at $850^{\circ} \mathrm{C}$ followed by helium-gas \\
& quenching at a rate of $17 \mathrm{C} \cdot \mathrm{s}^{-1}$ between 800 and $500^{\circ} \mathrm{C}$ \\
treatment (c): & $40 \%$ reduction at $850 \mathrm{C}$ followed by nitrogen-gas quenching \\
& at a rate of $9{ }^{\circ} \mathrm{C} \cdot \mathrm{s}^{-1}$ between 800 and $500^{\circ} \mathrm{C}$
\end{tabular}

*applied to all CR-DQ specimens

Figures $12 \mathrm{c}$ through $12 \mathrm{e}$ are microstructures of specimens with treatments (a) through (c), respectively, as described in table 1. The corresponding DPH numbers are also given along with each microstructure at the upper left corner of each micrograph in figure 12 .

Three distinct microstructural features are shown in figure 12. Figure $12 \mathrm{a}$ shows that the main constituent is the equiaxed polygonal ferrite (white areas) with randomly dispersed second-phase patches (dark areas), which are thought to be a mixture of pearlite, bainite, and martensite. With increasing cooling rate, a portion of the polygonal ferrite becomes acicular in shape, as shown in figure 12b; the predominant feature is still polygonal ferrite. With the simplified CR-DQ processing, the predominant microstructural features of some specimens change drastically from polygonal ferrite to granular bainite (acicular ferrite) [20], as shown in figures 12c, $12 \mathrm{~d}$, and $12 \mathrm{e}$. The second-phase islands in these microstructures (figs. 12c, $12 \mathrm{~d}$, and $12 \mathrm{e}$ ) are thought to be a mixture of retained austenite and martensite [21,22]. The changes in microstructures are also reflected in the DPH measurements as indicated in figure 12.

We considered two ways to explain the change in microstructure from polygonal ferrite as shown in figures $12 \mathrm{a}$ and $12 \mathrm{~b}$ to granular bainite as shown in figures 12c, 12d, and 12e. First, we considered the higher cooling rates; 
that is, the polygonal ferrite nose was missed during cooling and granular bainite was obtained. According to the continuous-cooling transformation (CCT) diagram, as shown in figure 13, for the ASTM A710 steel [23], it is necessary to cool the steel from 800 to $500^{\circ} \mathrm{C}$ in less than 1 or $2 \mathrm{~s}$ in order to obtain a predominantly granular bainite microstructure. However, in the present investigation, it took from 18 [treatment (b)] to $35 \mathrm{~s}$ [treatment (c)] to cool from 800 to $500^{\circ} \mathrm{C}$. Therefore, these cooling rates were not expected to cause the observed drastic change in microstructure.

Second, we considered the increased (bainitic) hardenability of the steel due to the simulated CR-DQ process. This means that the polygonal ferrite nose in the CCT diagram is shifted to the right, as schematically shown in figure 14, and granular bainite forms at slower cooling rates. This best explains the observed microstructures. But what are the mechanisms that cause the hardenability to increase? Deformed, unrecrystallized austenite, as a result of controlled rolling, has been shown to decrease the hardenability of various steels $[24,25]$; this is contrary to what we observe here.

Hardenability is increased by an increase in austenite grain sizes before transformation [26]. After soaking at $1150^{\circ} \mathrm{C}$ for $5 \mathrm{~min}$, the austenite grain sizes were about $40 \mu \mathrm{m}$ in the present study, compared with $10 \mu \mathrm{m}$ for the CCT diagram [23]. The other probable cause of increased hardenability is a larger amount of alloying elements dissolved in the austenite before transformation; this reduces the rates of ferrite nucleation and growth. The alloying elements come from more dissolution of carbides and/or carbonitrides at the soaking temperature of $1150^{\circ} \mathrm{C}$. The dissolution of alloy carbides or carbonitrides is not possible in a conventional Q-T treatment with the austenitizing temperature of $900^{\circ} \mathrm{C}$.

The microstructures shown in figure 12 were taken from the middle of the specimens. The microstructures of the specimens without compression (figs. 12a and 12b) are uniform throughout the specimen. For the simulated CR-DQ-processed specimens, the microstructure varies from the surface to the middle of the specimen, as shown in figure 15. The variation of microstructure within a specimen is directly related to nonuniform deformation in cylindrical compression due to barreling. The total strain and the strain 
rate reach maxima at the middle of the specimen. They reach minima at points just beneath the contact surfaces; this area is called the "dead zone." The observed microstructures correlate well with this strain-pattern analysis: large strains at the middle of the specimen resulted in small and "pancaked" austenite grains, as shown in figure 15b; small strains near the surface resulted in large and equiaxed austenite grains, as shown in figure 15a. In light of this observation, we should be cautious in interpreting results obtained from a small-scale simulation.

The true $\sigma$-vs.- $\epsilon$ characteristics of each compression during the CR-DQ simulations are shown in figure 16. The initial flow stress for the second compression is considerably lower than the final flow stress during the first compression, which shows a strong indication that the austenite was already fully recrystallized before the second compression (by considering the true $\sigma$ vs. $-\epsilon$ characteristics of the second compressions). Figure 16 also shows a strong influence of temperature on true $\sigma-\epsilon$ curves.

The size of a sample after TMP processing with the hot-deformation apparatus is about $20 \mathrm{~mm}$ in diameter and $10 \mathrm{~mm}$ in height. This size is insufficient for machining a standard tension-test specimen. Therefore, the tensile strengths cannot be measured directly and must be inferred from other types of measurements. In the present study, using specimens taken from the same steel plates, we showed that there are good correlations between (1) yield strengths in tension and yield strengths in compression (fig. 17), and (2) tensile strengths and knoop hardness numbers (fig. 18).

Studies of Directly Cooled Forging Steels: The directly cooled microalloyed (MA) forging steels have been introduced to the automotive industry as economical substitutions for some quenched-and-tempered ( $Q-T)$ grades. These MA steels can achieve tensile strengths comparable to those of Q-T steels, but with lower impact properties. Research to improve the toughness of directly cooled MA steels is increasing. Several approaches to raise the toughness while lowering the ductile-to-brittle transition temperature have been cited in the literature $[28,29,30]$. These include: (1) lowering the carbon content from 0.58 to 0.35 or $0.25 \%$; (2) lowering the reheating temperature and the finish-forging temperature to control the austenite grain size; (3) adding Ti 
(to produce TiN particles) to control austenite grain size; (4) modifying the steel chemistry, such as increasing Mn or Si content; (5) controlling MnS inclusions to increase intragranular ferrite nucleation; and (6) producing low-carbon bainitic steels .

Our study is to provide metallurgical data measured during simulated forging processes so as to optimize forging design and forging procedures. The data will include the true $\sigma-\epsilon$ characteristics of MA steels at high temperature under high $\dot{\epsilon}$, CCT diagrams determined under different forging parameters (reheating temperature, finish-forging temperature, deformation rate), microstructure, and hardness characterization. This is an ongoing research, and this report presents the preliminary results obtained to date.

Materials: The materials used in this study are two MA steels: AISI 1141, a ferritic-pearlitic steel, and AISI 1522, a bainitic steel. The steels were supplied as $25.4-\mathrm{mm}$ (1141) and $31.75-\mathrm{mm}$-diameter (1522) round bars in the asrolled condition, produced from continuous casters. The chemical compositions in weight percent are

\begin{tabular}{|c|c|c|c|c|c|c|c|c|c|c|c|c|c|}
\hline & C & $\mathrm{Mn}$ & $\mathrm{P}$ & $S$ & $\mathrm{Si}$ & $\mathrm{Cu}$ & $\mathrm{Ni}$ & $\mathrm{Cr}$ & Mo & $\mathrm{V}$ & $\mathrm{Nb}$ & $\mathrm{Sn}$ & Al \\
\hline 1141 & 0.42 & 1.49 & 0.015 & 0.099 & 0.26 & 0.16 & 0.06 & 0.06 & 0.009 & -- & 0.039 & 0.006 & -- \\
\hline 1522 & 0.24 & 1.67 & 0.014 & 0.028 & 0.39 & 0.42 & 0.14 & 0.17 & 0.22 & 0.11 & - - - & 0.013 & 0.006 \\
\hline
\end{tabular}

Experimental Details: Cylindrical specimens, $9 \mathrm{~mm}$ in diameter by $18 \mathrm{~mm}$ in height, were taken from the bars. For 1522 steel, specimens were reheated to $1093^{\circ} \mathrm{C}$ and held for $10 \mathrm{~min}$. Specimens were then cooled to ambient temperature with different cooling rates using forced helium gas for establishment of a CCT diagram. To investigate the effects of deformation on the CCT diagram and final microstructure, a series of specimens were heated to $1260^{\circ} \mathrm{C}$ and held for 5 min. Specimens were then cooled to $1093^{\circ} \mathrm{C}$, at a rate of about $1{ }^{\circ} \mathrm{C} \cdot \mathrm{s}^{-1}$. At $1093^{\circ} \mathrm{C}$, the specimens were compressed 508 with a $\dot{\epsilon}$ of $10 \mathrm{~s}^{-1}$. Following the compression, the specimens were cooled to ambient temperature with different cooling rates to establish the CCT diagram. This experiment also produced true $\sigma-\epsilon$ curves at $1093^{\circ} \mathrm{C}$ under $\dot{\epsilon}$ of $10 \mathrm{~s}^{-1}$. To date two specimens have been 
tested with these treatments. This series of experiments is continuing, and plans include experiments with different combinations of reheating temperature, deformation temperature, and $\dot{\epsilon}$.

For 1141 steel, specimens were reheated to $1218^{\circ} \mathrm{C}$, and held for $5 \mathrm{~min}$. Specimens were then cooled to ambient temperature with different cooling rates using forced helium gas to establish a CCT diagram. Future plans for this steel are the same as those for 1522 steel, that is, we will study the effects of different combinations of reheating temperature, deformation temperature, and $\dot{\epsilon}$.

For both steels, selected specimens processed with different processing parameters will be characterized and evaluated using optical metallography or electron microscopes, if necessary, and a microhardness tester.

\section{Results and Discussion:}

1522 Steel: Results obtained to date include the CCT diagram with specimens under heating and cooling (no deformation), microstructure of selected specimens, and true $\sigma-\epsilon$ curves at $1093^{\circ} \mathrm{C}$ with a $\dot{\epsilon}$ of $10 \mathrm{~s}^{-1}$. The CCT diagram is shown in figure 19. The far-right cooling curve in figure 19 is comparable to that of a $25-\mathrm{mm}$-diameter round bar transported on a conveyer. This cooling rate is typical of an automotive component (with the same size) transported on a conveyer after forging without forced cooling. The microstructure produced at this cooling rate is predominantly bainite, as shown in figure 19. This is confirmed by the light micrograph presented in figure 20b. Figure 20a shows the martensite produced after fast cooling, corresponding to the far-left curve in figure 19.

The temperatures at which phase transformation occurs can be best determined by dilatometric measurements. Figure 6 shows that the determination of phase-transformation temperature is not straightforward. In order to minimize the human factors in determining the phase-transformation temperatures, we use statistical techniques to analyze the dilation-vs.temperature data, such as that shown in figure 6. First, we performed the direct derivation on dilation-vs.-temperature data. The results produced too much scatter to give definite phase-transformation temperatures. Then, we 
used the seven-point incremental polynomial technique to smooth the data; this approach yielded results with less scatter. Representative curves obtained from this analysis are given in figure 21.

Although the polynomial technique makes it easier and less ambiguous to determine the phase-transformation temperatures, subjective judgement is still needed. This is especially true in the case of the martensite-finish temperature, $\mathrm{M}_{\mathrm{f}}$. This is clearly indicated in figure 21. The reason for the difficulty in $\mathrm{M}_{f}$ determination (in this study) is that the temperature difference between the $\mathrm{M}_{\mathrm{f}}$ temperature and the ambient temperature is relatively small, about 100 to $150^{\circ} \mathrm{C}$. This produces a relatively short linear portion in the derivative ( $d / / d T)$ of dilation with respect to temperature. Any deviation (the $\mathrm{M}_{f}$ temperature) from the linear line becomes ambiguous and is thus difficult to determine with certainty.

A true $\sigma-\epsilon$ curve is calculated from the load-vs.-stroke movement data acquired during compression. A representative curve obtained at $1093^{\circ} \mathrm{C}$ with a $\dot{\epsilon}$ of $10 \mathrm{~s}^{-1}$ is given in figure 22 .

1141 Steel: Using the same procedures described earlier, we produced a CCT diagram of the MA 1141 steel as shown in figure 23. Also included in figure 23 is the cooling profile (dashed line) typically found in a forging without forced cooling [31]. This cooling profile is similar to that shown in the far-right curve on figure 23. Selected microstructures corresponding to different cooling rates are presented in figure 24. Figure 24a is a ferriticpearlitic microstructure produced with the slowest cooling rate in this investigation. Martensite with a small fraction of bainite (fig. 24d) is observed with the fastest cooling. Figures $24 \mathrm{~b}$ and $24 \mathrm{c}$ represent the microstructures obtained with intermediate cooling rates. Microstructure in figure $24 \mathrm{~b}$ is a mixture of pearlite with small areas of ferrite (Widmanstatten) and bainite. Bainite plus martensite is the microstructure observed in figure $24 \mathrm{c}$. 


\section{CONCLUSIONS AND SUMMARY}

A computer-controlled laboratory-scale hot-deformation apparatus has been designed and built at the National Institute of Standards and Technology (NIST). The use of this apparatus for studying thermomechanical processing of metals has the obvious advantages of economy, versatility, and reproducibility. In the past, the laboratory-scale apparatuses have been mainly applied to study plate steels. With the increased use of directly cooled forging steels, the apparatus described in this report can be used as an instrumented forging press for detailed study of these steels.

The apparatus has the following main features: a servohydraulic load frame with a $250 \mathrm{kN}$ capacity in tension or compression; a variable-actuator traveling speed up to $55 \mathrm{~mm} \cdot \mathrm{s}^{-1}$; a multiple-strike capability with controllable displacements and strain rates; a maximum heating rate of $150^{\circ} \mathrm{C} \cdot \mathrm{s}^{-1}$ with a $10 \mathrm{~kW}$ induction heater (for a cylindrical steel specimen $9 \mathrm{~mm}$ in diameter and $18 \mathrm{~mm}$ in height); a maximum cooling rate of $25^{\circ} \mathrm{C} \cdot \mathrm{s}^{-1}$ with helium-gas cooling; and vacuum to $1.33 \times 10^{-3} \mathrm{~Pa}\left(1 \times 10^{-5}\right.$ Torr $)$ within 25 min.

The apparatus has been used to simulate direct quenching of ASTM A710 steel and forging followed by direct cooling of microalloyed AISI 1522 and 1141 steels. For the A710 steel, the results indicated that bainitic (granular) hardenability was greater with the controlled rolling followed by direct quenching ( $C R-D Q$ ) than with the conventional quenching-and-tempering (Q-T) process. The positive implication of the observation is that the strength of the steel can be increased with CR-DQ processing, or the amount of alloying elements can be reduced while maintaining the same strength level.

For the MA 1522 and 1141 steels, CCT diagrams were determined from the derivatives of the dilation-vs.-temperature data using the seven-point incremental polynomial technique. Although the technique using the smoothed derivatives helps to make the determination of phase-transformation temperatures less ambiguous, subjective judgement is sometimes still needed, especially in the case of martensite-finish temperature. Microconstituents, such as ferrite, pearlite, bainite, and martensite, shown in the CCT diagrams 
were confirmed with microstructures revealed by optical metallography. In addition to producing CCT diagrams and microstructures of specimens cooled at different rates, we will also conduct experiments in forging simulation to develop the information needed for the optimization of forging processes. The information includes high-temperature, high strain-rate flow characteristics and the effects of reheating temperature and finish-forging temperature on the CCT diagrams and final properties. 


\section{v. ACKNOWLEDGMENTS}

The microalloyed AISI 1522 and 1141 steels were supplied by K. Grassl of Chaparral Steel Company and J.H. Hoffmann of Chrysler Motors Corporation, respectively. Special thanks are due to $C$. Ouchi of the NKK Corporation for many helpful discussions on the simulation of thermomechanical processing. Dr. S.W. Thompson of Colorado School of Mines is appreciated for helpful discussion on metallography. Assistance from D.T. Lovering, J.D. McColskey, and D.P. Vigliotti of NIST, and A. Cossa and M.C. Mataya of Rockwell International during various stages of installation of the apparatus is appreciated. The assistance of D.A. Shepherd and A. Tomer (on leave from Nuclear Research Center, Israel) of NIST in performing optical metallography and hardness measurements is also acknowledged. 
[1] M. J. Steward, "Constant True Strain Rate Compression: The Cam Plastometer," Canadian Metallurgical Quarterly, Vol. 13, No. 3 (JulySept. 1974), pp. 503-509.

[2] H. Weiss, D. H. Skinner, and J. R. Everett, "A Torsion Machine for Programmed Simulation of Hot Working," J. of Physics E: Scientific Instruments, Vol. 6 (1973), pp. 709-714.

[3] 0. Pawelski and V. Gopinathan, "Comparison of Material Flow and Deformation Resistance of HSLA Steel Deformed by Hot Rolling and Flat Compression under Simulated Conditions," J. of Mechanical Working Technology, Vol. 5 (1981), pp. 267-280.

[4] C. Ouchi and S. Yamamoto, "Development of Hot Deformation Equipment 'THERMECMASTER-Z' and Studies of Hot Deformation Behaviors of Steels," Technical Research Center, Nippon Kokan K. K., Japan.

[5] R. A. P. Djaic and J. J. Jonas, "Static Recrystallization of Austenite between Intervals of Hot Working," J. of the Iron and Steel Institute (April 1972), pp. 256-261.

[6] C. Ouchi, T. Okita, T. Ichihara and Y. Ueno, "Hot Deformation Strength of Austenite during Controlled Rolling in A Plate Mill," Trans. the Iron and Steel Institute of Japan, Vol. 20 (1980), pp. 833-841.

[7] T. Sakai, M. G. Akben and J. J. Jonas, "Dynamic Recrystallization during the Transient Deformation of a Vanadium Microalloyed Steel," Acta Metall., Vol. 31, No. 4 (1983), pp. 631-642.

[8] Y. Z. Zheng, A. J. DeArdo, R. M. Fix and G. Fitzsimons, "Achieving Grain Refinement through Recrystallization Controlled Rolling and Controlled Cooling in V-Ti-N Microalloyed Steels," in HSLA Steels: Technology \& Applications, ASM, Metals Park, OH (1984), pp. 85-94.

[9] Y. W. Cheng and H. I. McHenry, "A Hot-Deformation Apparatus for Thermomechanical Processing Simulation," in Proceedings of Intl. Symp. on Physical Simulation of Welding, Hot Forming and Continuous Casting, Ottawa, Ontario, Canada, May 2-4, 1988. (in press)

[10] K. Namiki, K. Isokawa and T. Kato, "Microalloyed Steel Wire for Automotive Fasteners," in Fundamentals of Microalloying Forging Steels, the Metallurgical Society, Inc., Warrendale, PA (1987), pp. 521-537.

[11] R. Barbosa, S. Yue, J. J. Jonas and P. J. Hunt, "Accelerated Cooling Applied to the Recrystallization Controlled Rolling of Seamless Tubing," in the Proceedings of the Intl. Symp. on Accelerated Cooling of Rolled Steel, Pergamon Press (1988), pp. 373-386. 
[12] C. Ouchi, Technical Research Center, Nippon Kokan K. K., Japan, private communication.

[13] M. C. Mataya, Rockwell International, Golden, Co., private communication.

[14] G. L. Kehl, The Principles of Metallographic Laboratory Practice, 3rd edition, McGraw-Hill Book Company, Inc., 1949.

[15] ASYST Software Technologies, Inc., 100 Corporate Woods, Rochester, NY. (Commercial systems are mentioned for identification only; no endorsement is intended.)

[16] Y. Rosenthal and Y. W. Cheng, "Computerization of a Thermomechanical Processing Research System," J. of Intelligent Instruments and Computers, March/April 1989.

[17] Vu-Point, S-Cubed: a Division of Maxwell Laboratories, Inc., P. 0. Box 1620, La Jolla, CA 92038. (Commercial systems are mentioned for identification only; no endorsement is intended.)

[18] K. A. Taylor and S. S. Hansen, "Structure and Properties of Some Directly-Quenched Martensitic Steels," in Accelerated Cooling of Rolled Steel (Winnipeg.), G. E. Ruddle and A. F. Crawley, eds., Pergamon Press (1988), pp. 85-101.

[19] Annual Book of ASTM Standards, Vol. 01.04, Section 1, American Society for Testing and Materials, Philadelphia, PA (1987), pp. 664-667.

[20] L. J. Habraken and M. Economopoulos, "Bainitic Microstructures in Low-Carbon Alloy Steels and Their Mechanical Properties," in Transformation and Hardenability in Steels, Climax Molybdenum Co., Ann Arbor, MI (1967), pp. 69-108.

[21] S. W. Thompson, Colorado School of Mines, Golden, Colorado; private communication.

[22] M. R. Krishnadev, "Development and Characterization of a New Family of Copper-Containing HSLA Steel," in HSLA Steels: Technology \& Applications (Philadelphia), ASM, Metals Park, OH (1984), pp. 129-147.

[23] G. R. Speich and T. M. Scoonover, "Continuous-Cooling-Transformation Behavior and Strength of HSLA-80 (A710) Steel," in Proceedings of the Intl. Symp. on Processing, Microstructure, and Properties of HSLA Steels (Pittsburgh), A. J. DeArdo ed., TMS-AIME, Warrendale, PA (1988), pp. 263 286.

[24] R. Kaspar, A. Streisselberger, and 0. Pawelski, "Thermomechanical Treatment of Ti- and Nb-Mo-Microalloyed Steels in Hot Strip Rolling," in Thermomechanical Processing of Microalloyed Austenite (Pittsburgh), A. J. DeArdo, G. A. Ratz, and P. J. Wray, eds., TMS-AIME, Warrendale, PA (1982), pp. 555-574. 
[25] C. M. Vlad, "The Effect of Cooling Rates on the Transformation Behavior of Deformed Austenites," in Accelerated Cooling of Steel (Pittsburgh), P. D. Southwick, ed., TMS-AIME, Warrendale, PA (1986), pp. 435-446.

[26] G. Krauss, Principles of Heat Treatment of Steels, ASM, Metals Park, OH (1980).

[27] G.E. Hicho, et. al, "Effect of Heat Treatment on Mechanical Properties and Microstructure of Four Heats of ASTM A710 Steel," NBSIR 84-2891, Gaithersburg, MD (1985).

[28] M. Korchynsky and J.R. Paules, "Microalloyed Forging Steels - A State of the Art Review," International Congress and Exposition, February 27-March 3, 1989, Detroit, MI, Paper No. 89081.

[29] T. Ouchi, T. Takahashi, and H. Takada, "Improvement of the Toughness of Hot Forged Products through Intragranular Ferrite Formation, "Proceedings of the 20th Mechanical Working and Steel Processing Conference, October 23-26, 1988, Dearborn, MI, pp. 65-72.

[30] K. Matysumoto, et. al., "Development of Low-Carbon Bainitic Bar Steel for Hot Forged Use," ibid., pp. 73-81.

[31] J.H. Hoffmann, Chrysler Motors Corporation, Highland Park, MI, private communication. 


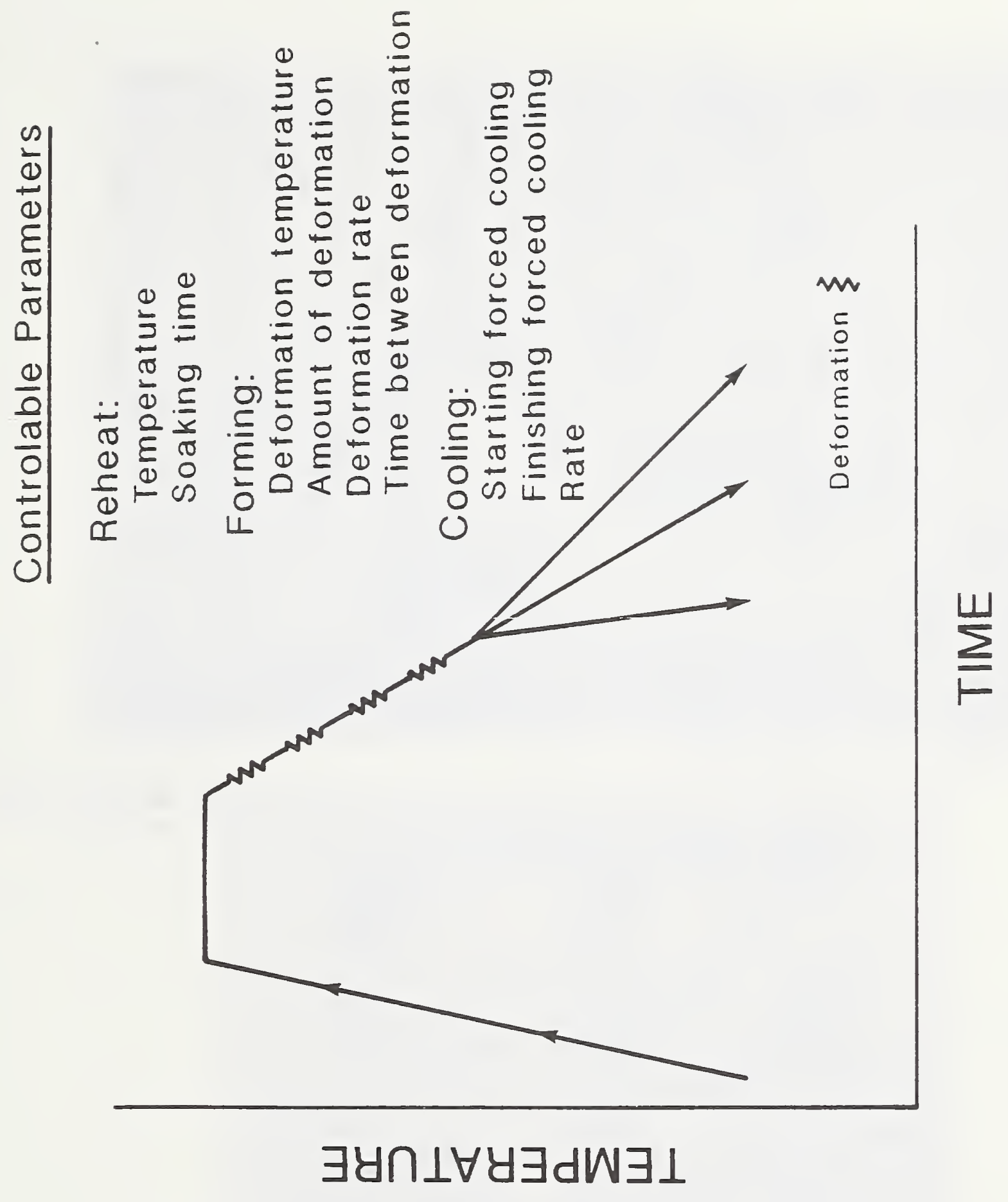

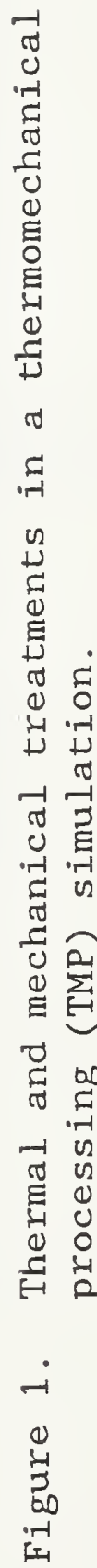



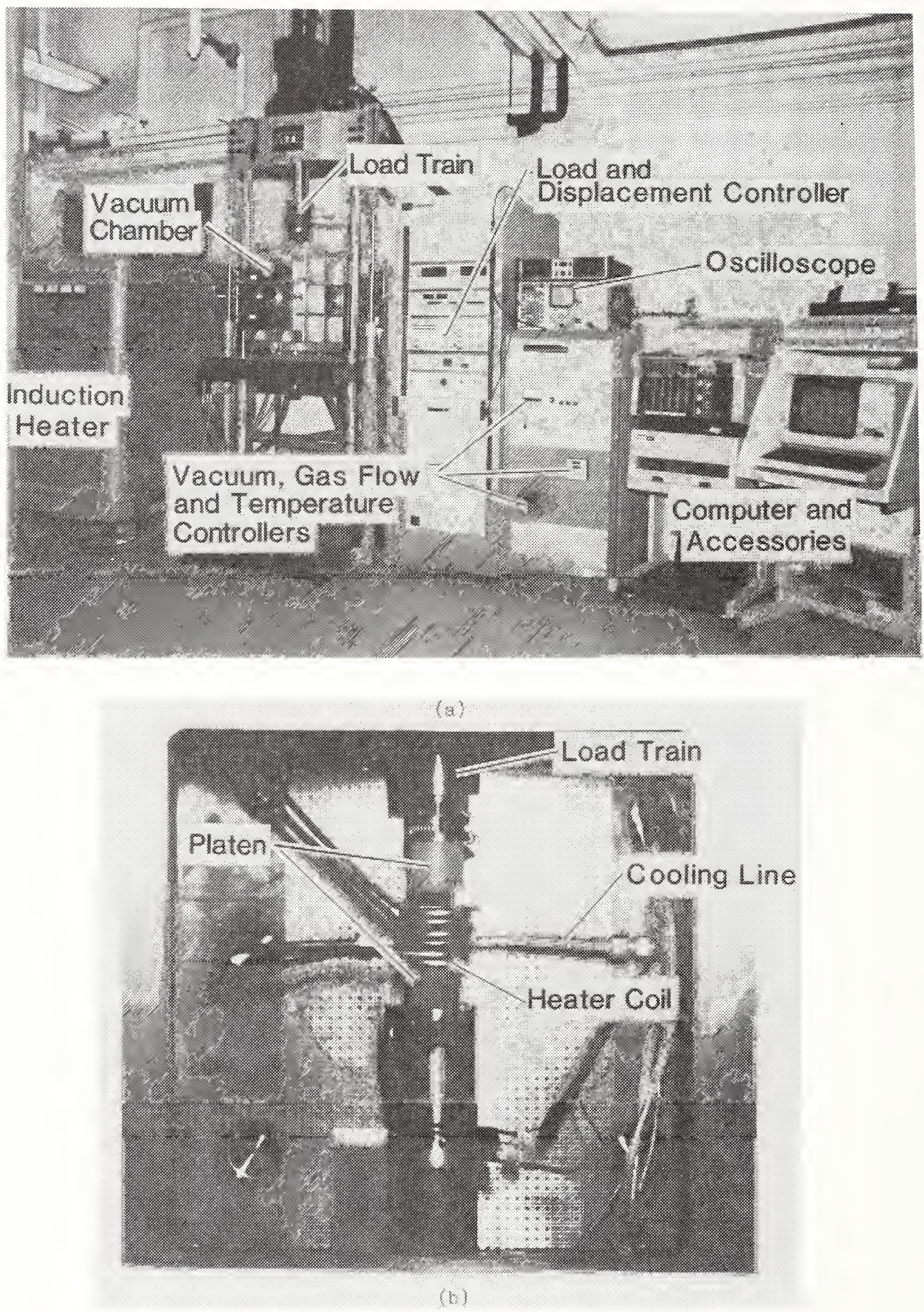

Figure 2. Hot-deformation apparatus.

(a) overall view; (b) interior of the vacuum chamber. 


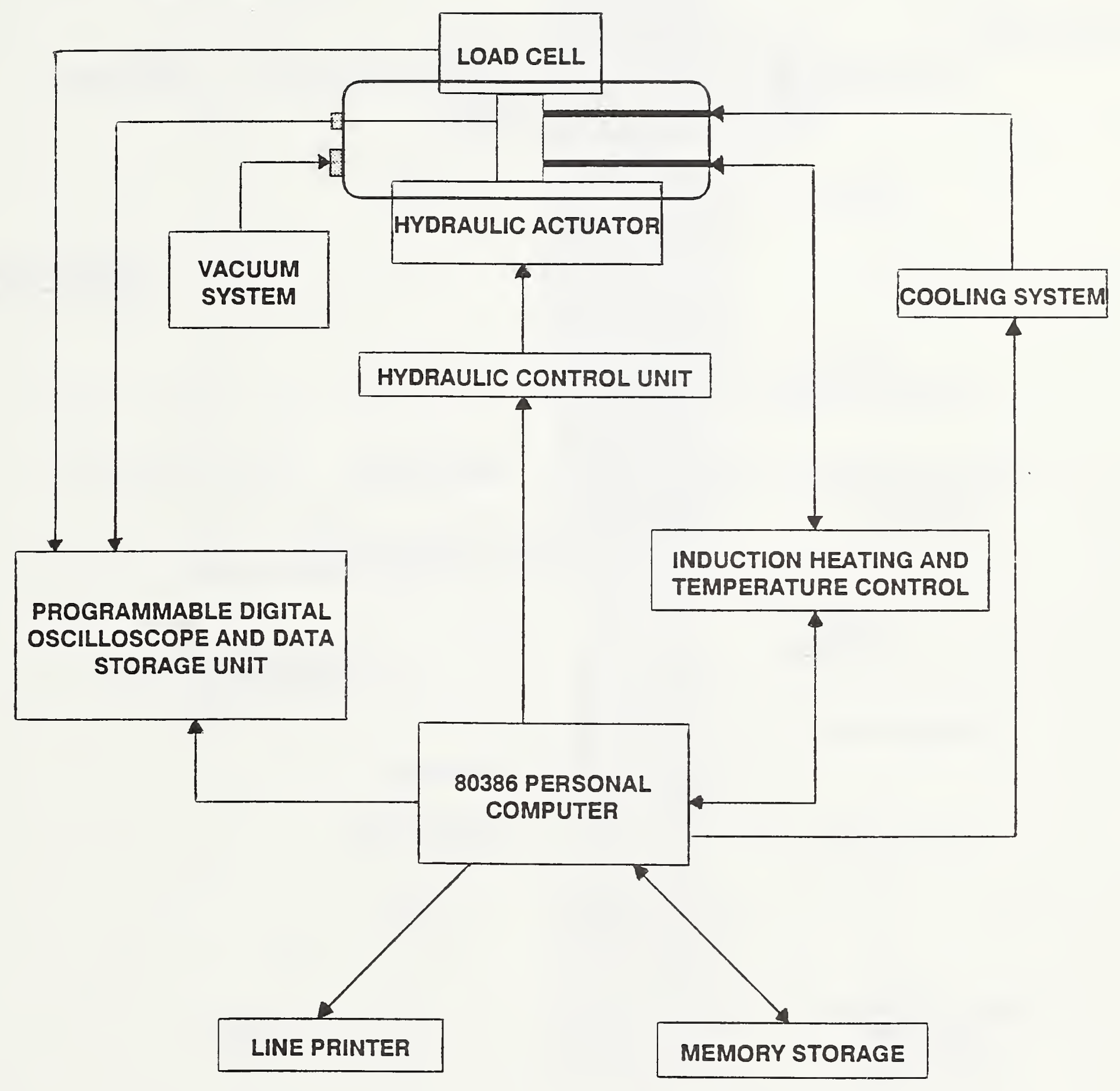

Figure 3. The basic components of the hot-deformation apparatus. 


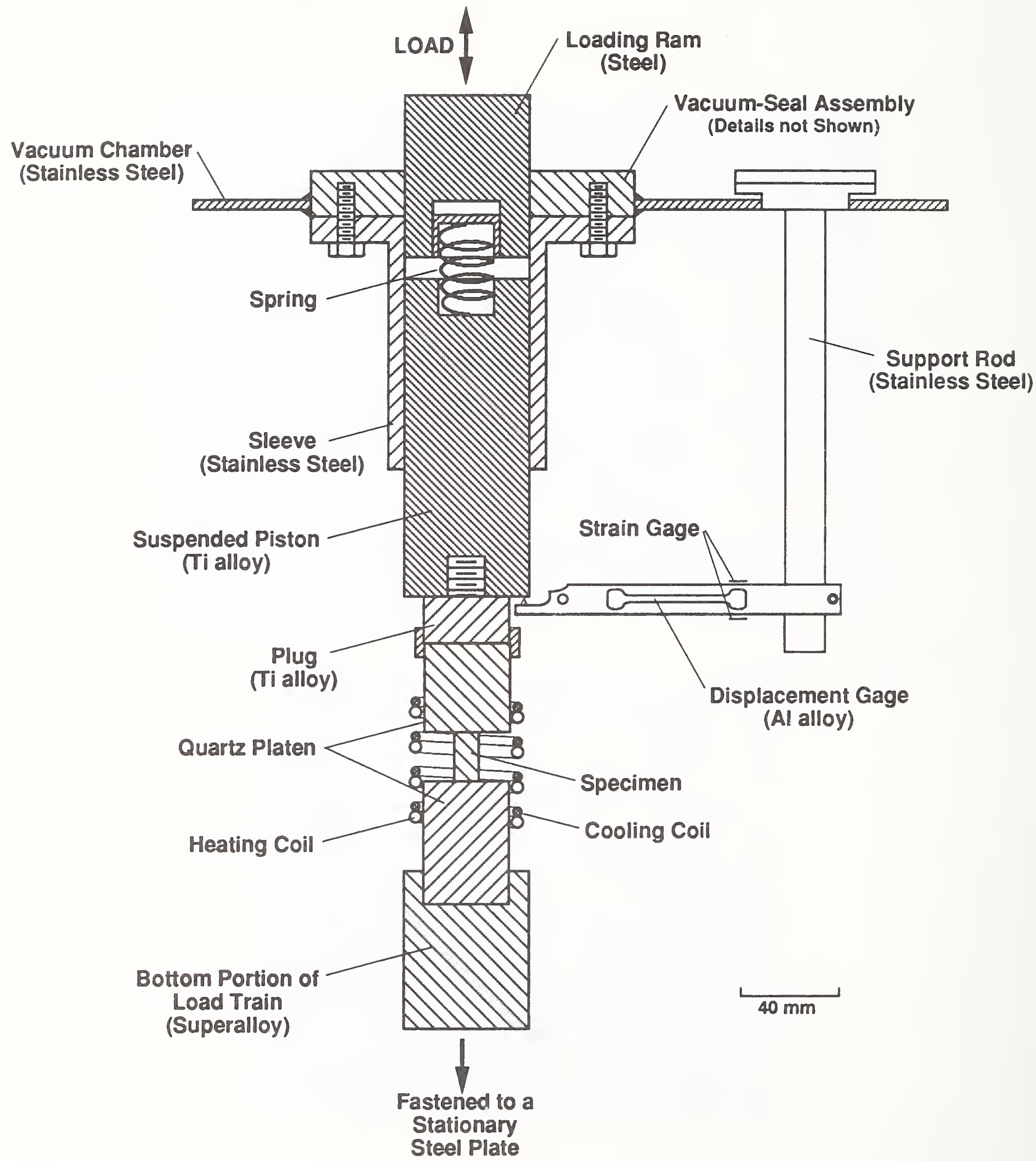

Figure 4. Drawing of the load train and the device for measurement of length change during cooling and phase transformation. 


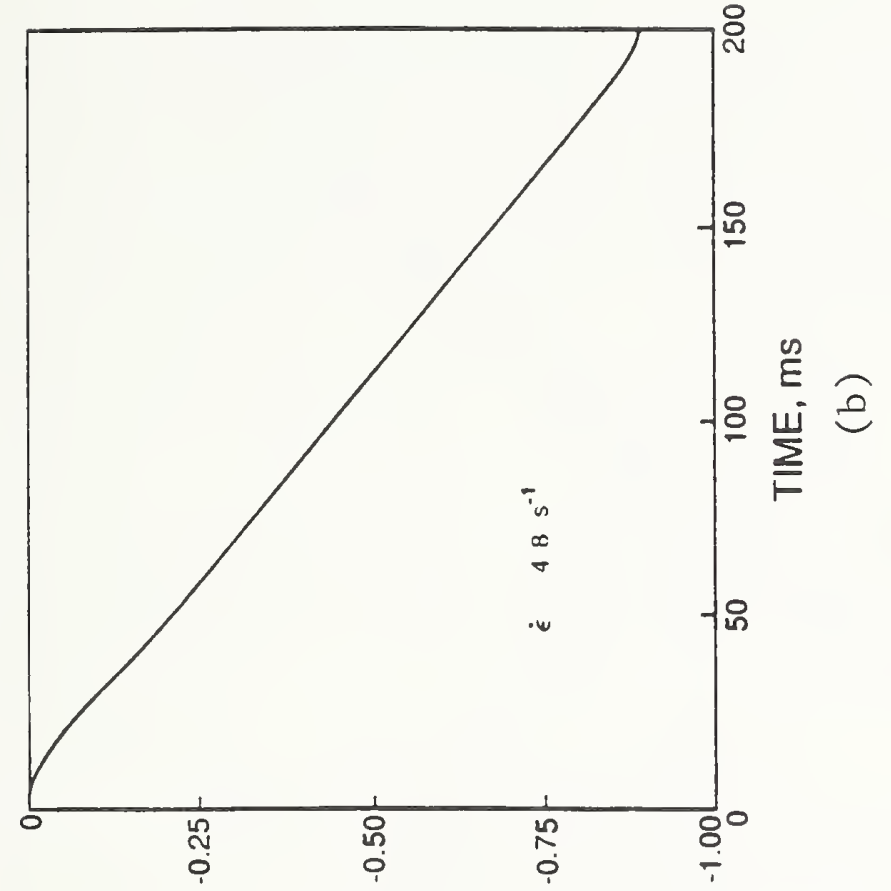

NIVUIS $\exists \cap U \perp 7 \forall \perp O \perp$

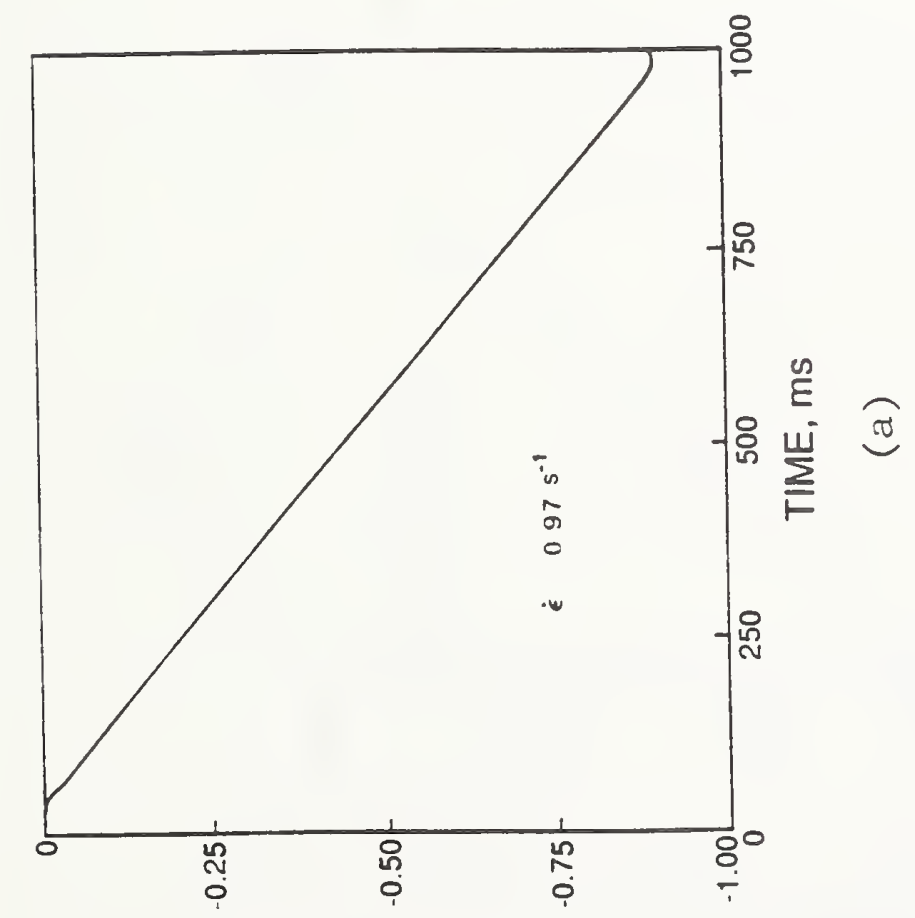

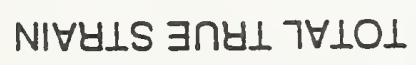

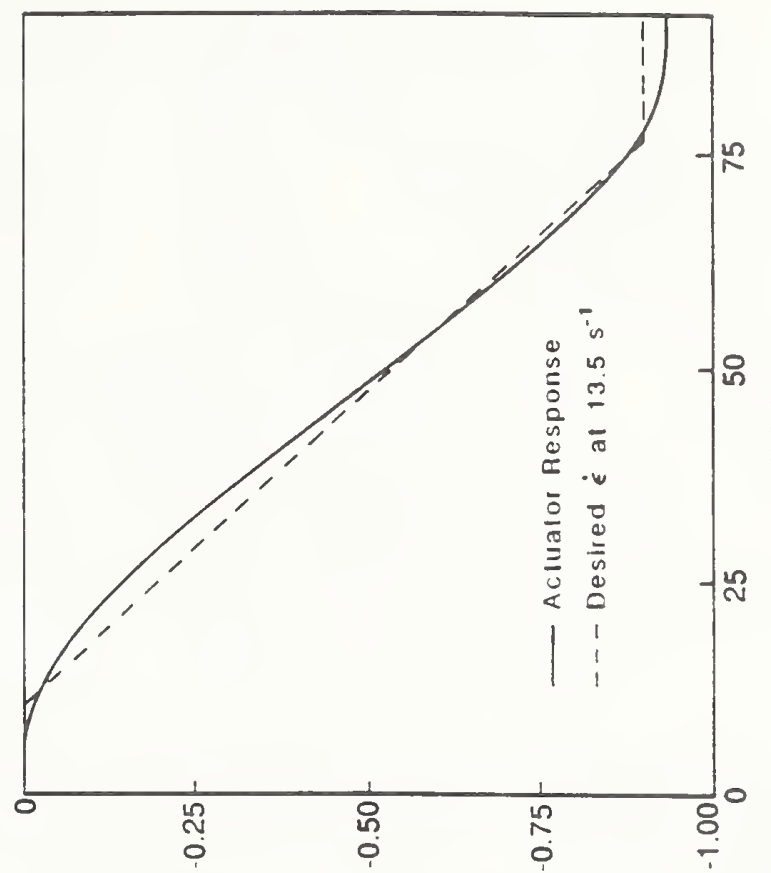

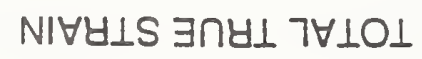

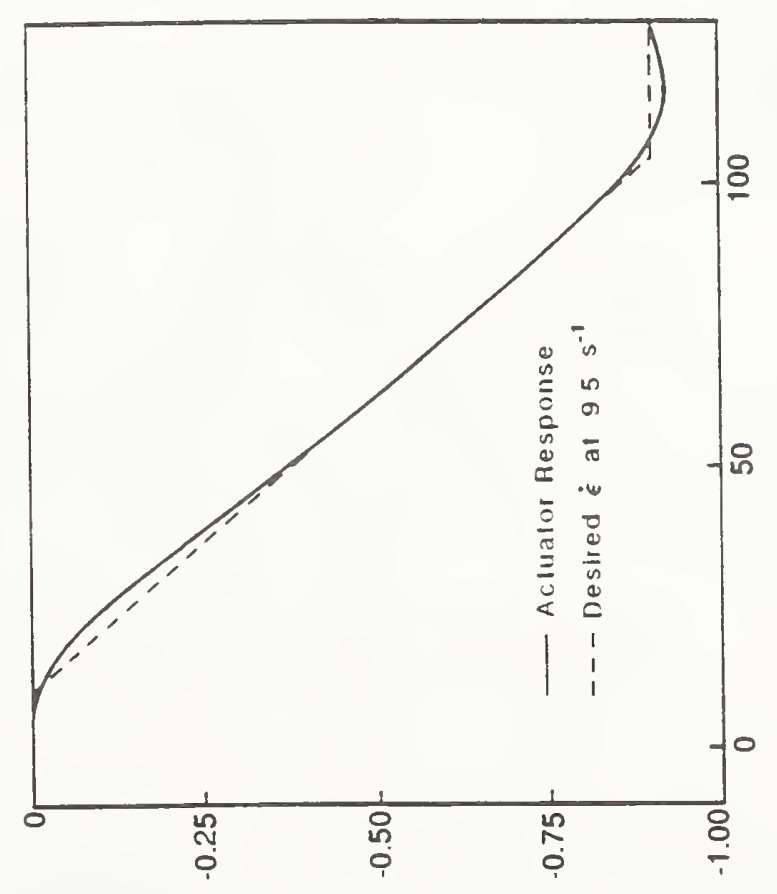

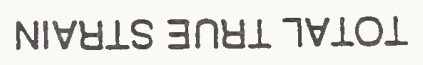

$\stackrel{\circ}{0} \because$

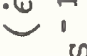

थ

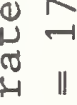

$E \cdot \omega$

क्ष (1)

os

en $\overrightarrow{1}$

E

एँ

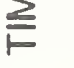

$4-11$

告

मे

$\stackrel{\text { đ }}{J} \|$

ש.

ชิ

u

$\because-7$

ज्ञ

if os

$\lambda^{\infty} \cdot$

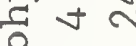

学 \| ॥

造

$\frac{d}{d}$ อ

ह

ij 0 us us

is $\sim$

जै

م.

Q

ש.

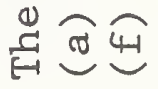

in

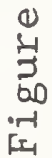




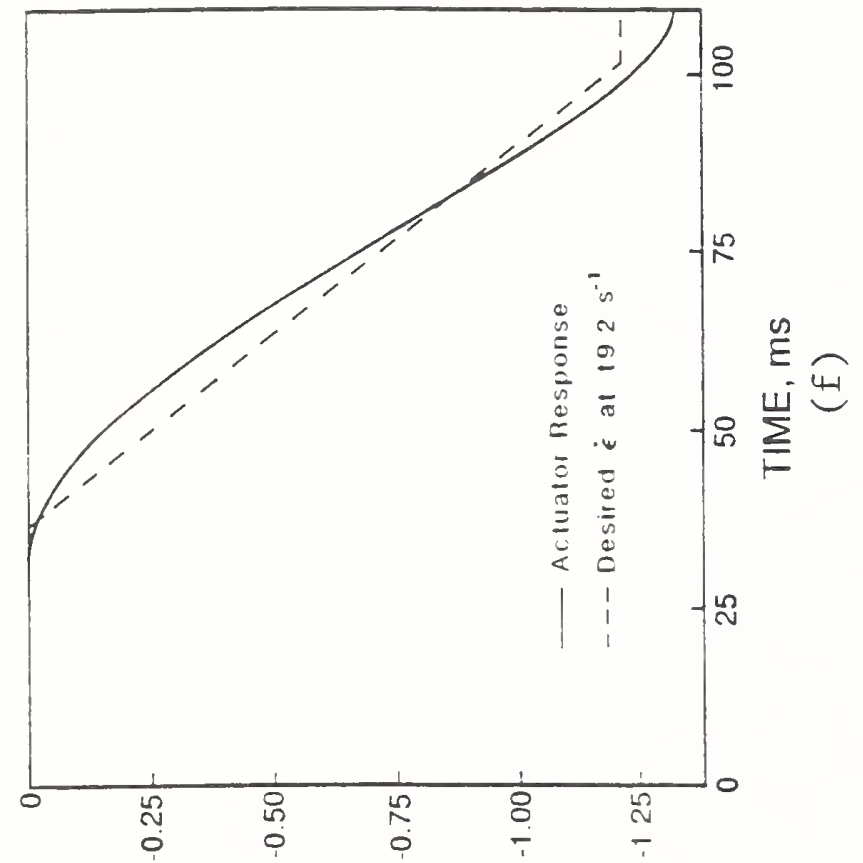

NI $\forall \forall \perp S \exists \cap \forall \perp 7 \forall \perp O \perp$

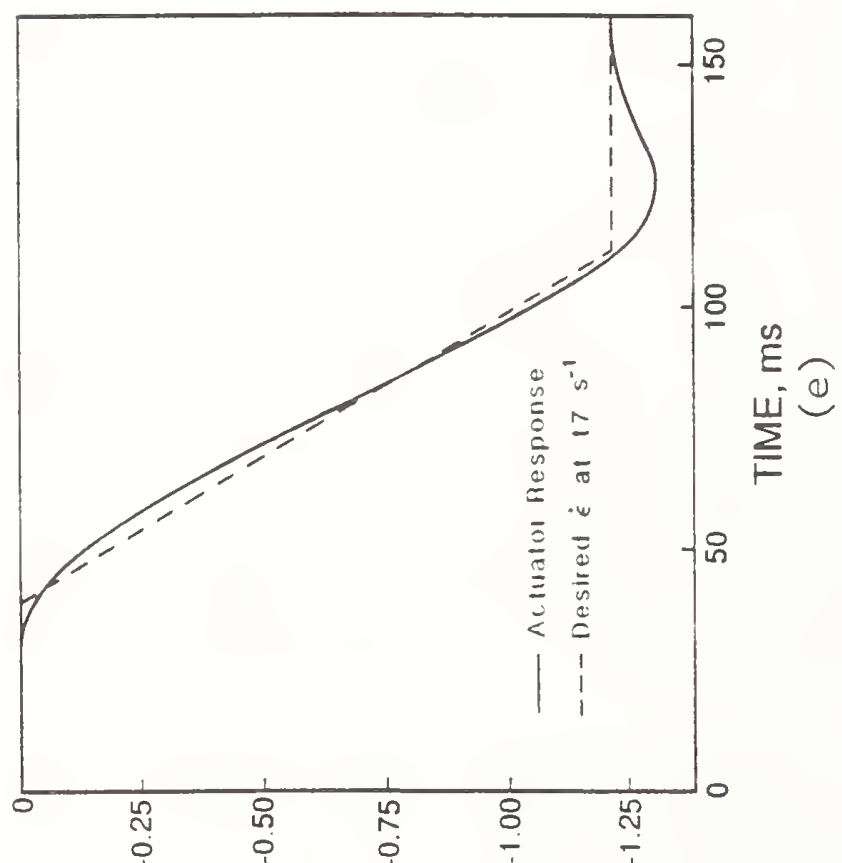

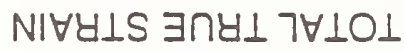

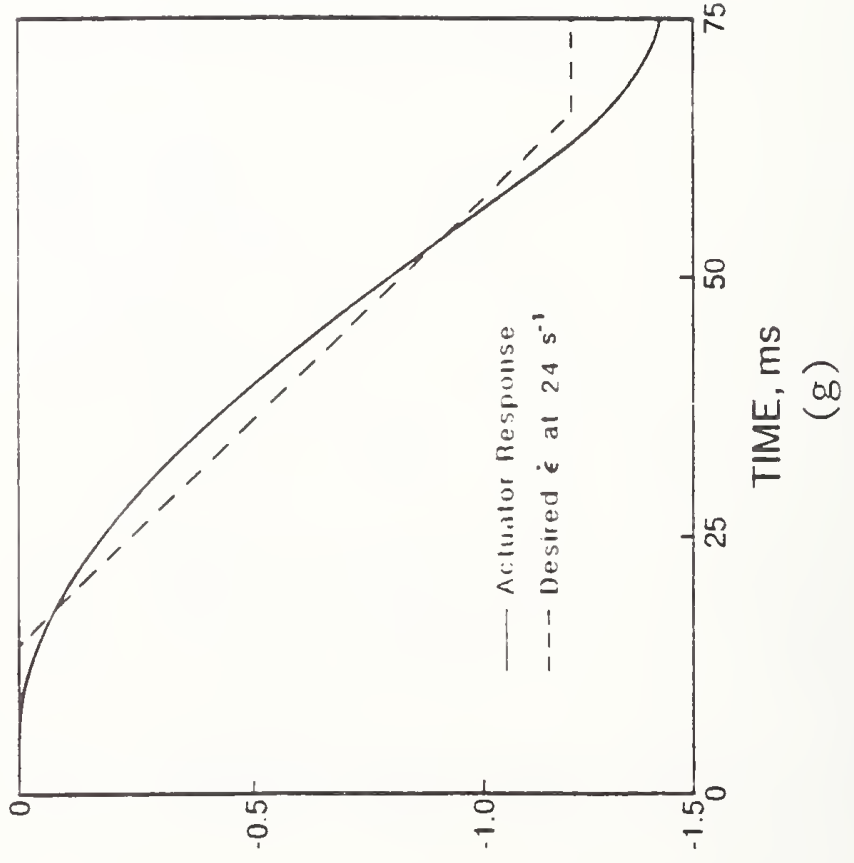

$N I \forall \forall \perp S \exists \cap \forall \perp 7 \forall \perp O \perp$ 


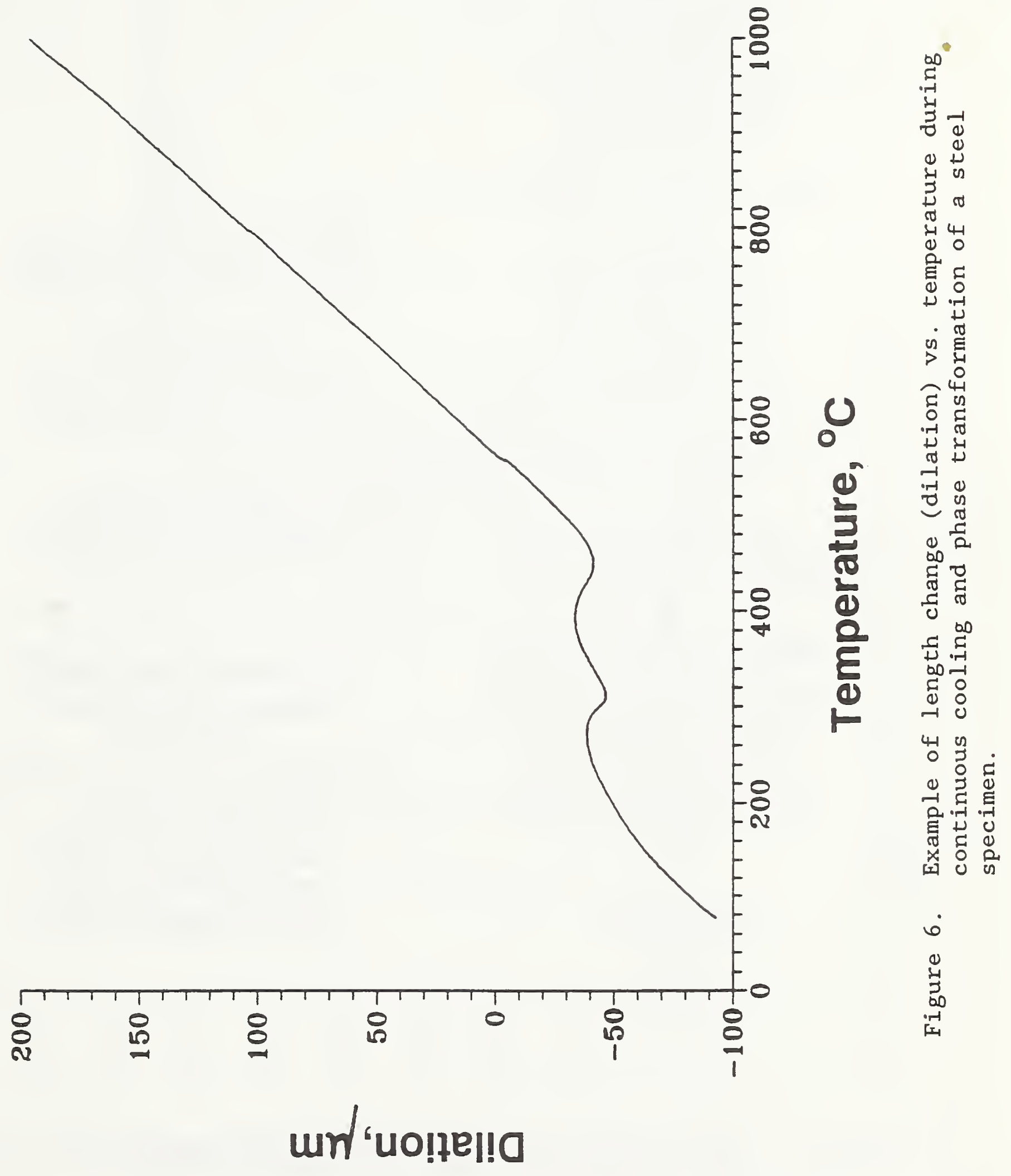




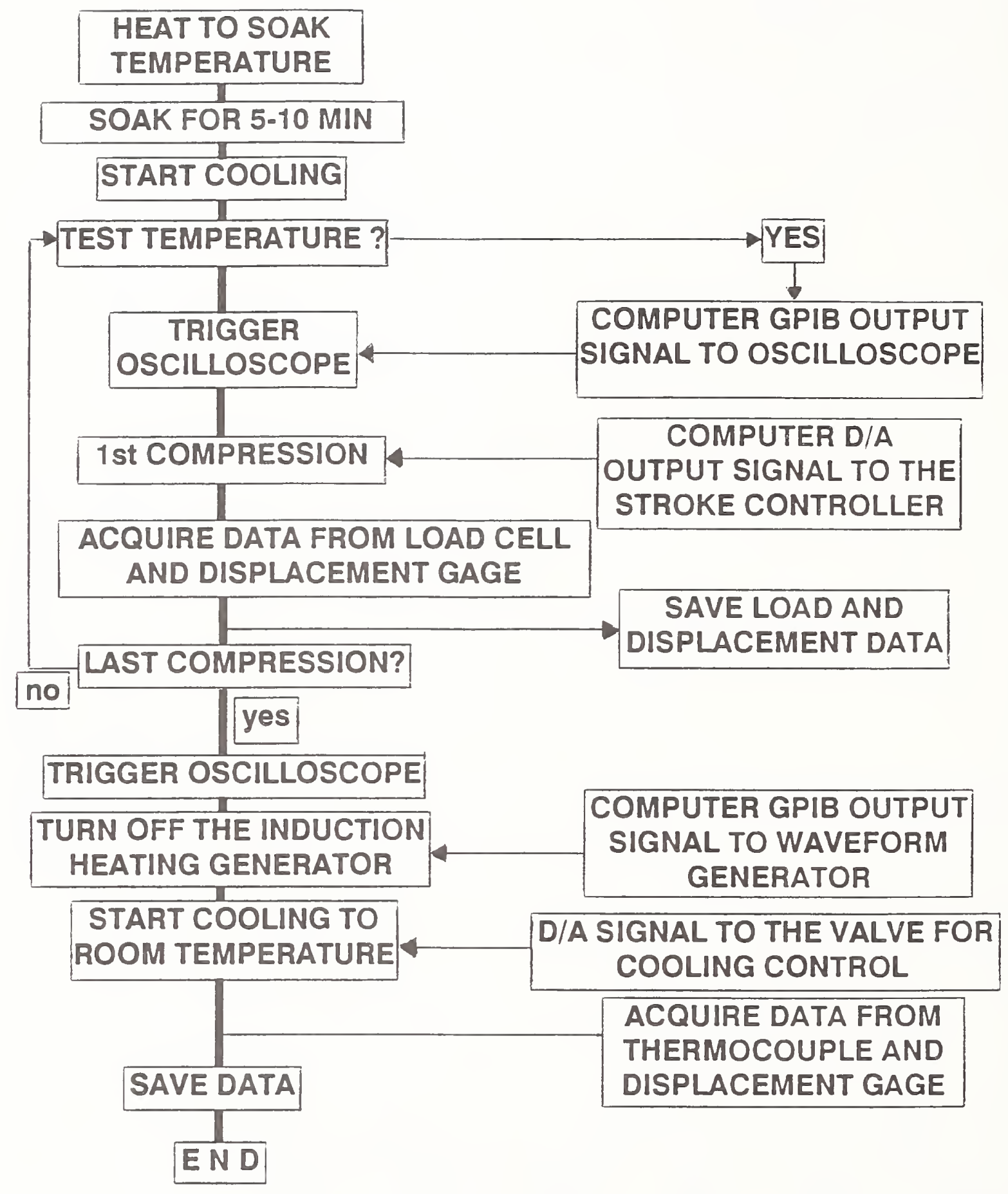

Figure 7. The detailed flow chart of the program for system control and data acquisition. 


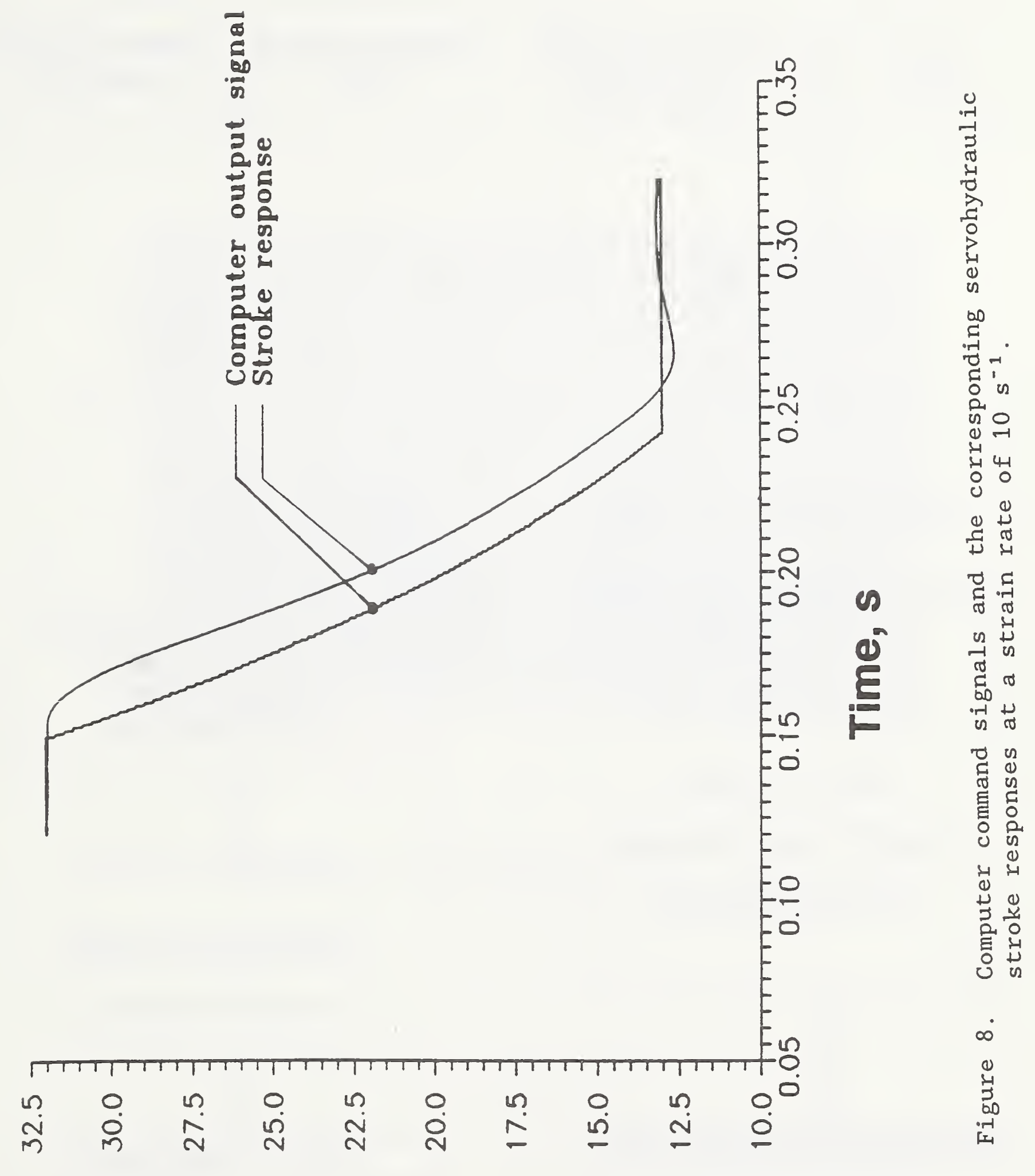

แس 'นนәแәวе|ds! 


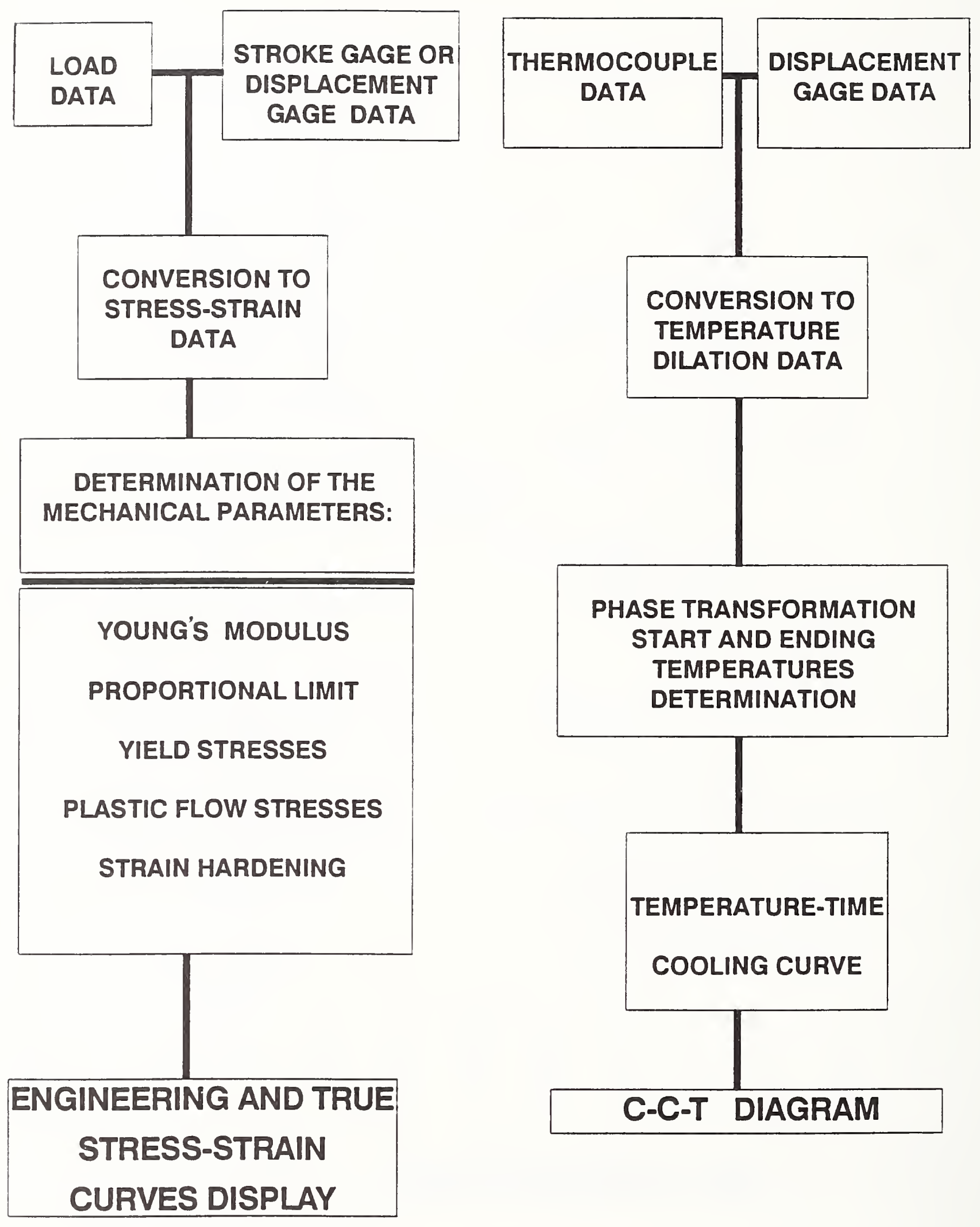

Figure 9. The flow diagram of the post-test analysis program. 


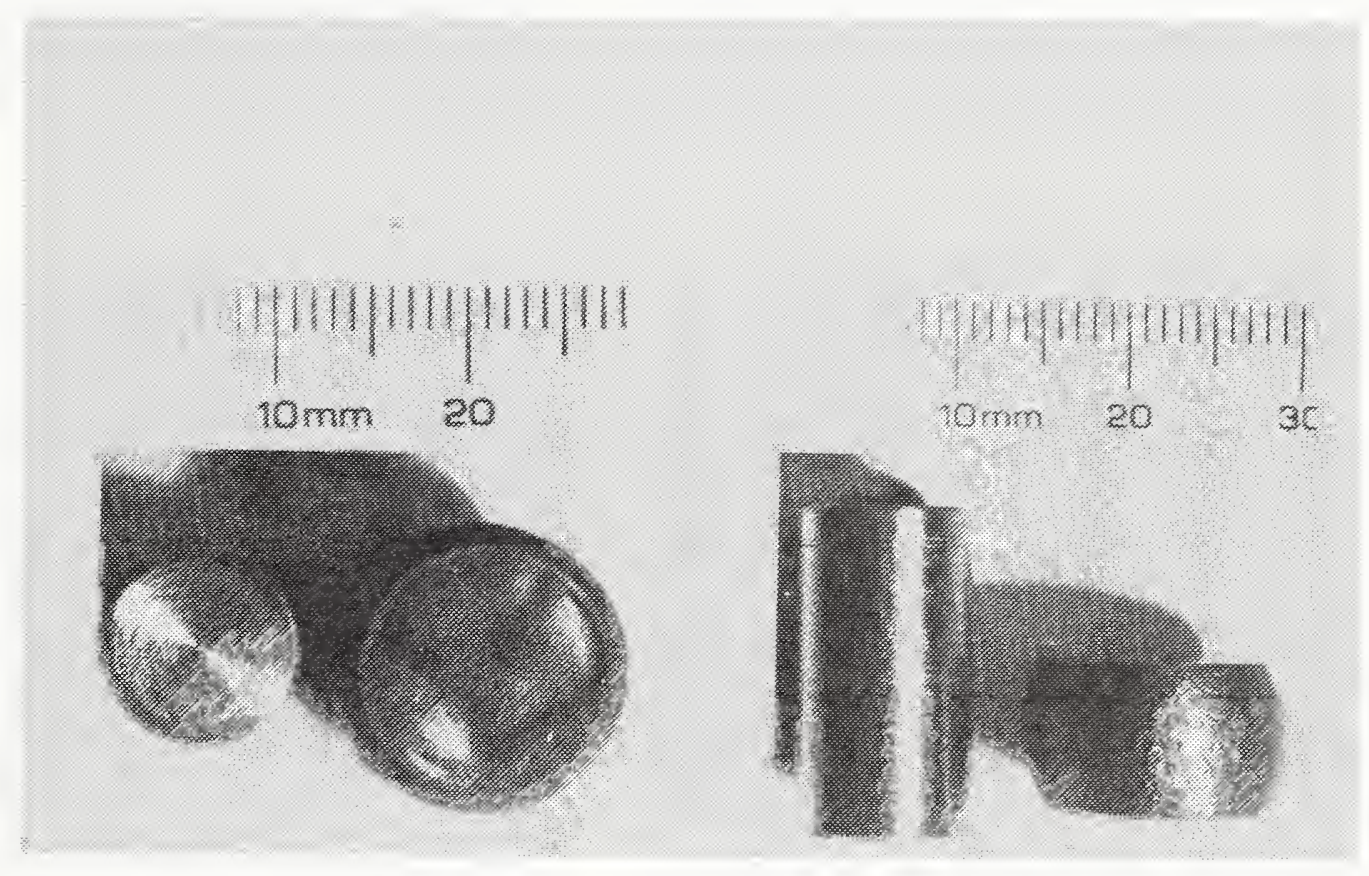

Figure 10. Pictures of the specimen used in the direct-quenching simulation study; before and after deformation. 


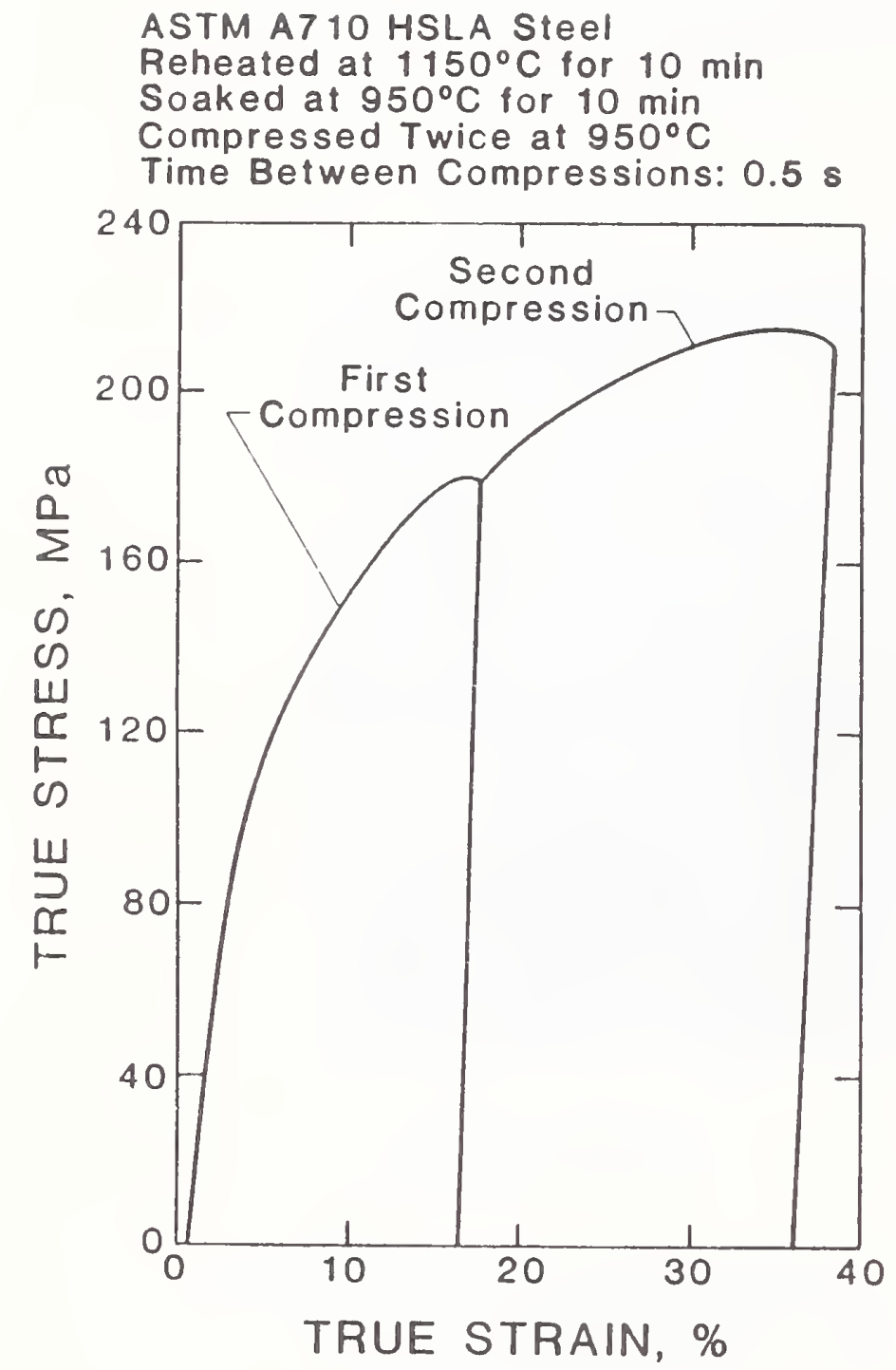

(a)
ASTM A710 HSLA Steel Reheated at $1150^{\circ} \mathrm{C}$ for $10 \mathrm{~min}$ Soaked at $1000^{\circ} \mathrm{C}$ for $10 \mathrm{~min}$ Compressed Twice at $1000^{\circ} \mathrm{C}$

Time Between Compressions: $30 \mathrm{~s}$

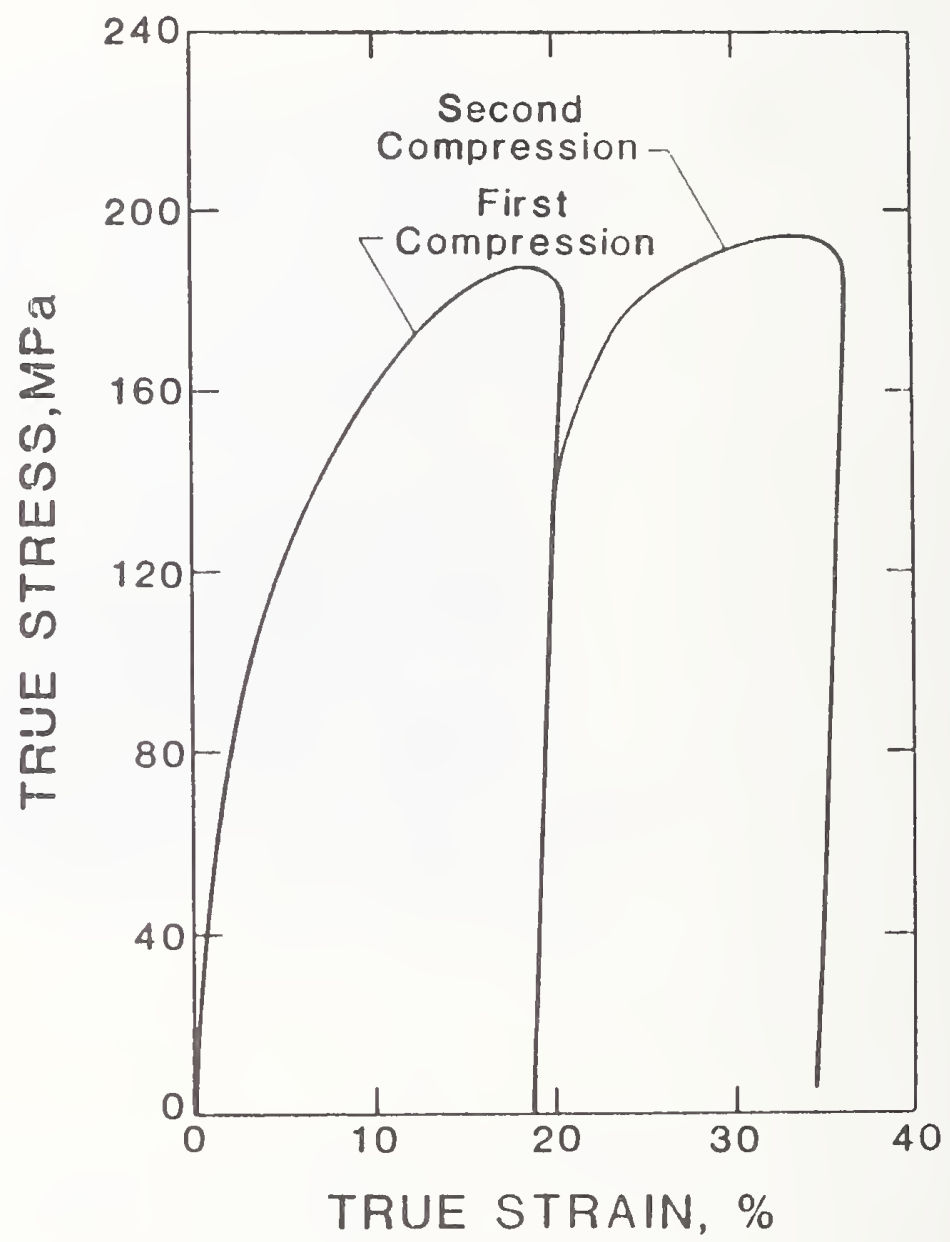

(b)

Figure 11. Results of double-deformation test on ASTM A710 steel. (a) no softening in the second compression indicating no recrystallization occurred; (b) softening in the second compression indicating some degree of recrystallization occurred. 


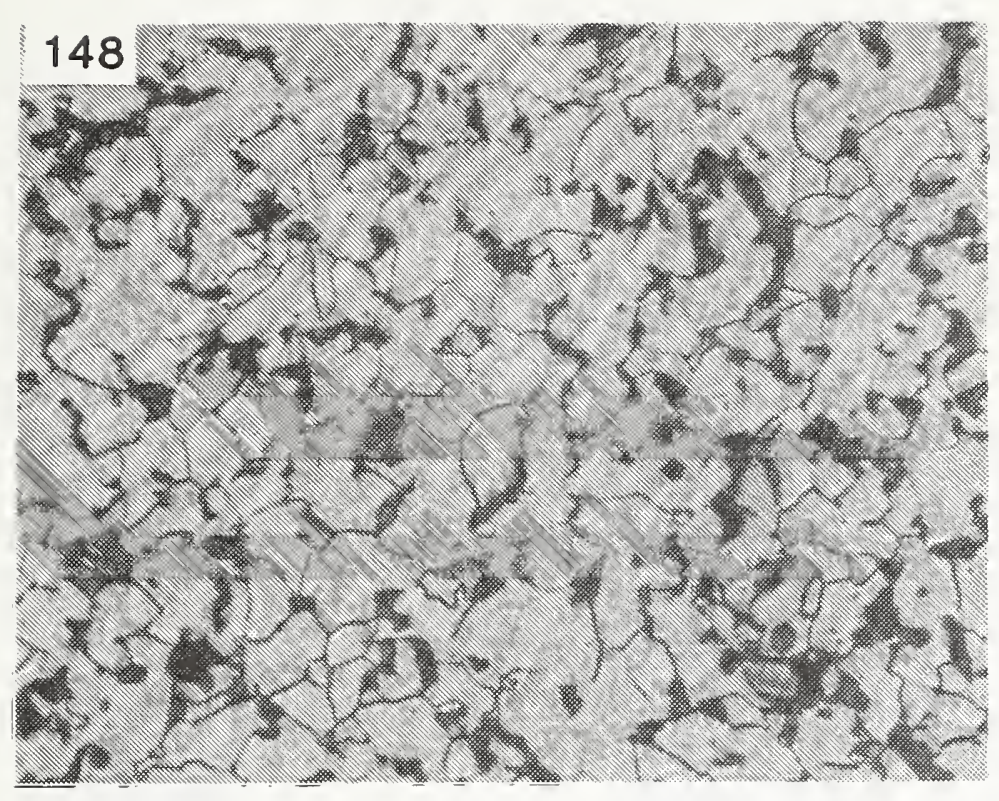

(a)

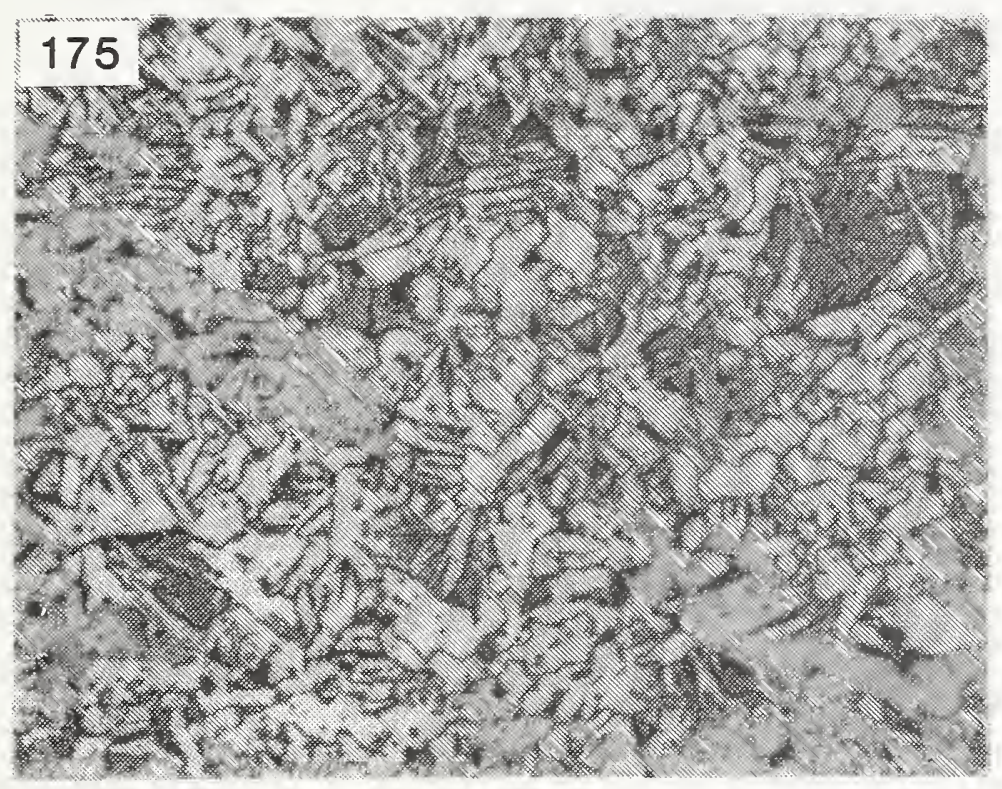

(b)

Figure 12. Microstructures of ASTM A710 steel specimens with different thermomechanical treatments; (a) and (b): reaustenitized at $910^{\circ} \mathrm{C}$ then cooled slowly and gas quenched, respectively, without deformation; (c) through (e): treatments a through $c$ described

in table 1. Etch: 38 nital.

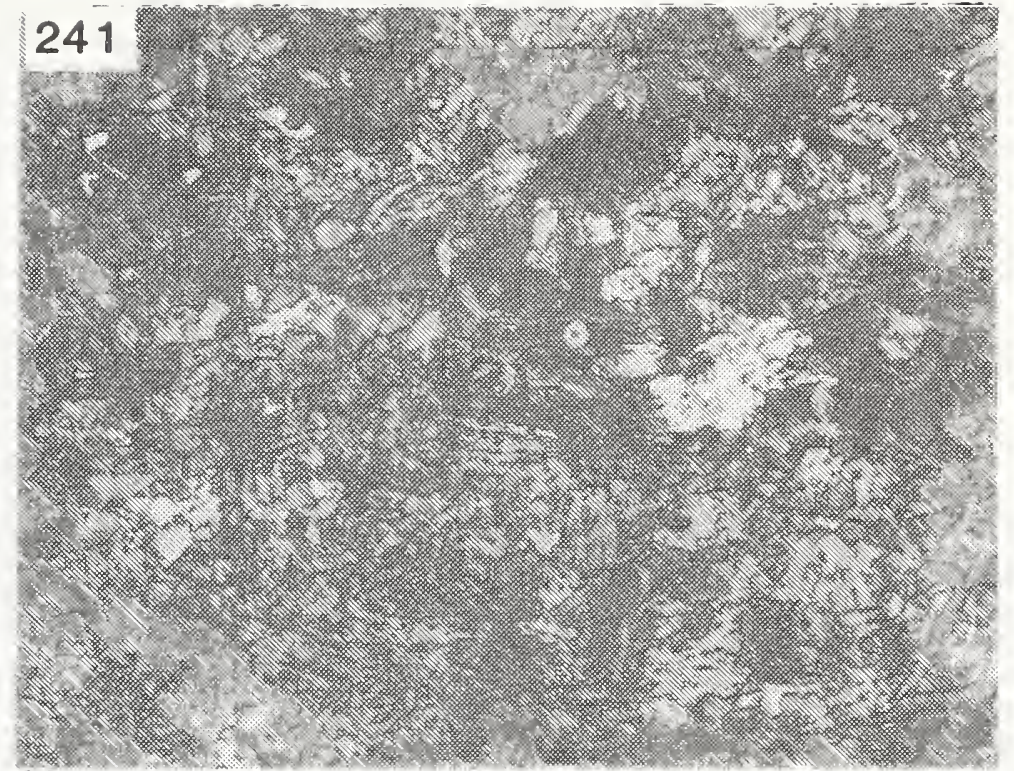

(c)

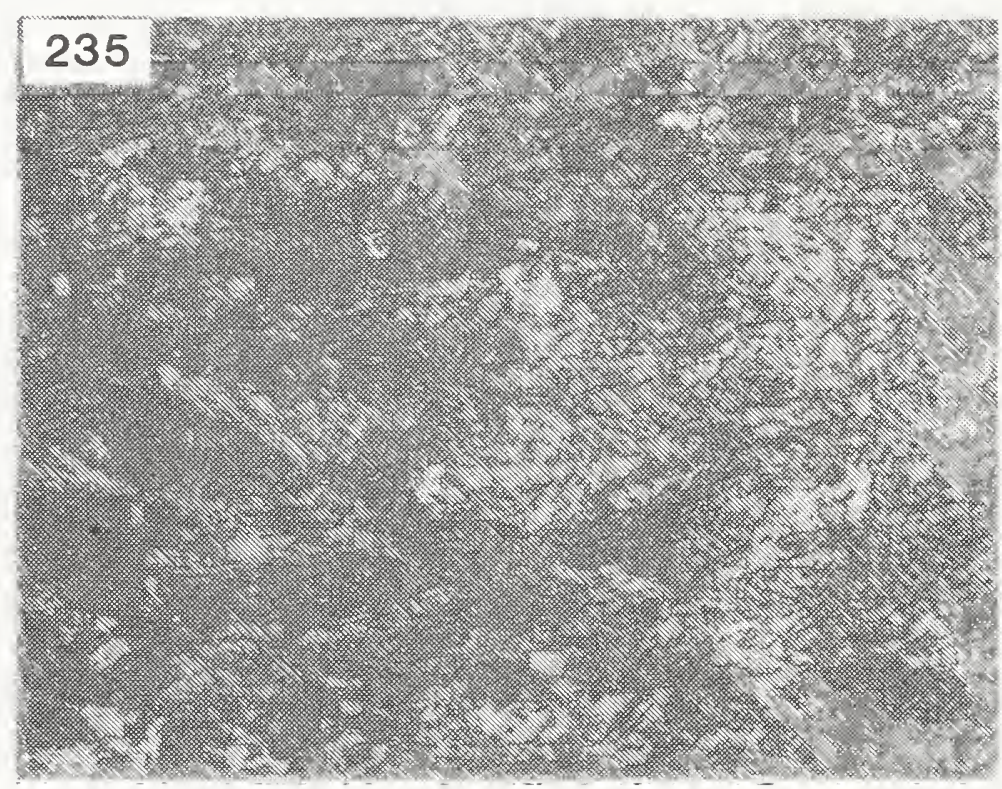

(d)

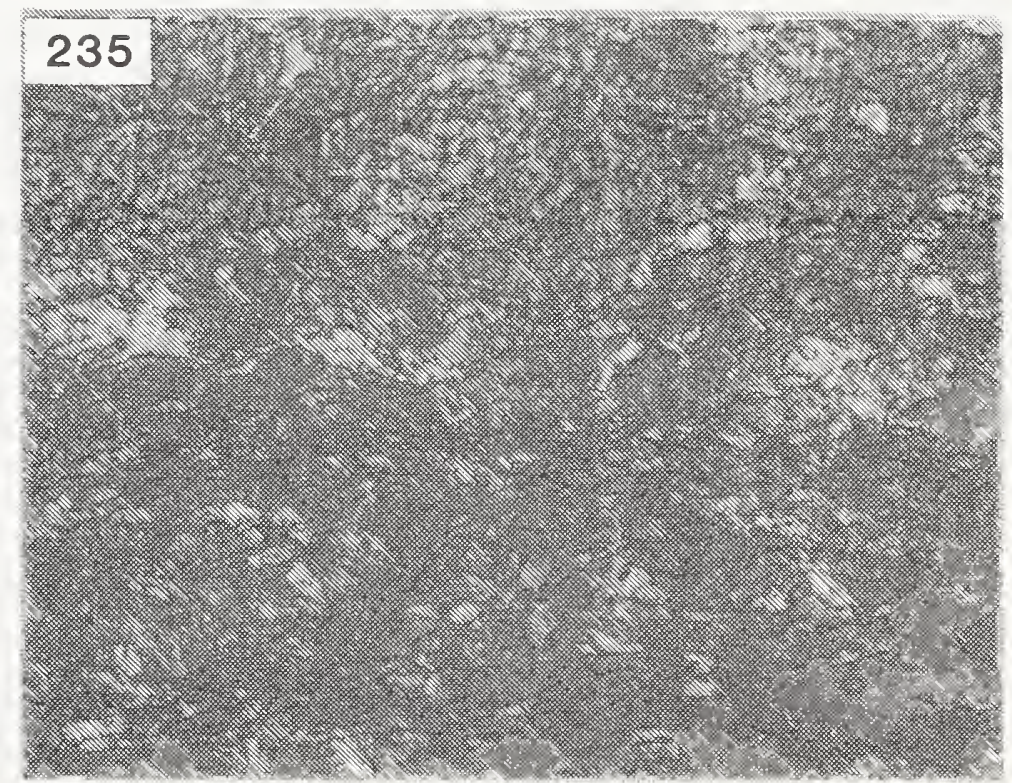

(e)

$\overline{40 \mu \mathrm{m}}$ 


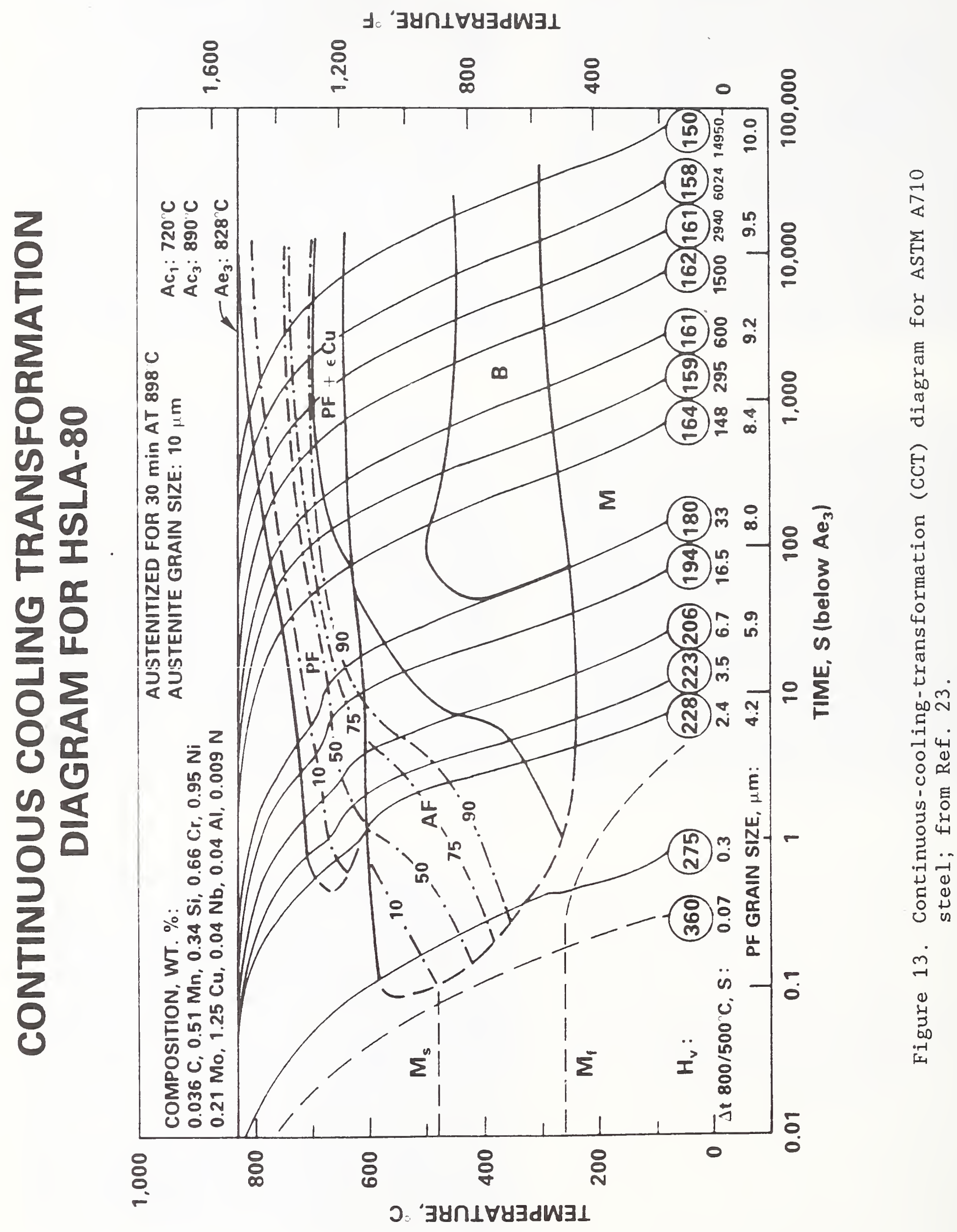



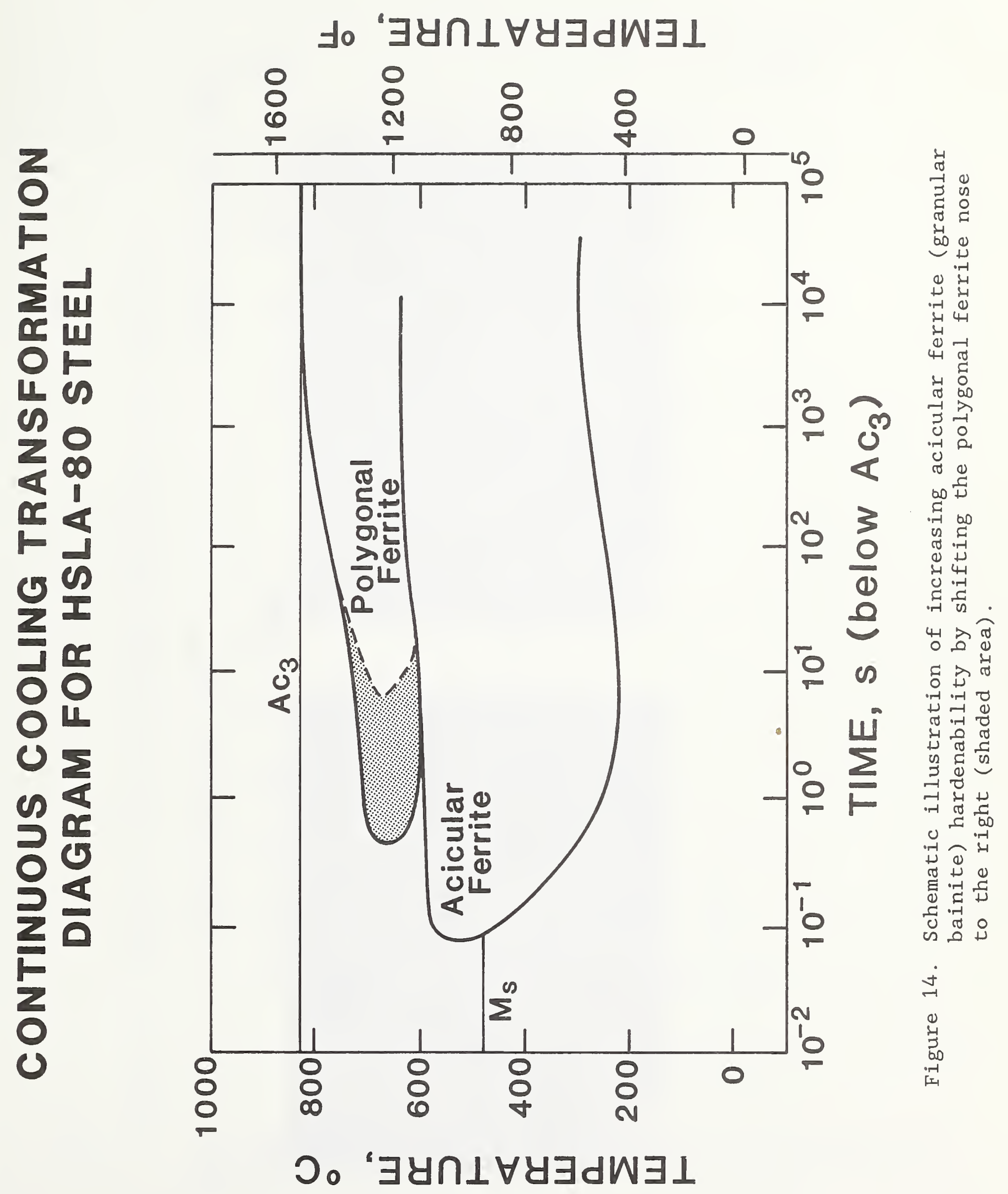

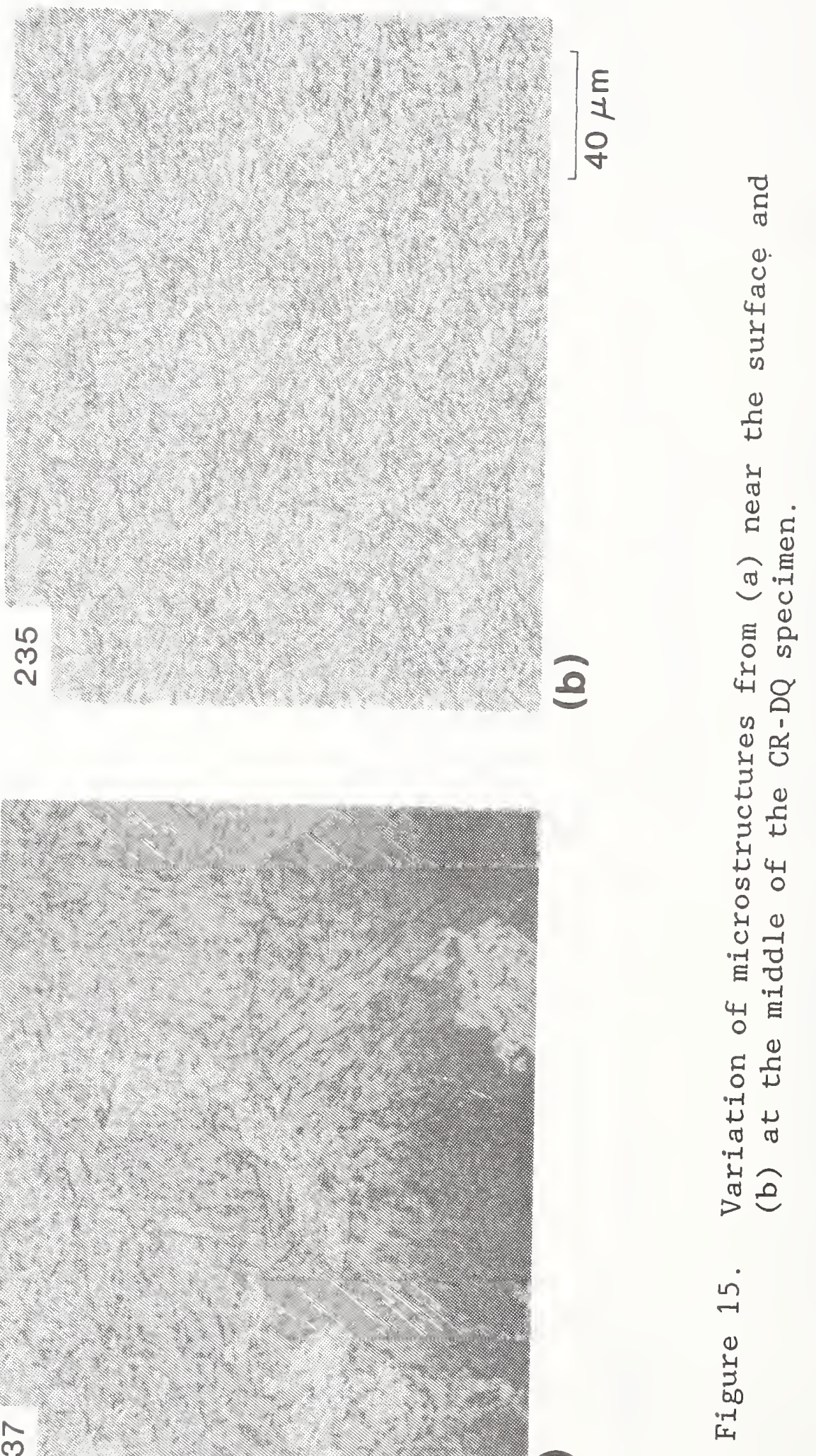


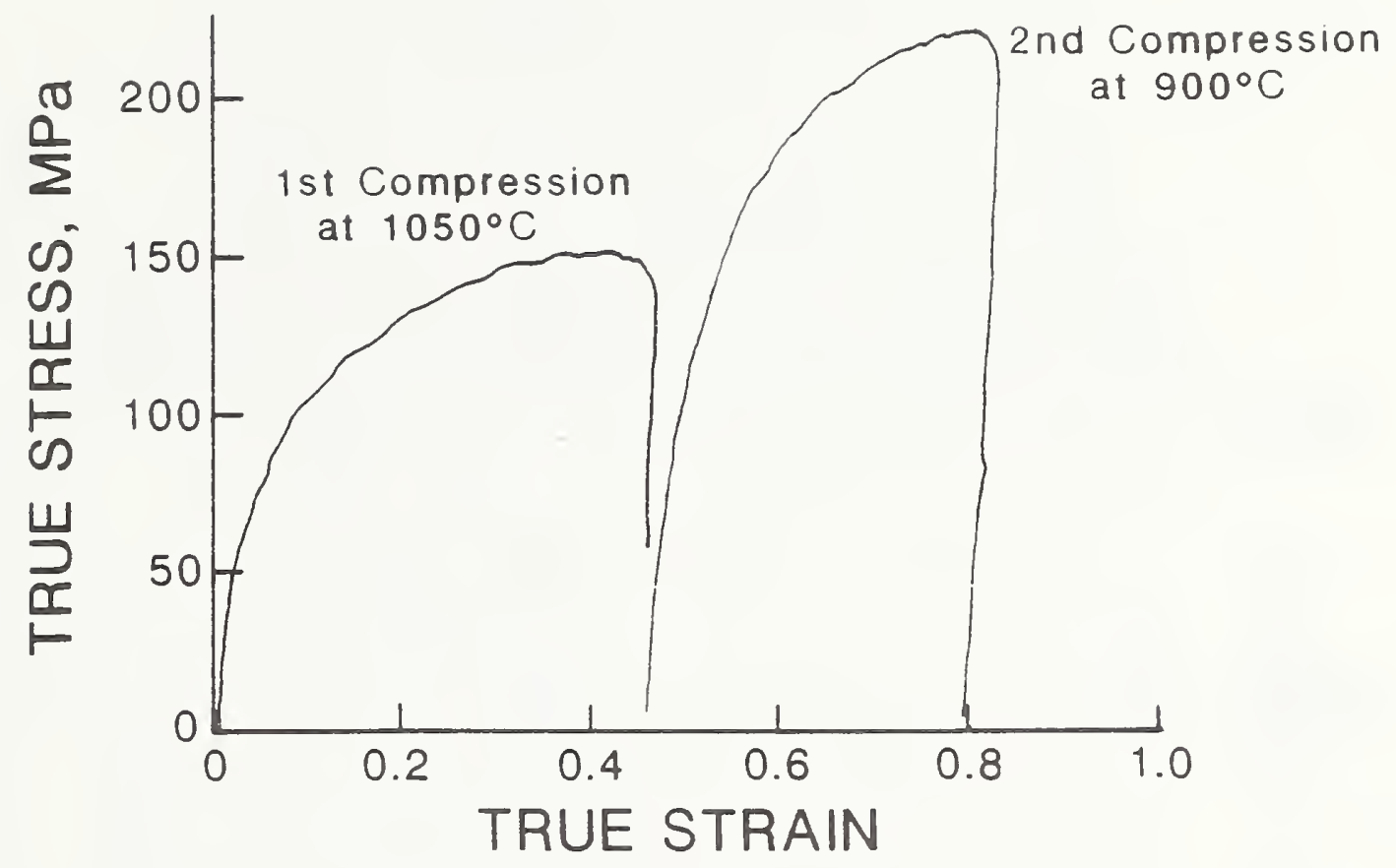

(a)

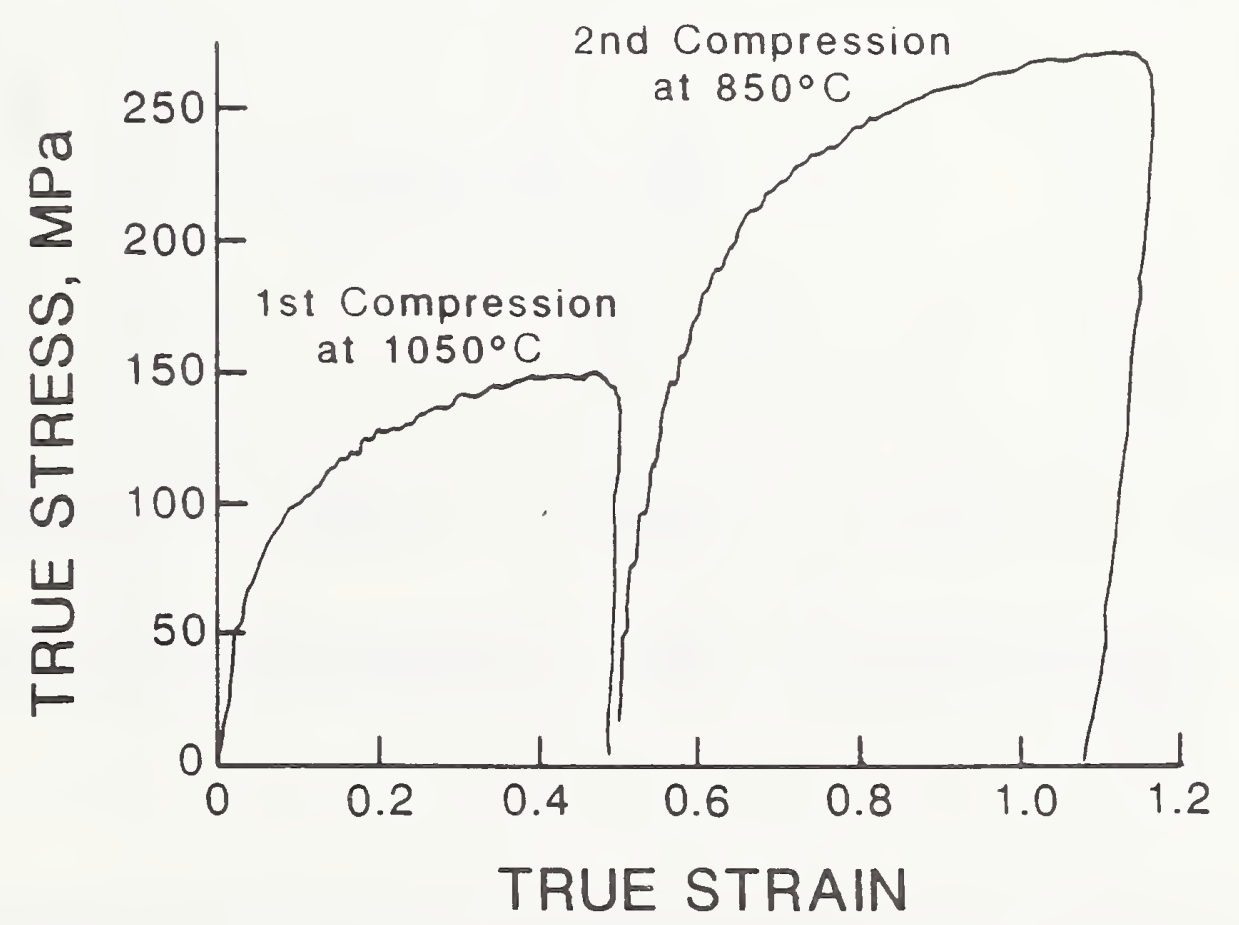

(b)

Figure 16. True $\sigma-\epsilon$ curves obtained in simulated CR-DQ experiments (see Table 1); (a) treatment a in Table 1; (b) treatment $c$ in Table 1. 


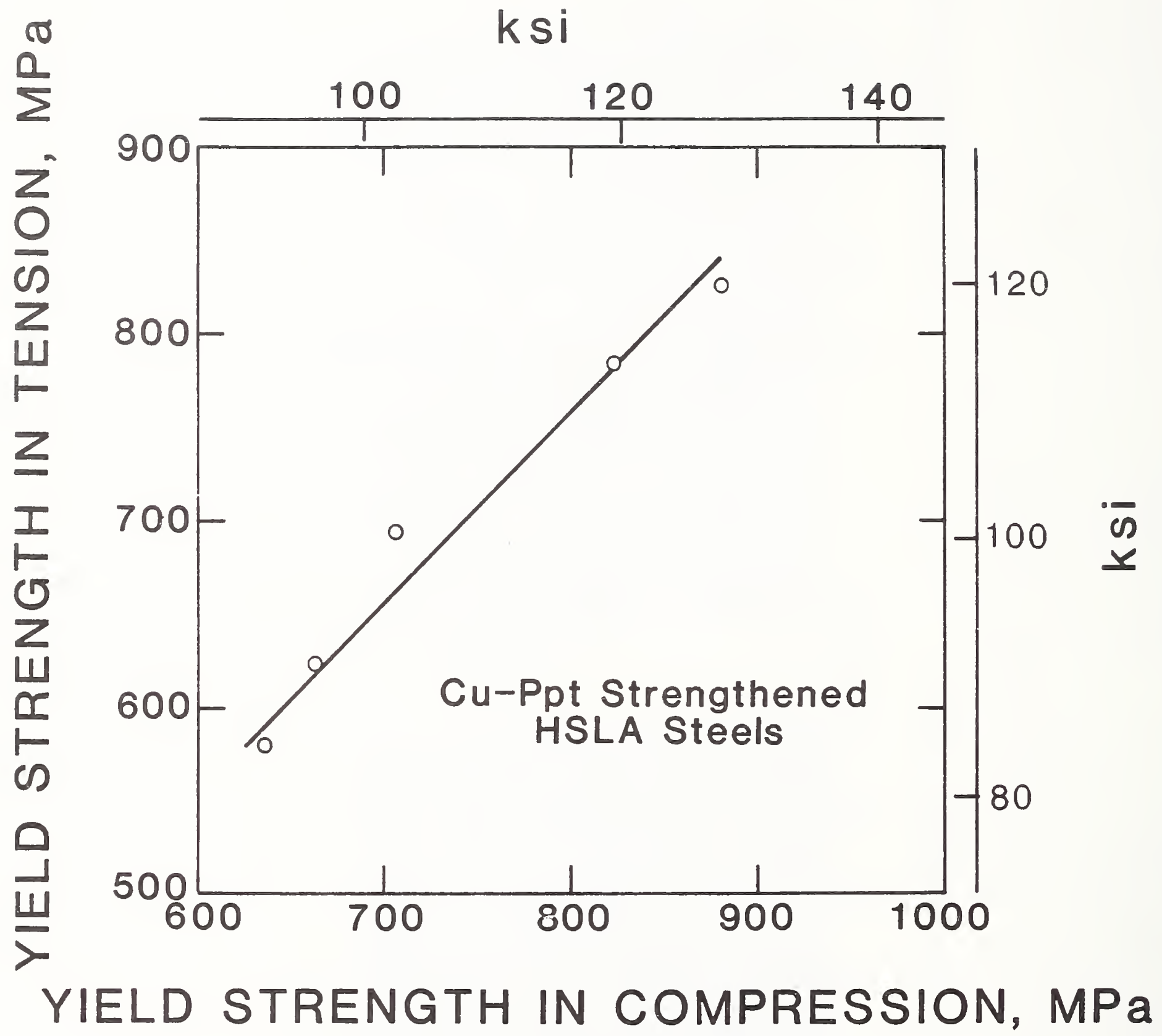

Figure 17. Correlation of yield strengths in tension and yield strengths in compression. Results of tension and compression at one strength level were obtained from the same steel plate. 
IS가

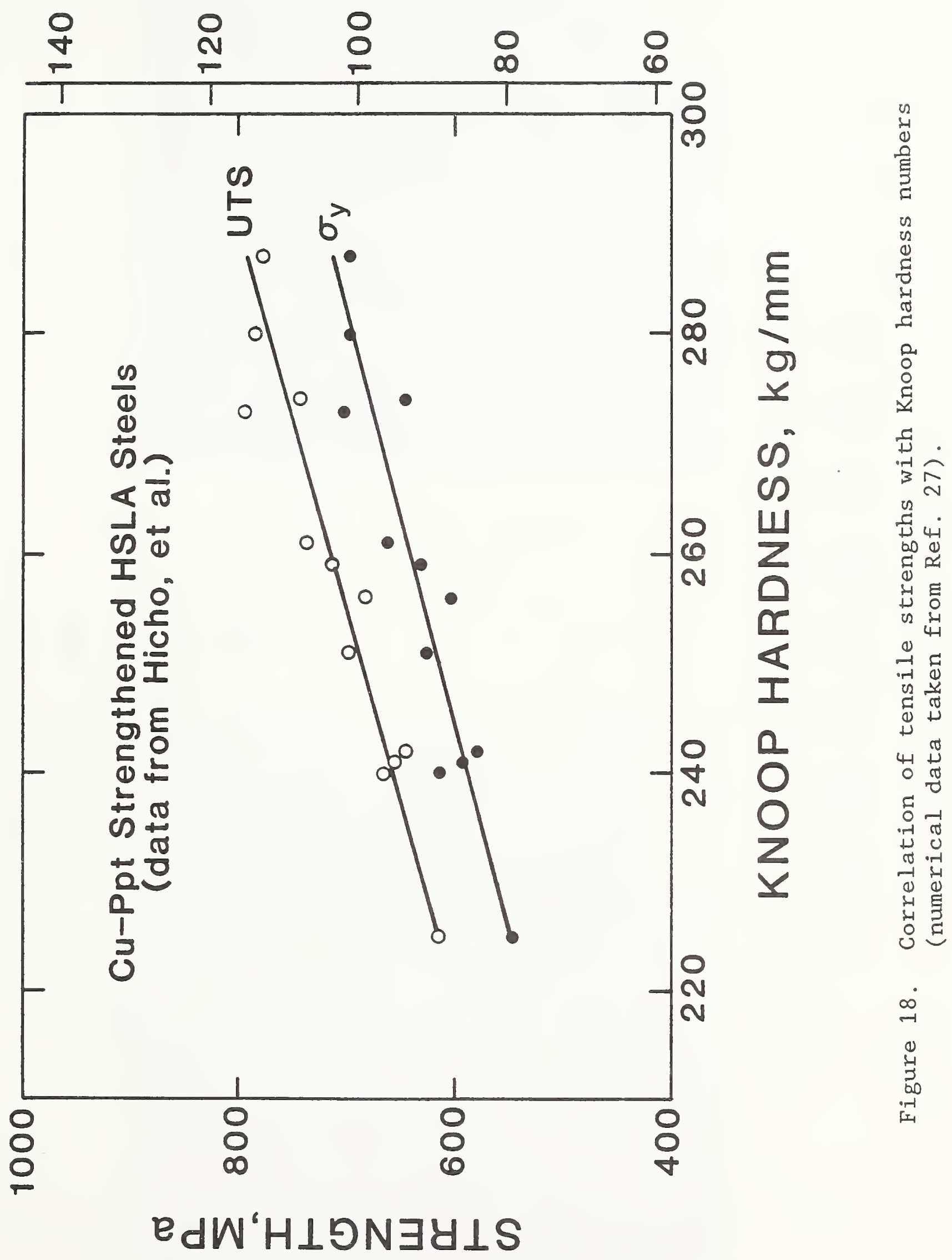




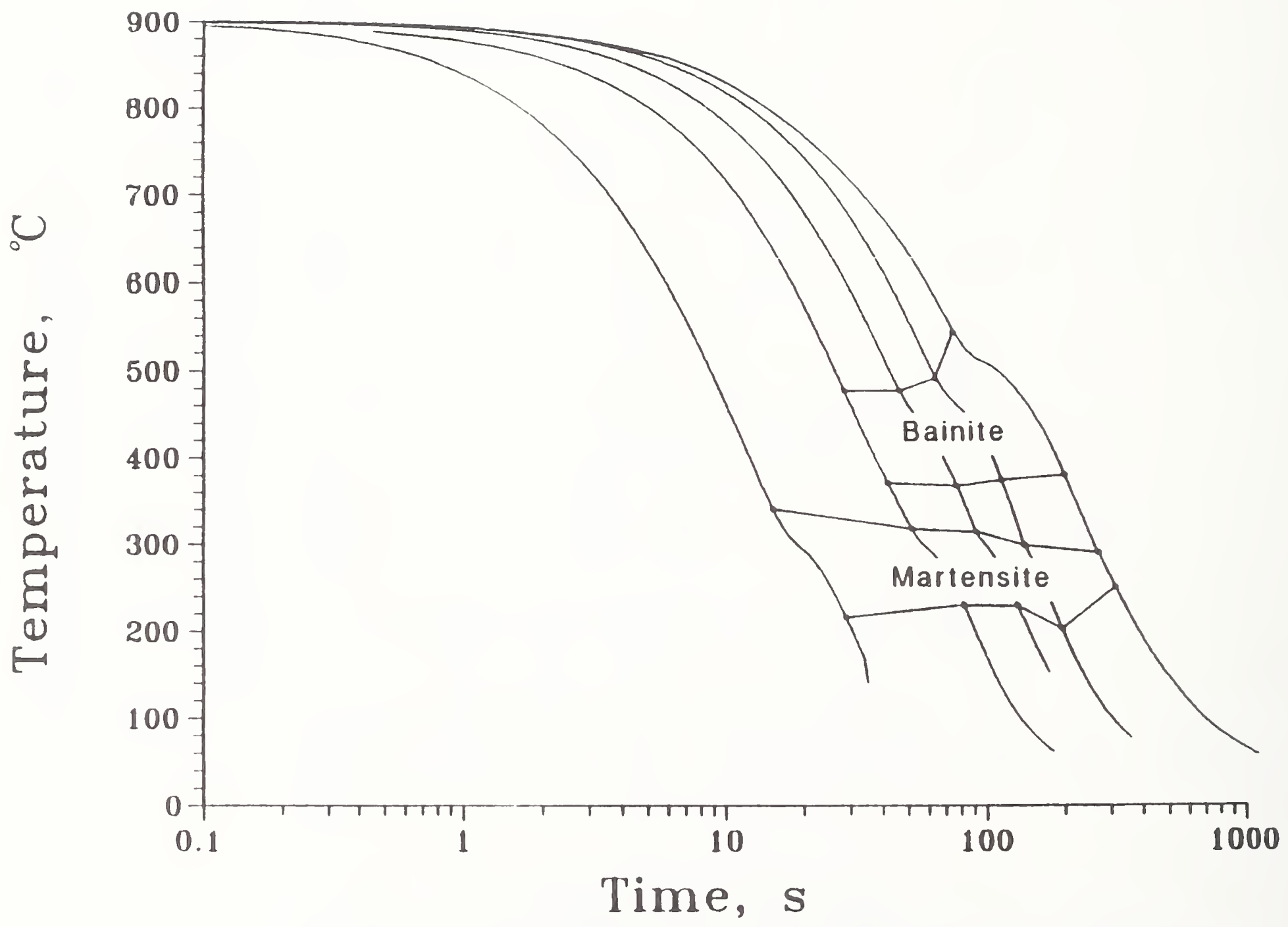

Figure 19. The CCT diagram of microalloyed 1522 forging steel. 

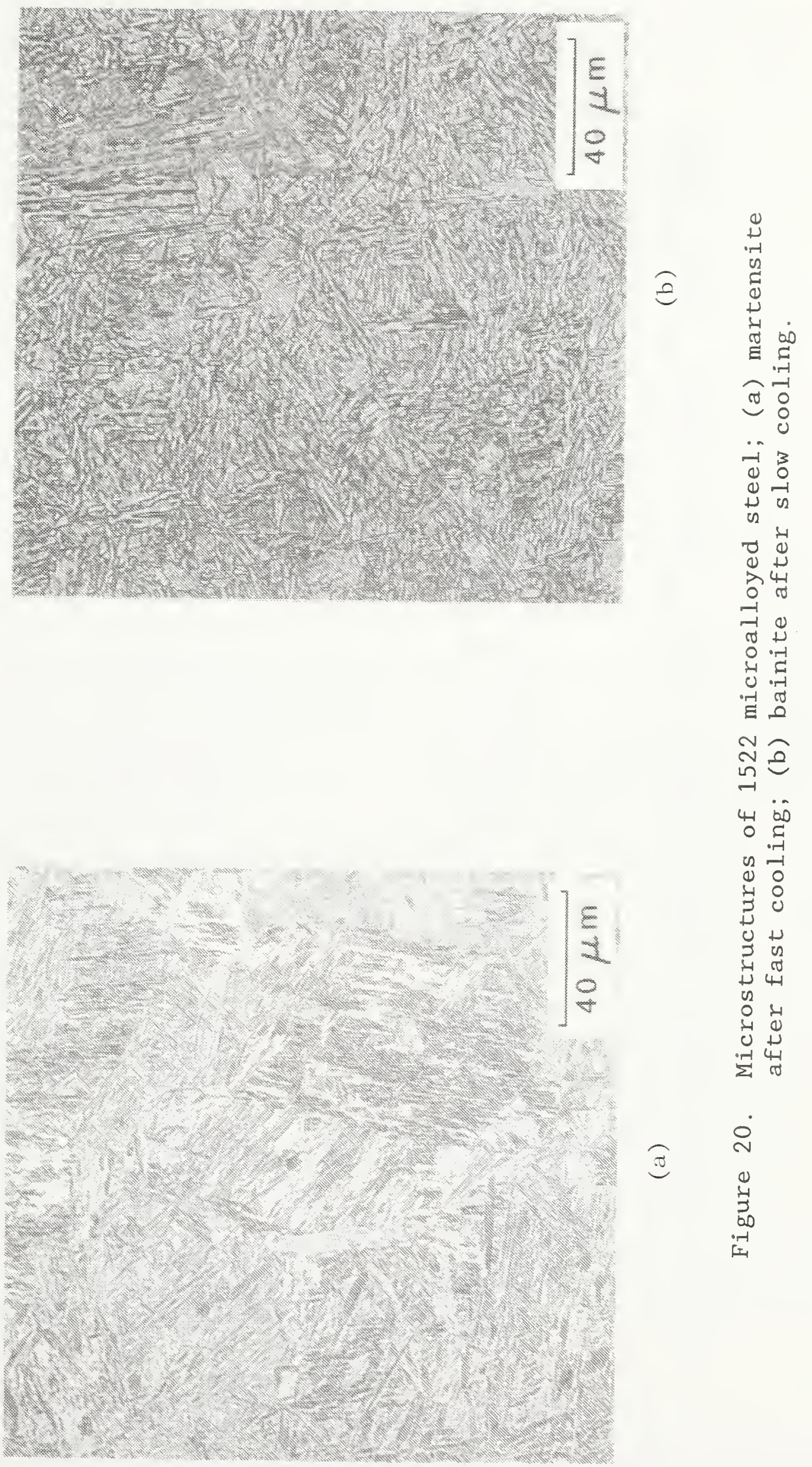

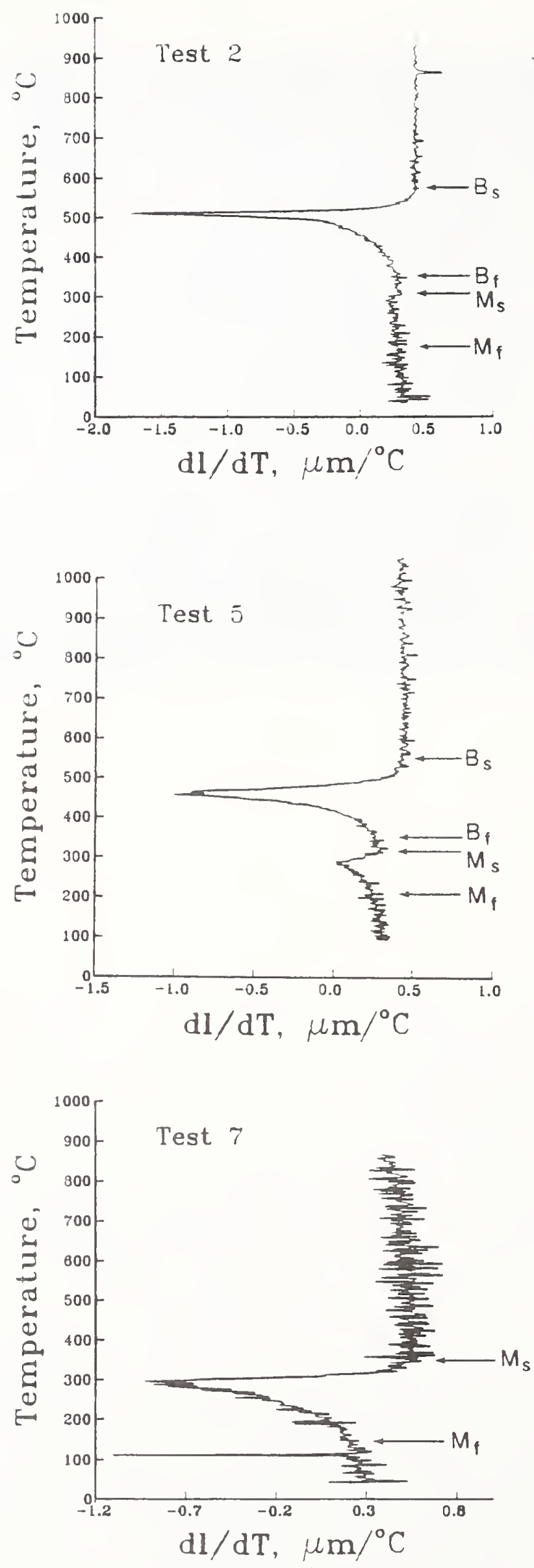

Figure 21. Determination of phase-transformation temperatures using the seven-point incremental polynomial technique. $B_{S}$ : bainite starts; $\mathrm{B}_{\mathrm{f}}$ : bainite finishes; $\mathrm{M}_{\mathrm{S}}$ : martensite starts; $\mathrm{M}_{\mathrm{f}}$ : martensite finishes. 


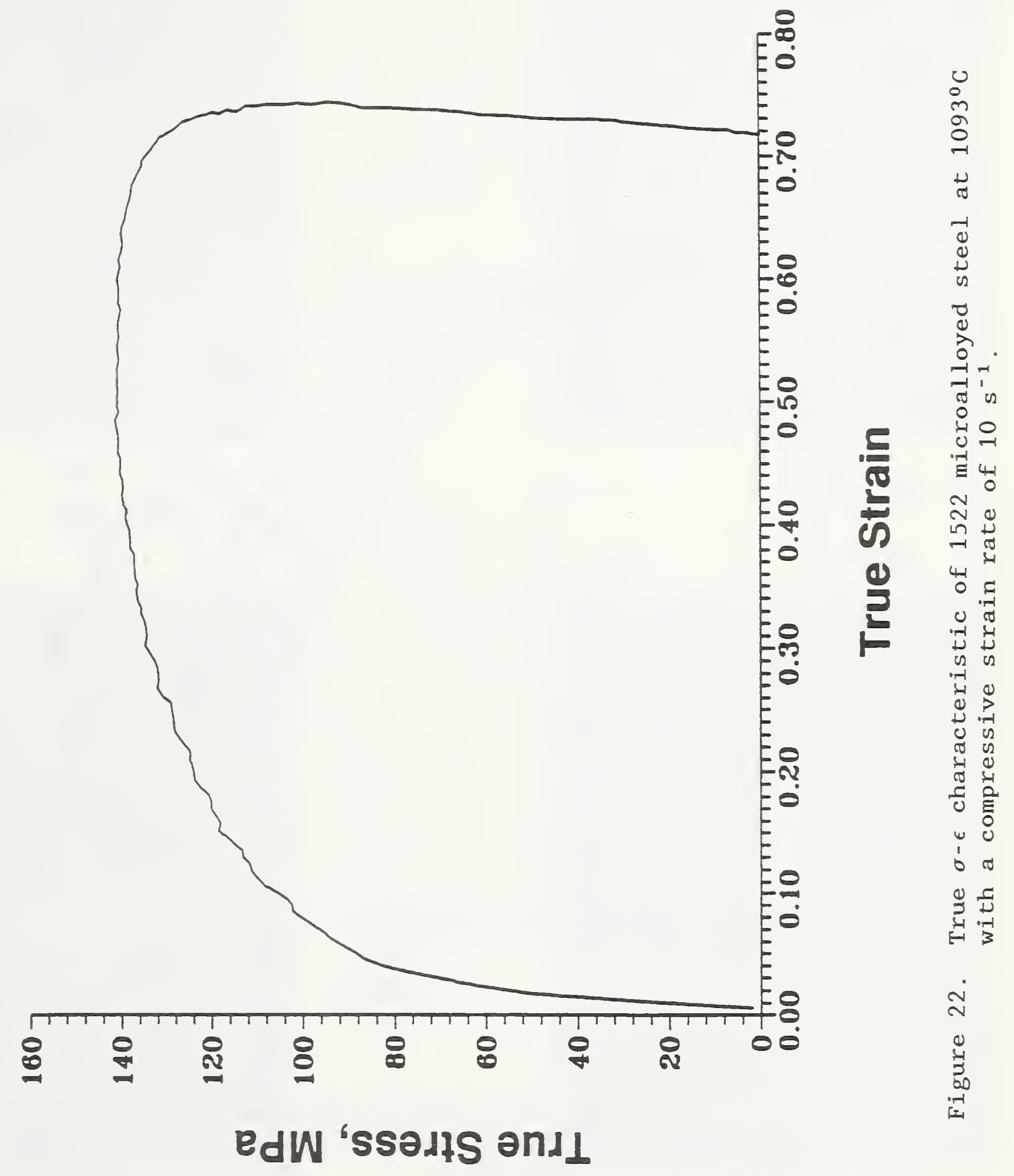




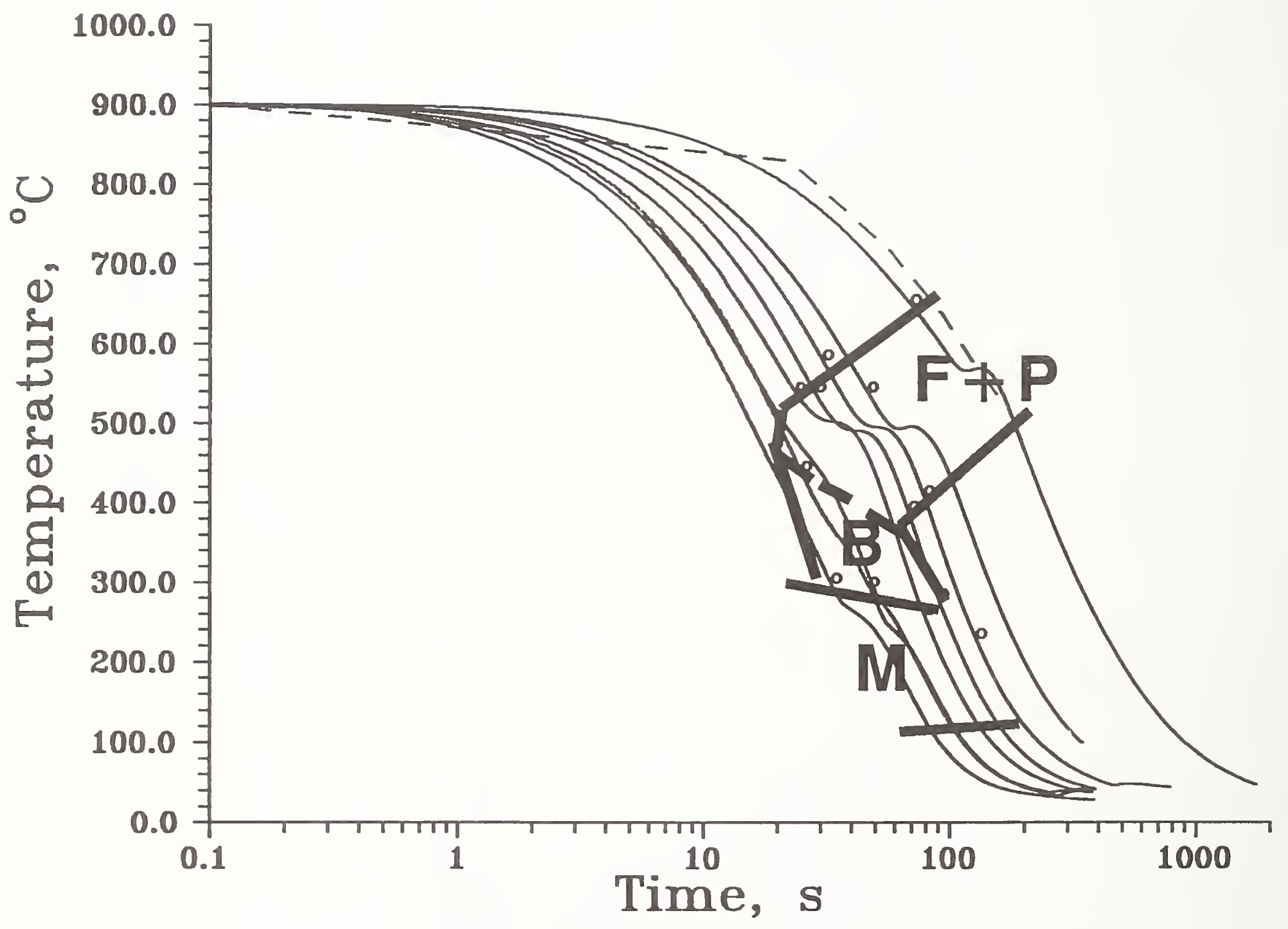

Figure 23. The CCT diagram of the 1141 microalloyed forging steel. Dashed line is the typical cooling rate found in a forging without forced cooling (Ref. 31). 


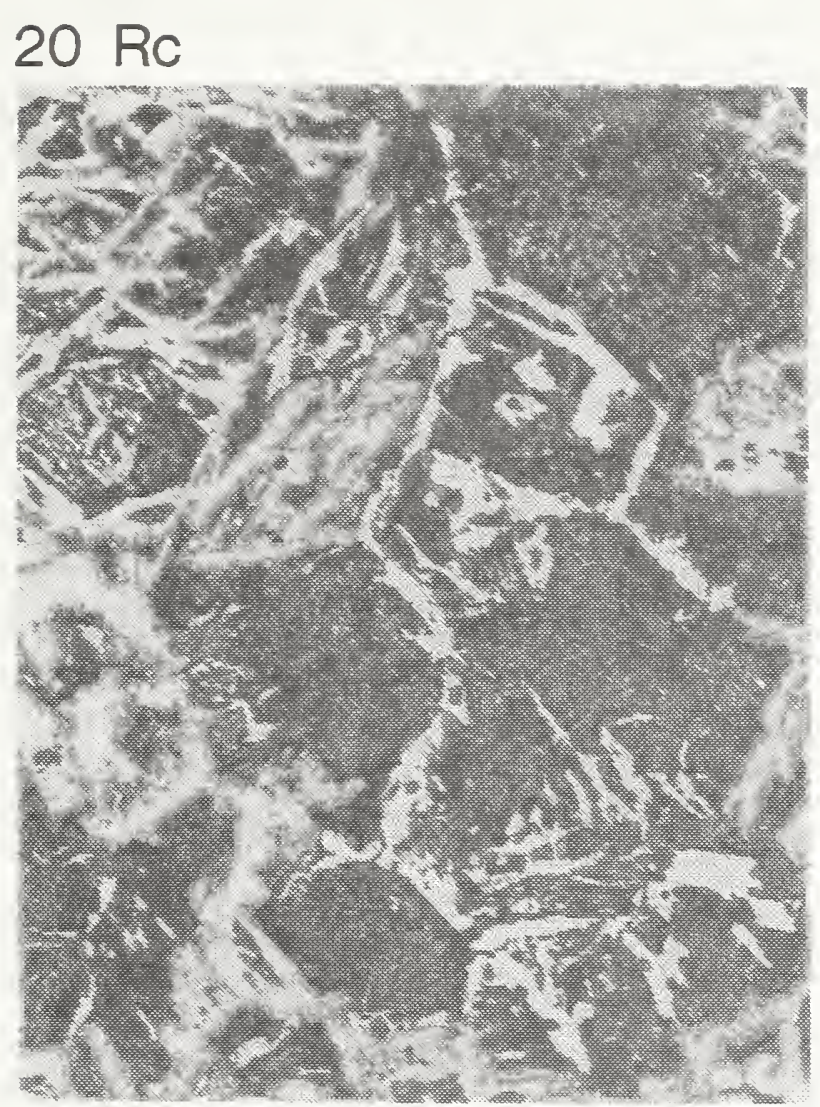

(a)

\section{$29 \mathrm{Rc}$}

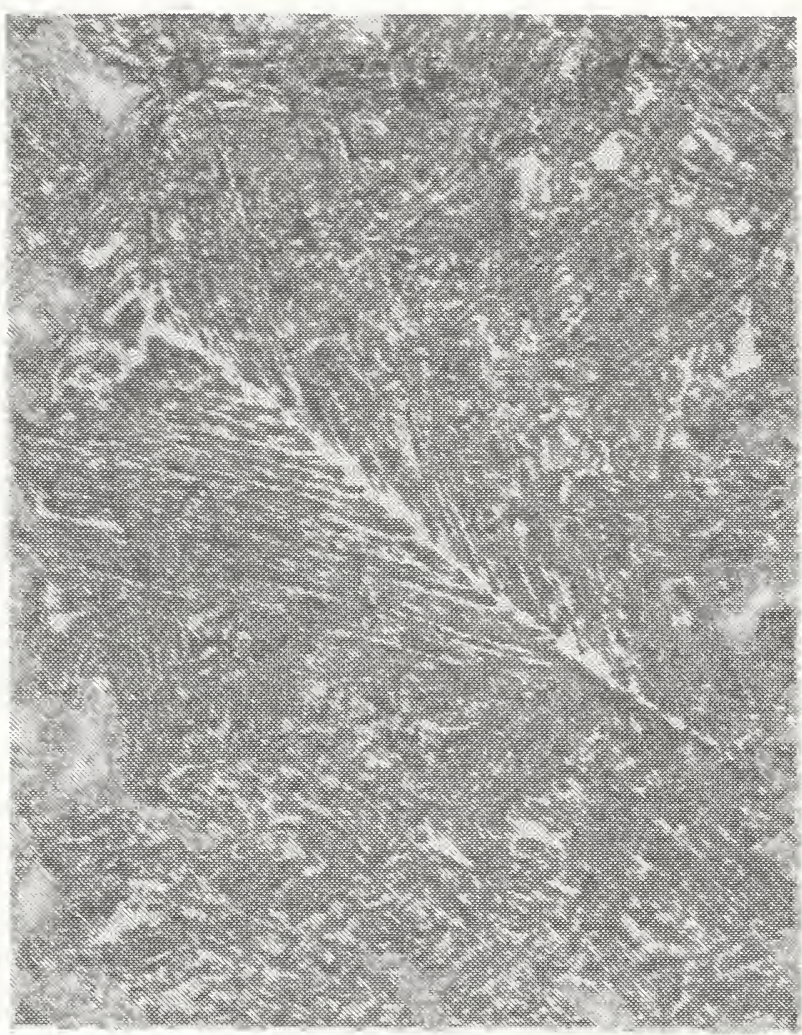

(b)

\section{$50 \mathrm{Rc}$}

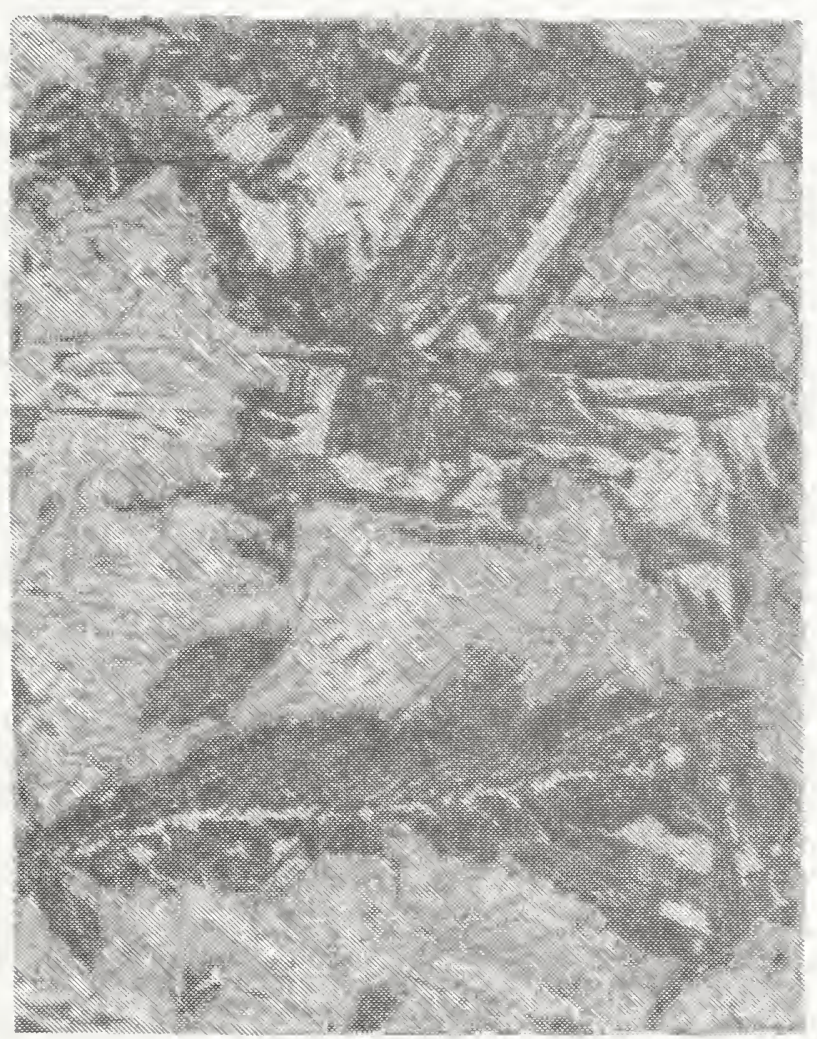

(c)
$42 \mathrm{Rc}$

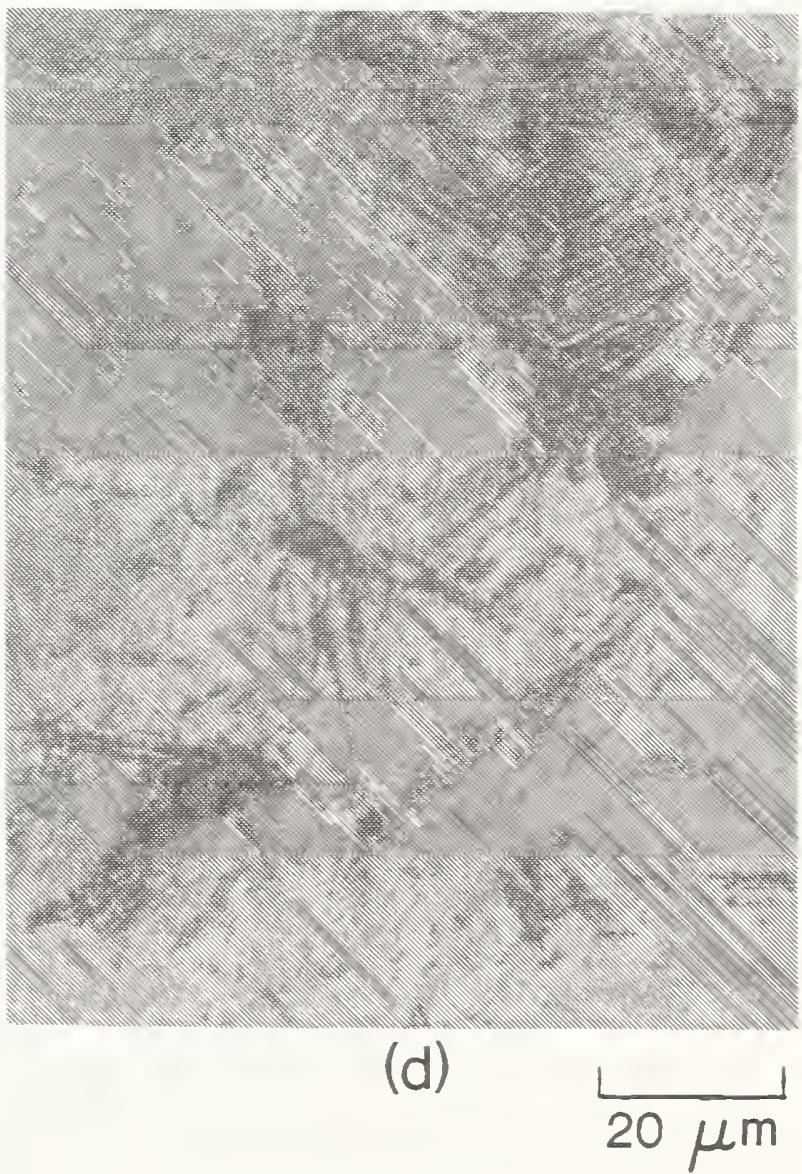

Figure 24. Microstructures of the microalloyed 1141 steel with different cooling rates. (a) ferrite plus pearlite; (b) pearlite-ferrite (Widmanstatten) plus small portion of bainite; (c) bainite plus small portion of martensite; (d) martensite plus small portion of bainite. 
APPENDIX 1. Computer Program Listing for System Control and Data Acquisition 


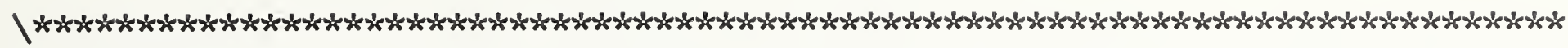
1 SYSTEM CONTROL AND DATA ACQUISITION PROGRAM

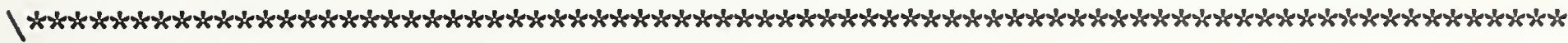

65280 SYSTEM. BUFFER. SIZE

DIM[ 10,50 ] STRING.ARRAY SCOPE.BACK

14 GPIB.DEVICE SCOPE SCOPE.BACK "GPIB.BUFFER

REAL DIM[ 50 ] ARRAY []DATA. WAVETEK

2 GPIB.DEVICE WAVETEK [] DATA.WAVETEK [] GPIB.BUFFER

SEND. INTERFACE. CLEAR

REMOTE. ENABLE.ON

4000 TIMEOUT

REAL SCALAR TOTALtime

SCALAR DELAY

SCALAR EPStotal

SCALAR STRKFACTOR

\Conversion factor (stroke): V to $\mathrm{mm}$

SCALAR PFACTOR

\Conversion factor (load): $\mathrm{V}$ to $\mathrm{kN}$

SCALAR ACTUORGAGE

$\backslash$ Checking if actuator or gage is used for strain

SCALAR VFACTOR

\ Starting point in displacement curve on oscilloscope.

SCALAR AA

SCALAR VALVEfactor

SCALAR TEMP

\Temperature inputs

SCALAR VTEMPmean

\20-point average for temperature determination in $\mathrm{mV}$

SCALAR VTEMP

\Average mV for temperature checking

SCALAR 1stTEMP

$\backslash 1$ st compression temperature

SCALAR TT

$\backslash$ Test temperature

INTEGER SCALAR NMAX

SCALAR ASCDIM

SCALAR ASCDIM1

40 STRING FILENAME

40 STRING FILENAME1

20 STRING SPECIMEN.NAME

20 STRING MATERIAL

64 STRING TREATMENT

15 STRING TEST.DATE 
20 STRING OPERATOR

64 STRING TEMPERATURE

64 STRING TEST.TYPE

64 STRING RESERVED

RAEL DIM[ 1000 ] ARRAY TTRANS

REAL DIM[ 1000 ] ARRAY DTRANS

REAL DIM[ 200 ] ARRAY VOLTOUT

REAL DIM[ 200 ] ARRAY TIMEI

REAL DIM[ 50 ] ARRAY PARAM

REAL DIM[ 1500 ] ARRAY PLOAD

REAL DIM[ 1500 ] ARRAY DISPL.

REAL DIM[ 1500 ] ARRAY STRESS

REAL DIM[ 1500 ] ARRAY STRAIN

REAL DIM[ 1500 ] ARRAY SIGMA

REAL DIM[ 1500 ] ARRAY EPSILON

REAL DIM[ 1500 ] ARRAY EPLAST

REAL DIM[ 1500 ] ARRAY L

Instantaneous gage length

REAL DIM[ 1500 ] ARRAY STS

REAL DIM[ 1500 ] ARRAY STN

REAL DIM[ 9 ] ARRAY deltaH

REAL DIM[ 9 ] ARRAY tTEMP

0 . PARAM :=

0 . PLOAD :=

0. DISPL. : =

0 . STRESS :=

0 . STRAIN $:=$

0 . SIGMA :=

0 . EPSILON :=

0 . EPLAST $:=$

0 . $\mathrm{L}:=$

0 . VOLTOUT :=

0 . TIMEI :=

0 . TTEMP :=

0 . deltaH :=

0. $\operatorname{STN}:=$

0 . $\operatorname{STS}:=$ 

0 . TTRANS :=
0 . DTRANS :=
DT2820

$0 \quad 0$ D/A.TEMPLATE DTOA

11 D/A.TEMPLATE DToA1

33 A/D. TEMPLATE T

11 A/D. TEMPLATE $G$

." INPUT.PARAMETERS "

: INPUT . PARAMETERS

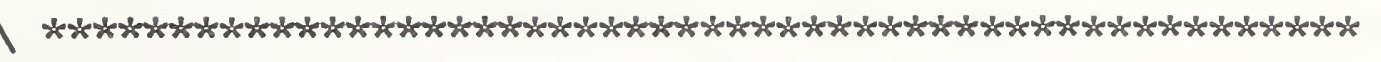

0 . PARAM :=

CR CR

. Enter the specimen name (8 CHARACTERS EXACTLY $1111 !$ )" "INPUT

SPECIMEN.NAME ":=

CR CR ." Enter the material (20 CHARACTERS) " "INPUT .

MATERIAL ":=

CR CR ." Enter the thermal treatment (64 CHARACTERS) " "INPUT

TREATMENT ":=

CR CR ."Enter the test date (MM/DD/YY) " "INPUT

TEST.DATE ":=

CR CR ." Enter the operator's name (20 CHARACTERS) " "INPUT

OPERATOR ":=

CR CR

. Enter the test temperatures for future record (64 CHARACTERS) " "INPUT

TEMPERATURE ":=

CR CR

." Enter the test type (Tension/Compression with/without ext. etc.,(64 CHAR.) " "INPUT

TEST.TYPE ":=

CR CR ." Enter any additional data (64 CHAR.) " "INPUT

RESERVED ":=

CR CR ." Hit 0 for TENSION or 1 for COMPRESSION " \#INPUT

PARAM [ 2 ] := \Tension/Compression

CR CR ." Enter the initial height of the stroke (mm) "\#INPUT

PARAM [ 4 ] :=

CR CR ." Enter gage length Lo/Ho (mm) " \#INPUT

PARAM [ 5 ] :=

Total initial length (Lo) 
CR CR ." Enter specimen's area Ao (sq. mm) " \#INPUT

PARAM [ 6 ] : :=

\Initial area (AO)

$\backslash$ PARAM [ 16 ] is reserved for NMAX

CR CR ." Enter FILE NAME for data saving (20 CHAR.) " "INPUT

FILENAME ":=

SCREEN.CLEAR

CR CR ." How many hits do you want? (up to 10) " \#INPUT

PARAM [ 1 ] :=

CR CR ." Enter how-many-N per $1 \mathrm{~V}$ (Newtons) " \#INPUT

PFACTOR :=

CR CR ." Enter how-many-V (stroke) per $1 \mathrm{~mm}$ (volts) " \#INPUT

STRKFACTOR :=

PFACTOR PARAM [ 3 ] :=

CR CR ." Enter 1 for ACTUATOR, 0 for GAGE " \#INPUT

ACTUorGAGE :=

ACTUOIGAGE PARAM [ 7 ] :=

CR CR ." Enter the desired true strain rate (1/s) " \#INPUT

PARAM [ 19 ] :=

CR CR ." Enter the COOLING-RATE $(0 .=0 \mathrm{~V}$ equivalent to valve close;

$5 .=5 \mathrm{~V}$ equivalent to valve fully open) "\#INPUT

VALVEfactor :=

VALVEfactor PARAM [ 17 ] :=

CR CR ." Enter the desired FINAL height after the 1st HIT (mm) " \#INPUT PARAM [ 21 ] :=

CR CR ." Enter the temperature (deg. C) for the 1st Hit "\#INPUT

1 stTEMP :=

1stTEMP PARAM [ 18 ] :=

CR CR

NORMAL. DISPLAY

PARAM [ 1 ] $1>$ IF

PARAM [ 1 ] 1 DO

." Enter Delta-Height (mm) for hit No - " I $1+. . "$ \#INPUT

deltaH [ I ] :=

CR CR

LOOP

deltaH [ 1 ] PARAM [ 8 ] :=

2nd hit 


$\begin{array}{llll}\text { deltaH [ } 2 \text { ] PARAM [ } 9]:= & \backslash 3 \text { rd hit } \\ \text { deltaH [ } 3 \text { ] PARAM [ } 10]:= & \backslash 4 \text { th hit } \\ \text { deltaH [ } 4 \text { ] PARAM [ } 11]:= & \backslash 5 \text { th hit } \\ \text { deltaH [ } 5] \text { PARAM [ } 12]:= & \backslash 6 \text { th hit } \\ \text { deltaH [ } 6 \text { ] PARAM [ } 13]:= & \backslash 7 \text { th hit } \\ \text { deltaH [ } 7 \text { ] PARAM [ } 14]:= & \backslash 8 \text { th hit } \\ \text { deltaH [ } 8] \text { PARAM [ } 15]:= & \backslash 9 \text { th hit }\end{array}$

NORMAL. DISPLAY

PARAM [ 1 ] 1 DO

."Enter the temperature (deg. C) for hit No " I $1+$. . \#INPUT

tTEMP [ I ] :=

CR CR

LOOP

tTEMP [ 1 ] PARAM [ 20]:= \2nd hit temperature

TTEMP [ 2 ] PARAM [ 22 ] := \3rd

tTEMP [ 3 ] PARAM [ 42$]:=\backslash 4$ th

tTEMP [ 4 ] PARAM [ 43$]:=\backslash 5$ th

tTEMP [5] PARAM [50]:= \6th

THEN

SCREEN. CLEAR

CR ." "INVERSE.ON ." Important !!!!" INVERSE.OFF

CR CR CR CR

." After you return to the main menu type $S$ to exit and enter a value for the time INTERVAL (ms between dilation-temperature data points during cooling); " CR CR ." For example: "

CR CR CR ." 300. INTERVAL := "

CR CR CR ." Then, type NAR to return to the main menu and start the test " $\mathrm{CR} C \mathrm{CR} C \mathrm{CR}$." Hit $\langle\mathrm{RET}>$ to continue............" \#INPUT

. SAVE. PARAMETERS "

: SAVE. PARAMETERS |

FILE. TEMPLATE

9 COMMENTS

REAL DIM[ 50 ] SUBFILE

REAL DIM[ 1500 ] SUBFILE

3 TIMES 
REAL DIM[ 9 ] SUBFILE

2 TIMES

END

FILENAME DEFER $>$ FILE.CREATE FILENAME DEFER $>$ FILE.OPEN

$\begin{array}{lll}\text { FILENAME } & 1 & \text { >COMMENT } \\ \text { SPECIMEN. NAME } & 2 & >\text { COMMENT } \\ \text { MATERIAL } & 3 & >\text { COMMENT } \\ \text { TREATMENT } & 4 & >\text { COMMENT } \\ \text { TEST. DATE } & 5 & >\text { COMMENT } \\ \text { OPERATOR } & 6 & \text { >COMMENT } \\ \text { TEMPERATURE } & 7 & \text { >COMMENT } \\ \text { TEST.TYPE } & 8 & >\text { COMMENT } \\ \text { RESERVED } & 9 & >\text { COMMENT }\end{array}$

1 SUBFILE PARAM ARRAY>FILE

2 SUBFILE PLOAD ARRAY>FILE

3 SUBFILE DISPL. ARRAY $>$ FILE

4 SUBFILE L ARRAY>FILE

5 SUBFILE TTEMP ARRAY>FILE

6 SUBFILE deltaH ARRAY $>$ FILE

FILE.CLOSE

;

. INITIALIZE.SYSTEM "

: INITIALIZE.SYSTEM

0 . PLOAD :=

0. DISPL. : =

0 . STRESS :=

0 . STRAIN :=

0 . SIGMA :=

0 . EPSILON $:=$

0 . EPLAST :=

0 . VOLTOUT $:=$

0 . TIMEI :=

0 . $\mathrm{AA}:=$

0 . $\operatorname{STN}:=$

0 . $\operatorname{STS}:=$

DT2820 DtoA D/A. INIT 2048. D/A.OUT 
: CHECK.TEMP ।

NORMAL. DISPLAY

CR CR CR CR CR

INVERSE. ON

. Waiting for the correct test temperature ! " INVERSE.OFF

\section{BEGIN}

0 . VTEMPmean $:=$

T A/D.INIT

211 DO

A/D.IN VTEMPmean + VTEMPmean :=

LOOP

VTEMPmean 20. / 2048. - 2048. / 100. * VTEMP :=

VTEMP $130.268 *-3.8403$ VTEMP $2 . * * *+0.104154$

VTEMP $3 . * * *+11.7469+$ TEMP $:=$

TEMP $\mathrm{TT}<=$

UNTIL

: READ.TEMP.AND.DILATION \Acquire dilation-temperature data during cooling

SCREEN . CLEAR

CR CR CR CR CR

INVERSE.ON

. Reading temperature and dilation data ....." INVERSE.OFF

10011 DO

$\mathrm{T} A / D . I N I T A / D$. IN TTRANS [ I ] :=

G A/D.INIT A/D. IN DTRANS [ I ] :=

INTERVAL MSEC.DELAY

LOOP

TTRANS 2048. TTRANS :=

TTRANS 2048. / TTRANS :=

TTRANS 100. * TTRANS :=

10011 DO

TTRANS [ I ] $3 . * * 0.104154 *$ TTRANS [ I ] $2 . * *-3.8403 *+$ TTRANS [ I ]

$130.268 *+11.7469+$ TTRANS [ I ] :=

LOOP 
DTRANS 2048. - 2048. / -928.8878* DTRANS :=

STACK.CLEAR

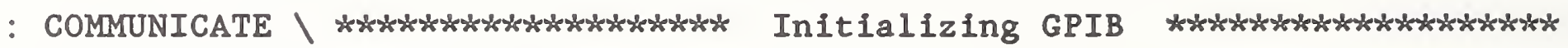
SCOPE.BACK "GPIB.BUFFER

ME TALKER SCOPE LISTENER OAH EOS.CHARACTER EOI.OFF EOS.ON

" C, 4,1,44 " GPIB.WRITE 10 ASCII" GPIB.WRITE

ME LISTENER SCOPE TALKER

BUFFER . LISTEN

;

: COMPUTER. CONTROL

ME TALKER SCOPE LISTENER OAH EOS.CHARACTER EOI.OFF EOS.ON

" Z1 " GPIB.WRITE 10 ASCII" GPIB.WRITE

ME LISTENER SCOPE TALKER

BUFFER.LISTEN

: TRIGGER.SCOPE.RIGHT

ME TALKER SCOPE LISTENER OAH EOS.CHARACTER EOI.OFF EOS.ON

" H,1,2 " GPIB.WRITE 10 ASCII" GPIB.WRITE

ME LISTENER SCOPE TALKER

BUFFER . LISTEN

;

: TRIGGER. SCOPE. LEFT

ME TALKER SCOPE LISTENER OAH EOS.CHARACTER EOI.OFF EOS.ON

" H,1,1 " GPIB.WRITE 10 ASCII" GPIB.WRITE

ME LISTENER SCOPE TALKER

BUFFER. LISTEN

;

: RECORD.SIGNAL

ME TALKER SCOPE LISTENER OAH EOS.CHARACTER EOI.OFF EOS.ON

" S, 0,0,0 " GPIB.WRITE 10 ASCII" GPIB.WRITE

ME LISTENER SCOPE TALKER

BUFFER. LISTEN

;

: CONTROL.BACK.TO.SCOPE

ME TALKER SCOPE LISTENER OAH EOS.CHARACTER EOI.OFF EOS.ON 
" ZO " GPIB.WRITE 10 ASCII" GPIB.WRITE

ME LISTENER SCOPE TALKER

BUFFER . LISTEN

;

. GET.DATA "

\Get data through A/D channel

: GET.DATA

DTOA D/A. INIT

PARAM [ 4 ] PARAM [ 21 ] / LN EPStotal :=

EPStotal PARAM [ 19 ] / TOTALtime :=

TOTALtime $5.0251 *$ DELAY :=

2011 DO

I 200. / TOTALtime * TIMEI [ I ] :=

TIMEI [ I ] PARAM [ 19 ] * 1 . * EXP $0.5 * \operatorname{PARAM}[4] * 2.5 /$

VOLTOUT [ I ] :=

LOOP

VOLTOUT VOLTOUT [ 1 ] - AA + VOLTOUT :=

VOLTOUT [ 200 ] AA :=

VOLTOUT - 1010 D/A.SCALE VOLTOUT :=

DELAY SYNC.PERIOD

SYNC . ERROR. OFF

SCOPE.BACK "GPIB.BUFFER

COMMUNICATE

COMPUTER . CONTROL

TRIGGER. SCOPE. RIGHT

100 MSEC.DELAY

2011 DO

\Operating the stroke

SYNCHRONIZE

VOLTOUT [ I ]

D/A.OUT

LOOP

RECORD.SIGNAL

CONTROL. BACK. TO . SCOPE

;

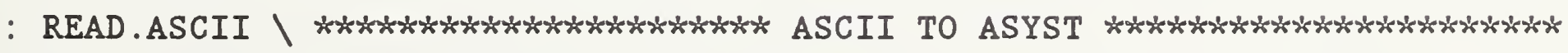

$C R$ CR CR ." Enter the name of the ASCII LOAD file....

- " "INPUT

DEFER > BASIC.OPEN 
BASIC.READ DROP

BEGIN

BASIC.READ DROP

CATENATE

?BASIC.EOF

UNTIL

BASIC.CLOSE

[]SIZE ASCDIM :=

$\operatorname{SUB}[1, \operatorname{ASCDIM}]-1$ * $*$ PLOAD SUB $[1$, ASCDIM ] :=

CR CR CR ." Enter the name of the ASCII DISPLACEMENT file .. - " "INPUT DEFER> BASIC.OPEN

BASIC.READ DROP

BEGIN

BASIC.READ DROP

CATENATE

?BASIC.EOF

UNTIL

BASIC.CLOSE

SUB [ 1, ASCDIM ] - 1 * DISPL. SUB [ $1, \operatorname{ASCDIM~]~:=~}$

CR CR CR

INVERSE.ON

. Enter V factor for the displacement starting point (on oscilloscope, negative V) "

CR CR \#INPUT

VFACTOR := INVERSE.OFF

DISPL. VFACTOR + DISPL. :=

PLOAD PARAM [ 3 ] * PLOAD :=

\Convert $\mathrm{V}$ to $\mathrm{N}$ (ewtons)

PARAM [ 7 ] $0>\mathrm{IF}$

DISPL. STRKFACTOR * DISPL. :=

\Convert V (actuator) to $\mathrm{mm}$

ELSE

DISPL. $\quad 0.1011 *$ DISPL. :=

Convert V (displacement gage) to $\mathrm{mm}$; $1 \mathrm{~V}=0.1011 \mathrm{~mm}$

THEN

PARAM [ 5 ] L [ 1 ] :=

ASCDIM $1+2$ DO

L [ 1 ] DISPL. [ I ] - L [ I ] := LOOP 
ASCDIM PARAM [ 16 ] :=

NORMAL. DISPLAY

;

." SAVE.DATA "

: SAVE.DATA

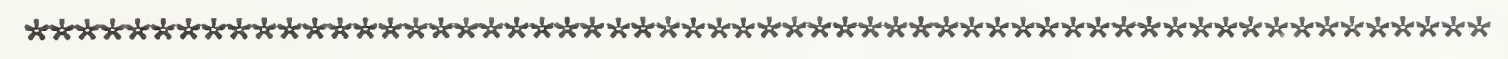

. "SAVE.DATA "

FILE. TEMPLATE

9 COMMENTS

REAL DIM[ 50 ] SUBFILE

REAL DIM[ 1500 ] SUBFILE

3 TIMES

REAL DIM[ 9 ] SUBFILE

2 TIMES

END

FILENAME DEFER $>$ FILE.CREATE FILENAME DEFER $>$ FILE.OPEN

FILENAME

$1>$ COMMENT

SPECIMEN. NAME $2>$ COMMENT

MATERIAL

$3>$ COMMENT

TREATMENT

$4>$ COMMENT

TEST.DATE

$5>$ COMMENT

OPERATOR

$6>$ COMMENT

TEMPERATURE

$7>$ COMMENT

TEST.TYPE

$8>$ COMMENT

RESERVED

$9>$ COMMENT

1 SUBFILE PARAM ARRAY $>$ FILE

2 SUBFILE PLOAD ARRAY $>$ FILE

3 SUBFILE DISPL. ARRAY $>$ FILE

4 SUBFILE L ARRAY $>$ FILE

5 SUBFILE TTEMP ARRAY $>$ FILE

6 SUBFILE deltaH ARRAY $>$ FILE

FILE. CLOSE

;

." SAVE.DATA1 "

: SAVE.DATA1

| ." SAVE.DATA1"

FILE. TEMPLATE 
9 COMMENTS

REAL DIM[ 50 ] SUBFILE

REAL DIM[ 1500 ] SUBFILE

3 TIMES

REAL DIM[ 9 ] SUBFILE

2 TIMES

END

FILENAME1 DEFER $>$ FILE.CREATE FILENAME1 DEFER $>$ FILE.OPEN

FILENAME1 1 >COMMENT

SPECIMEN.NAME $2>$ COMMENT

MATERIAL $3>$ COMMENT

TREATMENT $\quad 4$ >COMMENT

TEST.DATE $5>$ COMMENT

OPERATOR 6 >COMMENT

TEMPERATURE $7>$ COMMENT

TEST.TYPE $8>$ COMMENT

RESERVED 9 >COMMENT

1 SUBFILE PARAM ARRAY>FILE

2 SUBFILE PLOAD ARRAY $>$ FILE

3 SUBFILE DISPL. ARRAY $>$ FILE

4 SUBFILE L ARRAY $>$ FILE

5 SUBFILE TTEMP ARRAY $>$ FILE

6 SUBFILE deltaH ARRAY $>$ FILE

FILE. CLOSE

;

. "REPEATED.HITS "

: REPEATED.HITS

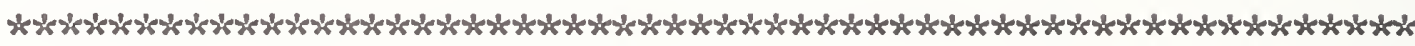

PARAM [ 18 ] TT :=

CHECK. TEMP

GET . DATA

PARAM [ 1 ] $1>$ IF

PARAM [ 1 ] 1 DO

PARAM [ 21 ] PARAM [ 4 ] :=

PARAM [ 21 ] deltaH [I ] - PARAM [ 21 ] :=

tTEMP [ I ] TT :=

CHECK. TEMP 
GET . DATA

FILENAME I "." 32 "COMPRESS "CAT FILENAME1 ":=

SAVE. DATA1

LOOP

THEN

50. MSEC.DELAY

DTOA D/A.INIT 40.96 5.* VOLTOUT [ 200 ] + D/A.OUT

" READ.FILE "

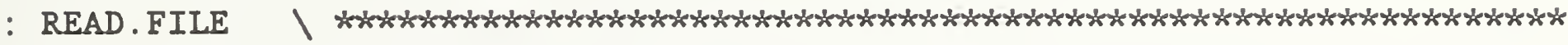

CR ." Enter name of file you want to load " "INPUT

DEFER > FILE.OPEN

1 COMMENT $>$ FILENAME $":=$

2 COMMENT $>$ SPECIMEN.NAME $":=$

3 COMMENT $>$ MATERIAL ":=

4 COMMENT $>$ TREATMENT $":=$

5 COMMENT $>$ TEST.DATE $":=$

6 COMMENT $>$ OPERATOR $":=$

7 COMMENT $>$ TEMPERATURE $":=$

8 COMMENT $>$ TEST.TYPE $":=$

9 COMMENT $>$ RESERVED $":=$

1 SUBFILE PARAM FILE $>$ ARRAY

2 SUBFILE PLOAD FILE $>$ ARRAY

3 SUBFILE DISPL. FILE>ARRAY

4 SUBFILE L FILE>ARRAY

5 SUBFILE tTEMP FILE $>$ ARRAY

6 SUBFILE deltaH FILE>ARRAY

FILE.CLOSE

DT2820 DtOA1 D/A.INIT 2048. D/A.OUT

DtoA D/A.INIT 2048. D/A.OUT

" SEE FILE "

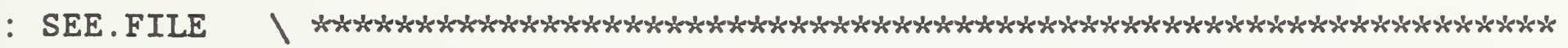

CR ." FIlename - " Filename "TyPe

CR ." SPECIMEN.NAME - " SPECIMEN. NAME "TYPE

CR ." MATERIAL - " MATERIAL "TYPE 
CR ." TREATMENT - " TREATMENT "TYPE

CR ." TEST.DATE - " TEST.DATE "TYPE

CR ." OPERATOR - " OPERATOR "TYPE

CR ." TEMPERATURE - " TEMPERATURE "TYPE

CR ." TEST.TYPE - " TEST. TYPE "TYPE

CR ." RESERVED - " RESERVED "TYPE

CR CR ." THE CURRENT VALUES ARE : I

511 DO PARAM [ I ] I

CR ."

PAUSE LOOP

CR CR ." THE DATA VALUES ARE: I

LOAD

DISPL. "

CR

15011 DO DISPL. [ I ] PLOAD [ I ] I

$\mathrm{CR}$."

PAUSE ?KEY IF KEY DROP LEAVE THEN LOOP

. DEFINE.PARAMETERS "

: DEFINE. PARAMETERS

|

$\mathrm{CR}$." Those are the names of the string parameters "

\begin{tabular}{|c|c|c|c|c|}
\hline CR & ." & SPECIM & 1EN . NAME & TEST.DATE \\
\hline CR &.$"$ & TEMPER & ATURE & OPERATOR " \\
\hline & ." & Those a & re the & meanings of the items in the PARAM array " \\
\hline & ." & PARAM & {$\left[\begin{array}{ll}1 & 1\end{array}\right]$} & - No of hits " \\
\hline CR &.$"$ & & 2 & - Tension/Compression ( $0=$ Tension ) " \\
\hline C &.$"$ & & 3 & - Load calibration factor (N per $1 \mathrm{~V}$ ) " \\
\hline &.$"$ & & 4 & - The initial height of the stroke above the lower anvil \\
\hline CR &.$"$ & & 5 & - Gage length (Lo/Ho) " \\
\hline CR &.$"$ & & 6 & - Initial area (AO) " \\
\hline CR &.$"$ & & 7 & - Actuator (param [7] =1) or Displacement Gage $(=0$ ) " \\
\hline $\mathrm{R}$ &.$"$ & & 8 & - DELTA H in hit No $2 "$ \\
\hline CR & . & & 9 & - DELTA H in hit No 3 " \\
\hline CR &.$"$ & & 10 & - DELTA $\mathrm{H}$ in hit No $4 "$ \\
\hline CR & . & & 11 & - DELTA H in hit No $5 "$ \\
\hline 8 &.$"$ & & 12 & - DELTA H in hit No $6 "$ \\
\hline CR & ." & & 13 & - DELTA H in hit No $7 "$ \\
\hline &.$"$ & & 14 & - DELTA $\mathrm{H}$ in hit No $8 "$ \\
\hline
\end{tabular}




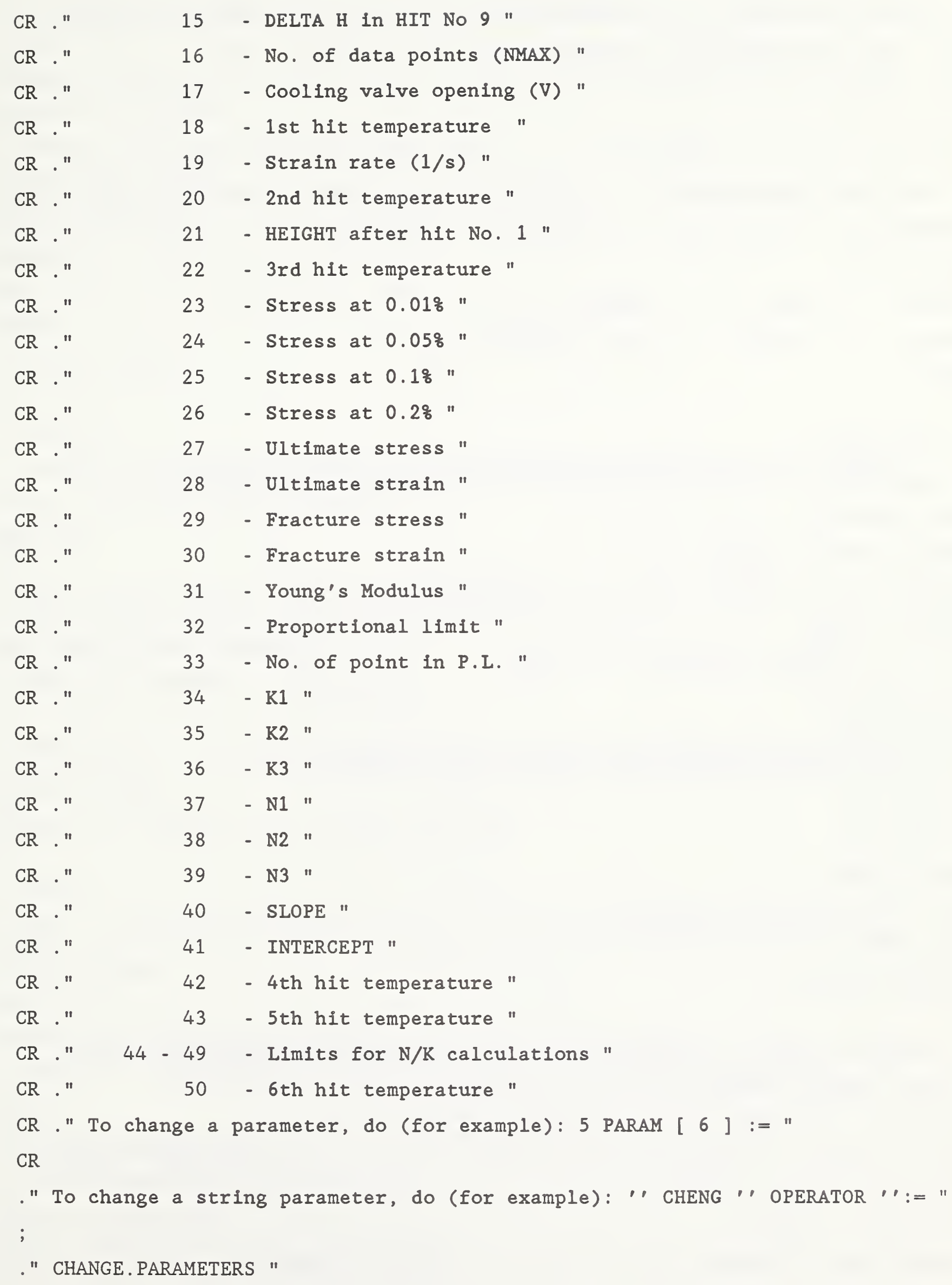


: CHANGE. PARAMETERS

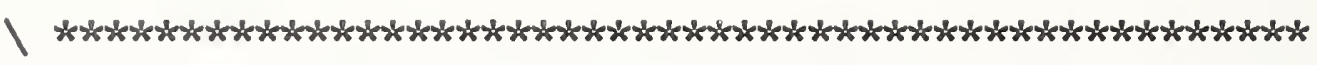

CR ." After hitting a key you will return to the system."

CR ." Change any parameters you want and type NAR to return to menu "

;

." CAlCUlate.stRess.STRAin "

: CALCULATE.STRESS.STRAIN

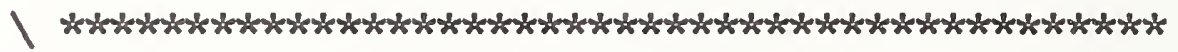
INVERSE.ON ." Please wait, I am THINKING " INVERSE.OFF

15011 DO

PLOAD [ I ] PARAM [ 6 ] / STRESS [ I ] :=

DISPL. [ I ] PARAM [ 5 ] / 100.* STRAIN [ I ] :=

LOOP

;

." SEE.CURVE "

: SEE. CURVE

|

AXIS . DEFAULTS

STRAIN SUB [ 2 , PARAM [ 16 ] 1 - ]

STRESS SUB [ 2 , PARAM [ 16 ] 1 - ] XY.AUTO.PLOT

NORMAL. COORDS

0.50 .05 POSITION " Strain, of " LABEL

90 LABEL.DIR

90 CHAR.DIR

0.0150 .3 POSITION CURSOR.OFF " Stress, Mpa " LABEL

0 LABEL.DIR

0 CHAR. DIR

WORLD . COORDS

CR ." Hit any key to continue "

KEY DROP

NORMAL. DIS PLAY

;

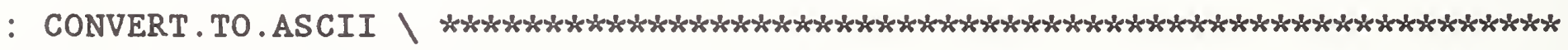
NORMAL.DISPLAY INVERSE.ON

CR CR CR ." An ASCII file named *t*k**. DAT will be created."

CR CR CR CR CR ." Hit any No key and <RET> to start data-conversion " \#INPUT INVERSE. OFF DROP

CR CR CR

STRESS SUB [ 1 , PARAM [ 16 ] $1-3 /, 3$ ] []SIZE ASCDIM1 := 
STRESS SUB [ 1 , PARAM [ 16 ] $1-3 /, 3$ ] STS SUB [ 1 , ASCDIM1 ] := STRAIN SUB [ 1 , PARAM [ 16 ] $1-3 /, 3$ ] STN SUB [ 1 , ASCDIM1 ] := SCREEN . CLEAR

CR CR CR CR CR CR

. Enter a name for the ASCII output file (8 chars.DAT)" CONSOLE.OFF "INPUT

DEFER $>$ OUT $>$ FILE

$\operatorname{ASCDIM1} 1+1$ DO

$\operatorname{STN}[\mathrm{I}] \cdot . ", " \operatorname{STS}[\mathrm{I}] \cdot \mathrm{CR}$

LOOP

OUT $>$ FILE . CLOSE

;

"GO.ON"

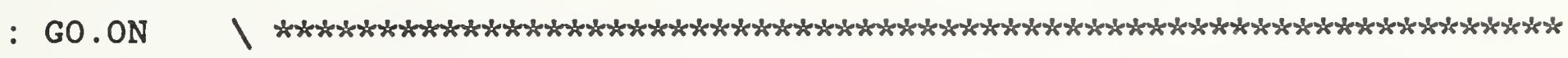
CR CR ."Hit any key to continue"

KEY DROP

;

: SEND.WAVETEK.SIGNAL \Shut-off the Induction generator

ME TALKER WAVETEK LISTENER

" P1F0.5A5D0B101C0IJ " GPIB.WRITE

;

: OPEN.VALVE

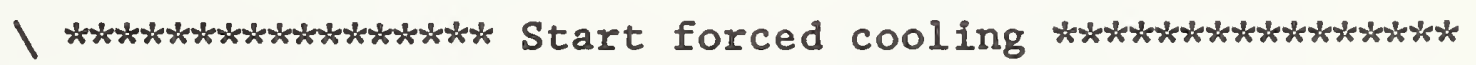

DtoA1 D/A.INIT

2048. 10. / PARAM [ 17 ] *2048. + D/A.OUT

;

. NAR "

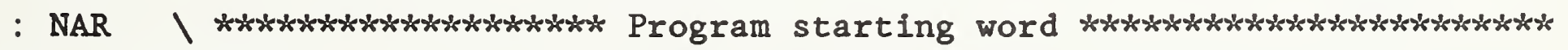
NORMAL. DIS PLAY

$15011 \mathrm{DO}$

SCREEN.CLEAR INTEN.ON INVERSE.ON

. F\&D Dv.: THERMOMECHANICAL PROCESSING GROUP-INTERACTIVE TESTING PROGRAM " CR CR

INTEN.OFF INVERSE.OFF

." Enter parameters for a new test ................HIT 1 "

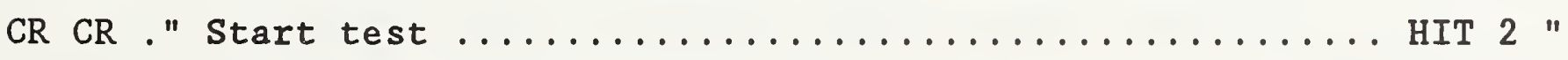

$\mathrm{CR} C \mathrm{CR}$." View s/e (engineering) curve ...............HIT 3 " 


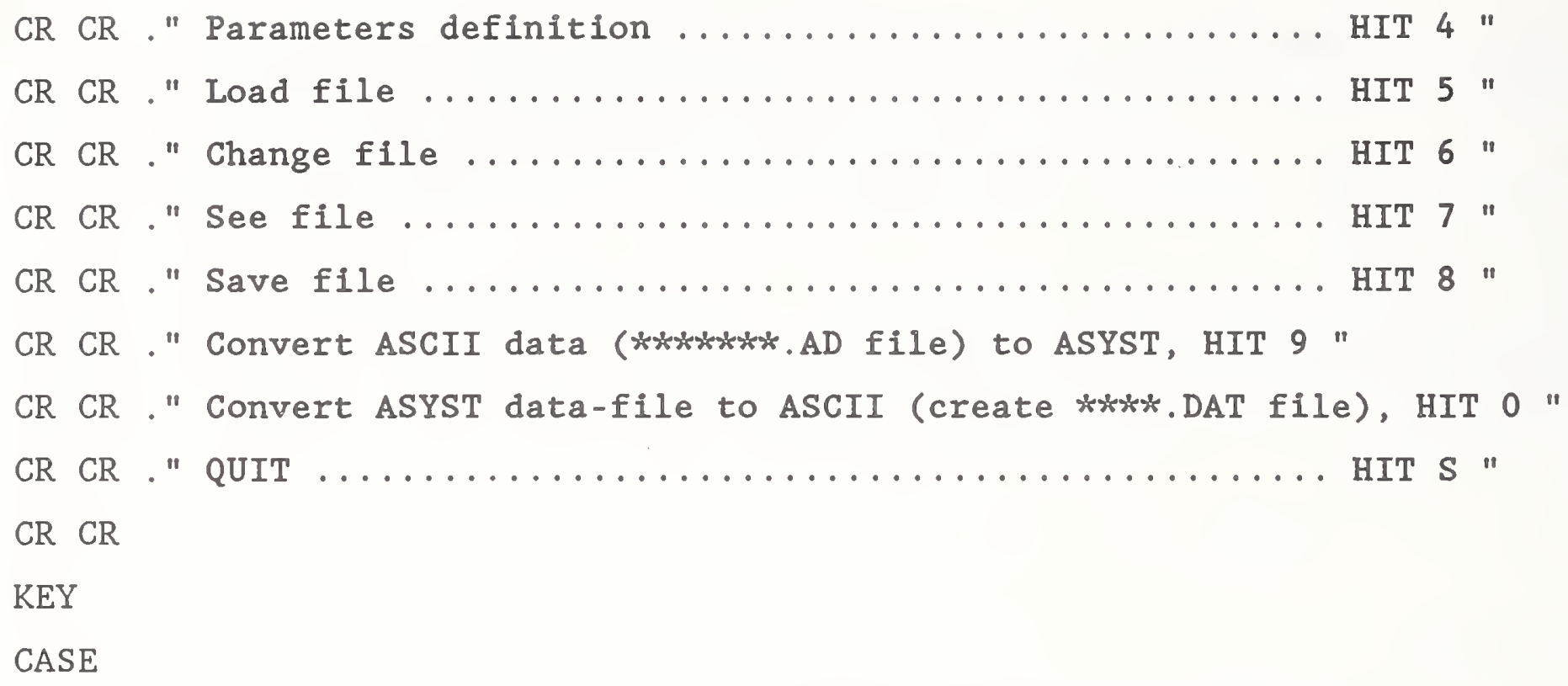


115 OF LEAVE ENDOF

NOP

ENDCASE

LOOP

; 
APPENDIX 2. Computer Program Listing for Post-Test Data Analysis 
|

1 DATA ANALYSIS AND SUMMARIZING REPORT PRODUCTION PROGRAM

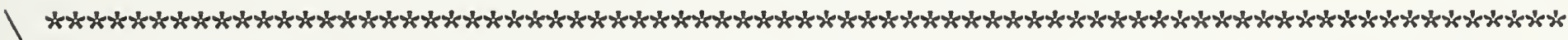

REAL SCALAR I1

SCALAR INDEX

SCALAR SLOPE

SCALAR INTERCEPT

SCALAR RIGHT

SCALAR LEFT

SCALAR LEFT1

SCALAR RANGE

SCALAR K1

SCALAR $N$

DIM[ 25,20 ] STRING.ARRAY FILENAMES

REAL DIM[ 1500 ] ARRAY E

REAL DIM[ 1500 ] ARRAY S

REAL DIM[ 1500 ] ARRAY YLEAST

REAL DIM [ 1500 ] ARRAY XLEAST

REAL DIM[ 2 ] ARRAY XYLEAST

REAL DIM[ 4 ] ARRAY CURSOR.POSITION

REAL DIM[ 25 ] ARRAY STATIS

REAL DIM[ 25 ] ARRAY STATIS1

REAL DIM[ 25 ] ARRAY MEANS

REAL DIM[ 25 ] ARRAY SDEV

REAL DIM[ 25，10 ] ARRAY TABLE4

REAL DIM[ 25，12 ] ARRAY TABLE5

0 . YLEAST $:=$

0 . XLEAST :=

0 . XYLEAST :=

0 . STATIS $:=$

0 . STATIS $1:=$

0 . MEANS $:=$

0 . SDEV $:=$

0 . TABLE4 $:=$

0 . $\mathrm{E}:=$ 
$0 . \mathrm{S}:=$

VUPORT VU1

00.21 VUPORT.ORIG

10.79 VUPORT.SIZE

2002580 WINDOW VU2

. GO.ON1"

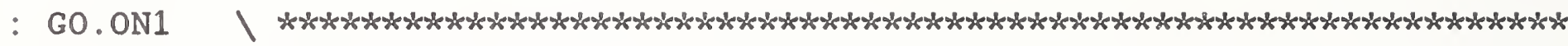
CR ." Enter 1 to continue :

BEGIN

\#INPUT 1 = IF EXIT THEN

AGAIN

. A "

: A \************** EPLAST, SIGMA, EPSILON Calculations $* * * * * * * * * * * * * * * *$ INVERSE.ON ." Please wait "INVERSE.OFF

PARAM [ 33 ] 1 DO

0 . EPLAST [ I ] :=

LOOP

PARAM [ 16 ] 1 + PARAM [ 33 ] DO

STRESS [ I ] $0 .>I F$

STRAIN [ I ] 100. / STRESS [ I ] PARAM [ 41 ] - PARAM [ 31 ] / - EPLAST [ I ] $:=$

THEN

LOOP

PARAM [ 2 ] $0>$

IF

1. EPLAST -

STRESS * SIGMA :=

PARAM [ 16 ] $1+2$ DO

$\mathrm{L}[\mathrm{I} 1$ - ] L [ I ] - L [ I ] / EPSILON [ I 1 - ] :=

LOOP

EPSILON ^SUM EPSILON :=

ELSE

1. EPLAST +

STRESS * SIGMA :=

PARAM [ 16 ] $1+2$ do 
L [ I ] L [ I 1 - ] - L [ I 1 - ] / EPSILON [ I 1 - ] := LOOP

EPSILON ^SUM EPSILON :=

THEN

;

. NKTABLE "

: NRTABLE

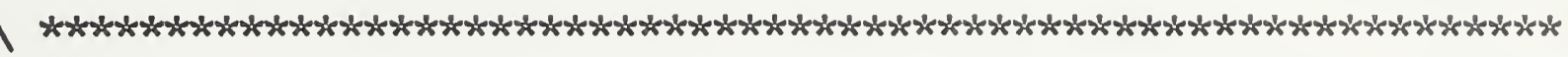
CR CR

." Specimen

N1

K1

N2

K2

N3

K3 "

CR

." name

MPA

MPA

MPA "

CR

."

CR

DUP

$1+1 \mathrm{DO}$

CR

FILENAMES "[ I ] "TYPE

123 FIX.FORMAT

TABLE5 [, 1$]$.

100 FIX. FORMAT

TABLE5 [ I , 2 ].

103 FIX.FORMAT

TABLE5 [, 3$]$.

100 FIX.FORMAT

TABLE5 [ I , ] .

103 FIX. FORMAT

TABLE5 [ I , 5].

100 FIX. FORMAT

TABLE5 [ I , 6].

LOOP

$\mathrm{CR}$

."

- 14 FIX. FORMAT

$1+1$ DO

CR 


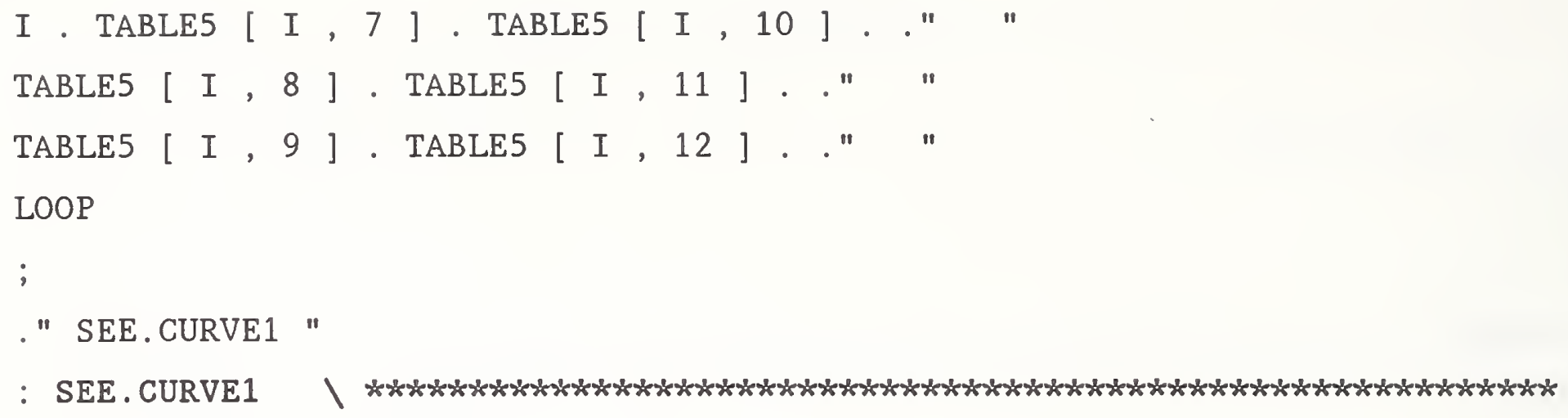


0.50 .05 POSITION "Strain, \& " LABEL

90 LABEL. DIR

90 CHAR.DIR

0.0150 .3 POSITION CURSOR.OFF " Stress, Mpa " LABEL

0 LABEL. DIR

0 CHAR. DIR

WORLD . COORDS

ARRAY.READOUT

SCREEN.CLEAR CR ." Define a line for Y.M. and "GO.ON1

READOUT . INDICES

$1+$ RIGHT :=

$1+$ LEFT : $=$

LEFT 1 = IF 2 LEF' := THEN

RIGHT LEFT - RANGE :=

XLEAST [ ] RAMP

WITHOUT.WEIGHTS

STRAIN SUB [ LEFT , RANGE ]

STRESS SUB [ LEFT, RANGE ] 1 LEASTSQ.POLY.FIT

XYLEAST :=

XYLEAST [ 1 ] SLOPE :=

SLOPE PARAM [ 40 ] :=

XYLEAST [ 2 ] INTERCEPT :=

INTERCEPT PARAM [ 41 ] :=

XLEAST XLEAST [ RIGHT ] / STRAIN [ RIGHT ] * XLEAST :=

XLEAST SLOPE * INTERCEPT + YLEAST :=

LEFT1 LEFT - RANGE :=

RANGE PARAM [ 16 ] > IF PARAM [ 16 ] LEFT - RANGE := THEN

XLEAST SUB [ LEFT, RANGE ] YLEAST SUB [ LEFT, RANGE ] XY.AUTO.PLOT

NORMAL. COORDS

0.50 .05 POSITION " Strain, के " LABEL

90 LABEL. DIR

90 CHAR. DIR

0.0150 .3 POSITION CURSOR. OFF " Stress, Mpa " LABEL

0 LABEL. DIR

0 CHAR.DIR

WORLD. COORDS 
STRAIN SUB [ LEFT, RANGE ] STRESS SUB [ LEFT, RANGE ] XY.DATA.PLOT NORMAL. COORDS

0.50 .05 POSITION " Strain, \& " LABEL

90 LABEL. DIR

90 CHAR. DIR

0.0150 .3 POSITION CURSOR.OFF " stress, Mpa " LABEL

0 LABEL. DIR

0 CHAR.DIR

WORLD . COORDS

SLOPE 100.* PARAM [ 31 ] :=

SCREEN. CLEAR

CR ." Y. Module $="$ PARAM [ 31 ].

$\mathrm{CR}$." Hit 1 to recalculate "

CR." Hit 2 to continue (P.L.) "

\#INPUT

$2=$ UNTIL

ARRAY.READOUT

SCREEN . CLEAR

CR ." Mark P.L. with right cursor and "

GO. ON1

READOUT . INDICES

LEFT + PARAM [ 33$]:=$

LEFT + LEFT :=

STRESS [ PARAM [ 33 ] ] DUP PARAM [ 32 ] :=

CR . " P.L. = ".

$\mathrm{CR}$." Hit 1 to recalculate "

$\mathrm{CR}$." Hit 2 to continue (UTS) "

\#INPUT

$2=$ UNTIL

THEN

STRAIN SUB [ $2, \operatorname{PARAM}[16$ ] 1 - ]

STRESS SUB [ 2 , PARAM [ 16 ] 1 - ] XY.AUTO.PLOT

NORMAL. COORDS

0.50 .05 POSITION " Strain, \& " LABEL

90 LABEL. DIR

90 CHAR.DIR 
0.0150 .3 POSITION CURSOR.OFF " stress, Mpa " LABEL

0 LABEL. DIR

O CHAR. DIR

WORLD . COORDS

ARRAY.READOUT

SCREEN.CLEAR

CR ." Define a zone for UTS, use INS and "

GO. ON1

GRAPHICS . READOUT

CURSOR. POSITION

READOUT $>$ ARRAY

SCREEN. CLEAR

CR ." Type *** HOME $* * *$ and "

GO. ON1

CURSOR.POSITION [ 2 ] PARAM [ 27 ] :=

CURSOR.POSITION [ 1 ] 100 / PARAM [ 27 ] PARAM [ 41 ] -

PARAM [ 31 ] / - $100 *$ PARAM [ 28]:=

SCREEN.CLEAR

PARAM [ 27 ] CR ." Ultimate stress = " .

PARAM [ 28 ] CR ." Ultimate strain = " .

GO. ON1

STRAIN SUB [ 2 , PARAM [ 16 ] 1 - ]

STRESS SUB [ 2 , PARAM [ 16 ] 1 - ] XY.AUTO.PLOT

NORMAL. COORDS

0.50 .05 POSITION " Strain, \& " LABEL

90 LABEL. DIR

90 CHAR. DIR

0.0150 .3 POSITION CURSOR.OFF " stress, Mpa " LABEL

0 LABEL. DIR

O CHAR.DIR

WORLD . COORDS

ARRAY.READOUT

SCREEN. CLEAR

CR ." Define a zone for FRACTURE, use INS and "

GO. ON1

GRAPHICS . READOUT 
CURSOR. POSITION

READOUT $>$ ARRAY

SCREEN. CLEAR

CR ." Type *** HOME *** and "

GO. ON1

CURSOR. POSITION [ 2 ] PARAM [ 29 ] :=

CURSOR. POSITION [ 1 ] 100 / PARAM [ 29] PARAM [ 41 ] -

PARAM [ 31 ] / - $100 *$ PARAM [ 30 ] :=

SCREEN. CLEAR

PARAM [ 29 ] CR . "Fracture stress =" .

PARAM [ 30 ] CR." Fracture strain = " .

GO.ON1

NORMAL. DISPLAY PREVIOUS.WINDOW DEF. VUPORT

A

SCREEN . CLEAR

CR ." Hit 1 for $N / K$ calculations, 2 to QUIT "

\#INPUT

$1=\mathrm{IF}$

41 DO

BEGIN

GRAPHICS.DISPLAY VU1 VU2

PARAM [ 16$] 1+1$ DO

EPSILON [ I ] $0 .<=$ IF I INDEX := THEN

LOOP

PARAM [ 16 ] INDEX - 4 - 1 INDEX + DO

EPSILON [ I ] LOG E [ I ] :=

SIGMA [ I ] LOG S [ I ] :=

LOOP

E S XY.AUTO.PLOT

NORMAL. COORDS

0.50 .05 POSITION " Log true strain " LABEL

90 LABEL. DIR

90 CHAR.DIR

0.0150 .3 POSITION CURSOR.OFF " Log true stress " LABEL

0 LABEL. DIR

0 CHAR.DIR 
WORLD . COORDS

ARRAY.READOUT

SCREEN. CLEAR

." Mark an area for fitting "

GO. ON1

READOUT. INDICES

RIGHT :=

1 INDEX + RIGHT + RIGHT :=

LEFT1 :=

1 INDEX + LEFT1 + LEFT1 :=

RIGHT LEFT1 - RANGE :=

WITHOUT.WEIGHTS

EPSILON SUB [ LEFT1 , RANGE ] LOG

SIGMA SUB [ LEFT1, RANGE ] LOG 1 LEASTSQ.POLY.FIT

XYLEAST :=

XYLEAST [ 1 ] $\mathrm{N}:=$

10 XYLEAST [ 2 ] ** K1 :=

SCREEN.CLEAR . " $\mathrm{N}=" \mathrm{~N}$. ." $\mathrm{K}=" \mathrm{~K} 1$. . $\mathrm{E} 1=$ " EPSILON [ RIGHT ]

. $\mathrm{E} 2$ = " EPSILON [ LEFT1 ].

CR ." Hit 1 to save values, 2 to recalculate "

\#INPUT

1. = UNTIL

EPSILON [ LEFT1 ] PARAM [ $43 \mathrm{I}+$ ] :=

EPSILON [ RIGHT ] PARAM [ $46 \mathrm{I}+$ ] :=

K1 PARAM [ $33 \mathrm{I}+$ ] :=

$\mathrm{N}$ PARAM [ $36 \mathrm{I}+$ ] :=

CR ." Hit 3 to EXIT $N / K$ calculations "

\#INPUT

3 = IF LEAVE THEN

LOOP

THEN

VERTICAL LINEAR

HORIZONTAL LINEAR

. "SPECIAL.POINTS1"

: SPECIAL. POINTS1

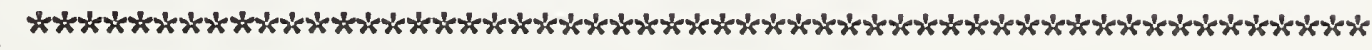


PARAM [ 16 ] $1+1$ DO DUP EPLAST [ I ] < IF LEAVE THEN I I1 := LOOP I1 PARAM [ $16]=$ IF DROP 0. THEN

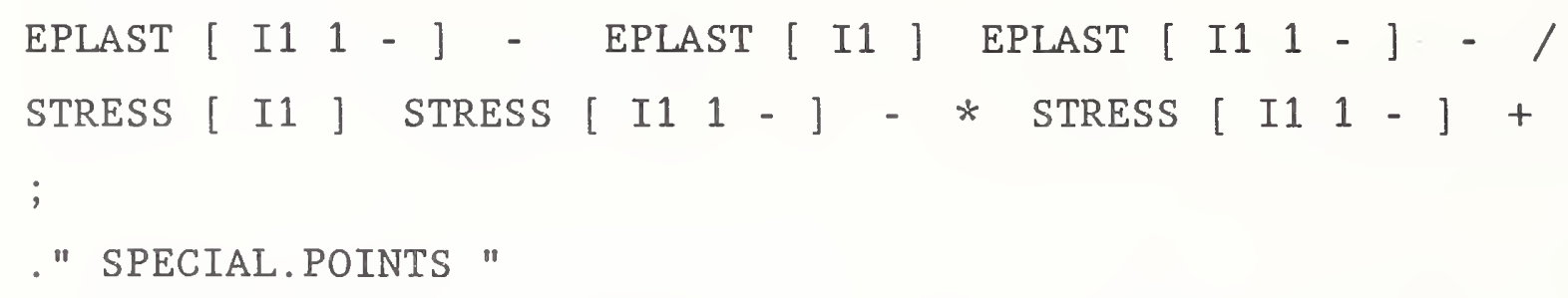

." Specimen Y. Modulus P.L. | Plastic Yield | S.U. E.U. S.F."

. E.F"

CR

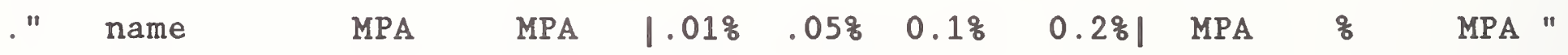

. 8 "

CR

"

" - - - "

$\mathrm{CR}$;

. TABLe2 "

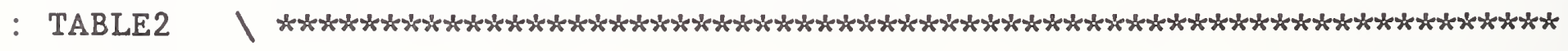
$1+1$ DO

CR

FILENAMES "[ I ] "TYPE

120 FIX. FORMAT

TABLE4 [ I 1$]$. 
60 FIX. FORMAT

TABLE4 [ I, 2].

70 FIX. FORMAT

TABLE4 [ I, 3].

60 FIX. FORMAT

TABLE4 [ I, 4].

60 FIX. FORMAT

TABLE4 [ I , 5].

70 FIX. FORMAT

TABLE4 [ I , 6] .

60 FIX. FORMAT

TABLE4 [ I , 7 ].

61 FIX. FORMAT

TABLE4 [ I , 8].

70 FIX. FORMAT

TABLE4 [ I , 9 ].

61 FIX. FORMAT

TABLE4 [ I 10].

- 14 FIX. FORMAT

LOOP

CR

. STATS "

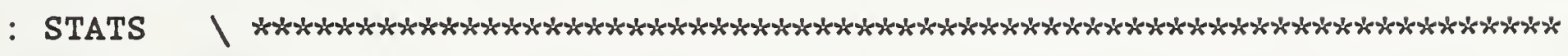
STATIS1:=

0 . INDEX :=

111 DO

STATIS1 [ I ] $0 .>$

IF INDEX $1+$ INDEX $:=\operatorname{STATIS1}[\mathrm{I}]$ STATIS [ INDEX ] := ELSE THEN LOOP ;

. TABLE3 "

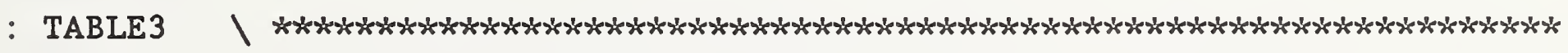

0. TABLE4:=

0. TABLE5 :=

CR ." How many specimens for table? "

\#INPUT DUP DUP 
$1+1$ DO

READ . FILE

SPECIMEN. NAME FILENAMES "[ I ] ":=

PARAM [ 31 ] TABLE4 [ I , 1 ] :=

PARAM [ 32 ] TABLE4 [ I , 2 ] :=

PARAM [ 23 ] TABLE4 [ I, 3 ] :=

PARAM [ 24 ] TABLE4 [ I , 4 ] :=

PARAM [ 25 ] TABLE4 [ I , 5 ] :=

PARAM [ 26 ] TABLE4 [ I , 6 ] :=

PARAM [ 27 ] TABLE4 [ I , 7 ] :=

PARAM [ 28 ] TABLE4 [ I, 8 ] :=

PARAM [ 29 ] TABLE4 [ I , 9]:=

PARAM [ 30 ] TABLE4 [I, 10]:=

PARAM [ 37 ] TABLE5 [ I , 1 ] :=

PARAM [ 34 ] TABLE5 [ I , 2 ] :=

PARAM [ 38 ] TABLE5 [ I , 3 ] :=

PARAM [ 35 ] TABLE5 [ I , 4 ] :=

PARAM [ 39 ] TABLE5 [ I , 5 ] :=

PARAM [ 36 ] TABLE5 [ I , 6 ] :=

PARAM [ 44 ] TABLE5 [ I , 7 ] :=

PARAM [ 45 ] TABLE5 [ I , 8] :=

PARAM [ 46 ] TABLE5 [ I , 9 ] :=

PARAM [ 47 ] TABLE5 [ I , 10] :=

PARAM [ 48 ] TABLE5 [ I , 11 ] :=

PARAM [ 49 ] TABLE5 [ I , 12] :=

LOOP

CR ." Arrange paper and hit 1 to print on printer "

\#INPUT 1 = IF OUT>PRINTER THEN

TABLE1

TABLE2

CR

."

. " . . "

111 DO

TABLE4 XSECT[ ! , I ] STATS

STATIS SUB [ 1 , INDEX ] MEAN MEANS [ I ] := 
INDEX $2<\operatorname{IF} 0 . \operatorname{SDEV}[\mathrm{I}]:=\mathrm{ELSE}$

STATIS SUB [ 1 , INDEX ] SAMPLE.VARIANCE SQRT SDEV [ I ] := THEN LOOP CR ." AVERAGE "

120 FIX. FORMAT

MEANS [ 1 ].

6 O FIX. FORMAT

MEANS [ 2 ].

70 FIX. FORMAT

MEANS [ 3 ].

60 FIX. FORMAT

MEANS [ 4 ].

60 FIX. FORMAT

MEANS [ 5 ].

70 FIX. FORMAT

MEANS [ 6 ] .

60 FIX. FORMAT

MEANS [ 7 ].

61 FIX. FORMAT

MEANS [ 8 ] .

70 FIX. FORMAT

MEANS [ 9 ] .

61 FIX. FORMAT

MEANS [ 10 ] .

CR ." S. DEV. "

120 FIX. FORMAT

SDEV [ 1 ].

71 FIX.FORMAT

SDEV [ 2 ].

$\operatorname{SDEV}[3]$ ].

61 FIX. FORMAT

SDEV [ 4 ].

SDEV [ 5 ].

71 FIX. FORMAT

$\operatorname{SDEV}[6$ ] .

61 FIX. FORMAT

SDEV [ 7 ]. 
51 FIX.FORMAT

SDEV [ 8 ] .

81 FIX. FORMAT

SDEV [ 9 ].

51 FIX. FORMAT

SDEV [ 10 ].

-14 FIX. FORMAT

CR

."

" - . - "

NKTABLE

CONSOLE

;

. " Plotter1 "

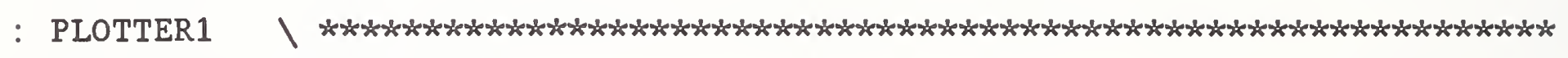
LOAD . OVERLAY HPPLOTR. SOV

HP7475

PLOTTER. DEFAULTS

710 PLOTTER.SIZE

1 COLOR

NORMAL . COORDS

30. SLANT 0.350 .99 POSITION " TMP group " LABEL 0. SLANT

0.850 .99 POSITION FILENAME LABEL

WORLD . COORDS

;

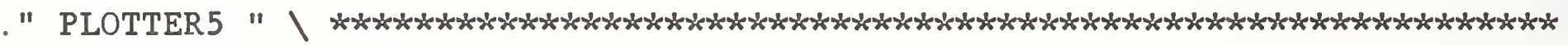

: PLOTTER5

NORMAL. COORDS

0.880 .05 POSITION " e $(\xi)$ " LABEL

0.180 .99 POSITION " S (MPA) " LABEL

WORLD. COORDS

;

. PLOTTER6 "

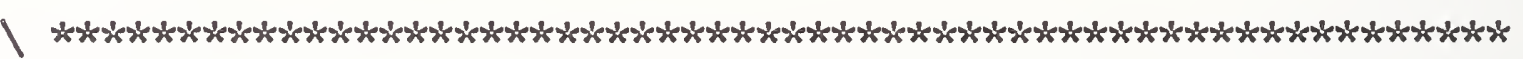

: PLOTTER6

NORMAL. COORDS

0.830 .08 POSITION " Log Epsilon " LABEL 
0.170 .99 POSITION " Log Sigma " LABEL

WORLD . COORDS

;

. PLOTTER16 "

*

: PLOTTER16

NORMAL . COORDS

0.850 .08 POSITION " Epsilon " LABEL

0.170 .99 POSITION "Sigma " LABEL

WORLD . COORDS

;

. PLOTTER2 "

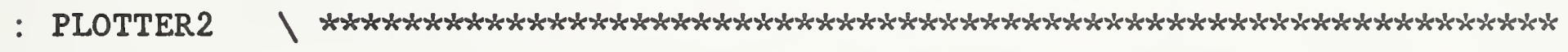
STRAIN SUB [ 2 , PARAM [ 16 ] 1 - ]

STRESS SUB [ 2 , PARAM [ 16 ] 1 - ] XY.AUTO.PLOT

;

. PLOTTER3 "

: PLOTTER 3 | STRAIN SUB [ 2, LEFT1 ] STRESS SUB [ 2, LEFT1 ] XY.AUTO.PLOT

;

. PLOTTER7 "

: PLOTTER7 | EPSILON SUB [ 1 INDEX + PARAM [ 16 ] INDEX - . 5 - ] LOG

SIGMA SUB [ 1 INDEX + PARAM [ 16 ] INDEX - 5 - ] LOG XY.AUTO.PLOT ;

. PLOTTER17"

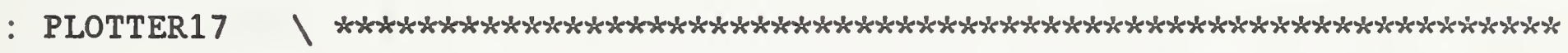
EPSILON SUB [ 1 INDEX + PARAM [ 16 ] INDEX - 5 - ]

SIGMA SUB [ 1 INDEX +, PARAM [ 16 ] INDEX - 5 - ] XY.AUTO.PLOT ;

. RETURN.PEN "

: RETURN.PEN ।

" SP; " GRAPH.COMMAND GRAPHICS.DISPLAY

;

. PLOTTER4 "

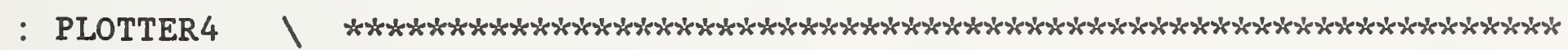

2 COLOR

0 XLEAST := 
0 YLEAST :=

XLEAST [ ]RAMP

XLEAST XLEAST [ PARAM [ 33 ] $20+$ ] / STRAIN [ PARAM [ 33 ] $20+$ ] * XLEAST := XLEAST PARAM [ 40 ] * PARAM [ 41 ] + YLEAST :=

5011 DO YLEAST [ I ] 0. > IF LEAVE THEN I INDEX := LOOP

XLEAST SUB [ INDEX, PARAM [ 33 ] INDEX - $5+$ ] YLEAST

SUB [ INDEX, PARAM [ 33 ] INDEX - $5+$ ] XY.DATA.PLOT

;

. PLOT.DATA "

: PLOT.DATA

| BEGIN

GRAPHICS . DISPLAY

VERTICAL GRID.OFF HORIZONTAL GRID.OFF

STRAIN SUB [ 2 , PARAM [ 16 ] 1 - ]

STRESS SUB [ 2 , PARAM [ 16 ] 1 - ] XY.AUTO.PLOT

NORMAL. COORDS

0.50 .05 POSITION " Strain, of " LABEL

90 LABEL. DIR

90 CHAR. DIR

0.0150 .3 POSITION CURSOR.OFF " Stress, Mpa " LABEL

0 LABEL. DIR

0 CHAR.DIR

WORLD . COORDS

SCREEN.CLEAR CR ." Hit 1 to plot on PLOTTER, 2 to continue "

\#INPUT $1=\mathrm{IF}$

PLOTTER1 PLOTTER5 PLOTTER2 PLOTTER4 RETURN.PEN

THEN

STRAIN SUB [ 2 , PARAM [ 16 ] 1 - ]

STRESS SUB [ 2 , PARAM [ 16 ] 1 - ] XY.AUTO.PLOT

NORMAL. COORDS

0.50 .05 POSITION " Strain, \& " LABEL

90 LABEL.DIR

90 CHAR. DIR

0.0150 .3 POSITION CURSOR.OFF " Stress, Mpa " LABEL

0 LABEL. DIR

0 CHAR. DIR 
WORLD . COORDS

ARRAY.READOUT

SCREEN.CLEAR CR GO.ON1

READOUT . INDICES

$1+$ RIGHT :=

$1+$ LEFT1 :=

STRAIN SUB[ 2 , LEFT1 ] STRESS SUB [ 2 , LEFT1 ] XY.AUTO.PLOT

NORMAL . COORDS

0.50 .05 POSITION "Strain, of " LABEL

90 LABEL.DIR

90 CHAR.DIR

0.0150 .3 POSITION CURSOR.OFF " Stress, Mpa " LABEL

0 LABEL.DIR

0 CHAR. DIR

WORLD . COORDS

SCREEN.CLEAR CR

"Hit 1 to plot on PLOTTER, 2 to continue "

\#INPUT 1 = IF

PLOTTER1 PLOTTER5 PLOTTER3 PLOTTER4 RETURN.PEN

THEN

SCREEN.CLEAR CR

. Hit 1 to PLOT again, 2 to STOP "

\#INPUT 2 = UNTIL

AXIS . DEFAULTS

. PLOT.DATA11"

: PLOT.DATA11

|

BEGIN

GRAPHICS . DISPLAY

VERTICAL GRID.OFF HORIZONTAL GRID.OFF

PARAM [ 16 ] $1+1$ DO

EPSILON [ I ] $0 .<=$ IF I INDEX := THEN

LOOP

PARAM [ 16 ] INDEX - 4 - 1 INDEX + DO

EPSILON [ I ] LOG E [ I ] :=

SIGMA [ I ] LOG S [ I ] := 
LOOP

E S XY.AUTO.PLOT

NORMAL . COORDS

0.50 .05 POSITION " True strain (LOG) " LABEL

90 LABEL. DIR

90 CHAR.DIR

0.0150 .3 POSITION CURSOR.OFF " True stress, Mpa (LOG) " LABEL 0 LABEL.DIR 0 CHAR.DIR

WORLD . COORDS

SCREEN.CLEAR CR ." Hit 1 to plot on PLOTTER, 2 to continue " \#INPUT $1=I F$

PLOTTER1 PLOTTER6 PLOTTER7 RETURN.PEN

THEN

SCREEN.CLEAR CR

. Hit 1 to PLOT again, 2 to STOP "

\#INPUT 2 = UNTIL

AXIS .DEFAULTS

;

. plot.data12 "

: PLOT.DATA12

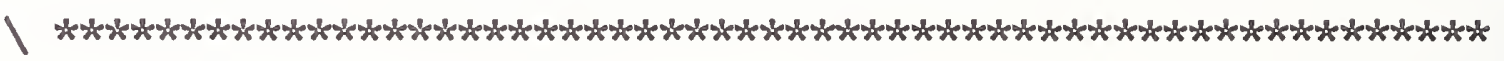
BEGIN

GRAPHICS . DISPLAY

VERTICAL GRID.OFF HORIZONTAL GRID.OFF

PARAM [ 16 ] $1+1$ DO

EPSILON [ I ] $0 .<=$ IF I INDEX := THEN

LOOP

EPSILON SUB [ 1 INDEX +, PARAM [ 16 ] INDEX - 5 - ]

SIGMA SUB [ 1 INDEX +, PARAM [ 16 ] INDEX - 5 - ] XY.AUTO.PLOT NORMAL.COORDS

0.50 .05 POSITION "True strain " LABEL

90 LABEL.DIR

90 CHAR.DIR

0.0150 .3 POSITION CURSOR.OFF " True stress, Mpa " LABEL

0 LABEL. DIR

0 CHAR. DIR

WORLD. COORDS

SCREEN.CLEAR CR ." Hit 1 to plot on PLOTTER, 2 to continue " 
\#INPUT $1=$ IF

PLOTTER1 PLOTTER16 PLOTTER17 RETURN. PEN

THEN

SCREEN.CLEAR CR

. Hit 1 to PLOT again, 2 to STOP "

\#INPUT 2 = UNTIL

AXIS.DEFAULTS

;

. PLOT.DATA1 " I

: PLOT.DAETA1

SCREEN. CLEAR

. Hit 1 to get Sigma/Epsilon plots "

\#INPUT

$1=$ IF PLOT.DATA12 THEN

. Hit 1 to get LOG Sigma / LOG Epsilon plots"

\#INPUT

$1=$ IF PLOT.DATA11 THEN

;

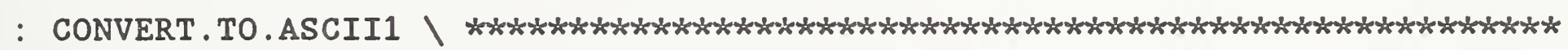
NORMAL.DISPLAY INVERSE.ON

CR CR CR ." An ASCII file named $* * * * * * \star * *$.DAT will be created. "

CR CR CR CR CR ." Hit any No key and <RET> to start data-conversion " \#INPUT INVERSE.OFF DROP

CR CR CR

SIGMA SUB[ 1 , PARAM [ 16 ] $1-3 /, 3$ ] []SIZE ASCDIM1 :=

SIGMA SUB [ 1 , PARAM [16 ] $1-3 /, 3$ ] STS SUB [ 1 , ASCDIM1 ] :=

EPSILON SUB [ 1 , PARAM [ 16 ] $1-3 /, 3$ ] STN SUB [ 1 , ASCDIM1 ] :=

SCREEN.CLEAR CR CR CR CR CR CR CR

. Enter a name for the ASCII output file ( 8 chars.DAT)"

CONSOLE.OFF

"INPUT DEFER $>$ OUT $>$ FILE

ASCDIM1 $1+1$ DO

$\operatorname{STN}[\mathrm{I}] . . ", " \operatorname{STS}[\mathrm{I}] \cdot \mathrm{CR}$

LOOP

OUT>FILE. CLOSE 
. YNG "

: YNG

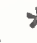

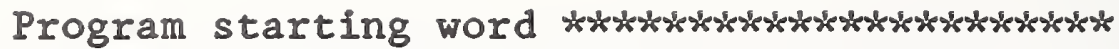

15011 DO

AXIS.DEFAULTS NORMAL.DISPLAY SCREEN.CLEAR INTEN.ON INVERSE.ON

." T-M-P Group - Interactive Analysis Program "

INTEN.OFF INVERSE.OFF

CR CR

. Analyse file (Engineering $s-e \ldots . \ldots \ldots \ldots \ldots \ldots$........... 1 "

CR CR

. Produce table.............................HIT 2 "

CR CR

. Plot data (Engineering $s-e) \ldots \ldots \ldots \ldots \ldots \ldots$............. 3 "

CR CR

." Plot data (True Sigma -Epsilon).................HIT 4 " $\mathrm{CR} \quad \mathrm{CR}$

. Acquisition (NAR) .............................. 5 "

CR CR

. Convert ASYST data file to ASCII (create *******. DAT)HIT 0 " CR CR

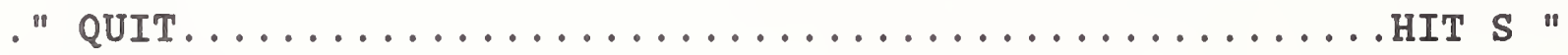

CR CR KEY

CASE

49 OF READ.FILE CALCULATE.STRESS.STRAIN SEE.CURVE1

SPECIAL.POINTS SAVE.DATA ENDOF

50 OF TABLE3 GO.ON ENDOF

51 OF READ. FILE CALCULATE.STRESS.STRAIN PLOT.DATA ENDOF

52 OF READ.FILE CALCULATE.STRESS.STRAIN A PLOT.DATA1 ENDOF

53 OF NAR ENDOF

48 OF READ. FILE CALCULATE.STRESS.STRAIN A CONVERT.TO.ASCII1

ENDOF

83 OF LEAVE ENDOF

115 OF LEAVE ENDOF

NOP

ENDCASE

LOOP

; 


\section{BIBLIOGRAPHIC DATA SHEET}

\section{PUBLICATION OR REPOAT NUMBER}

NISTIR 89-3925

2. PERFORMING ORGANIZATION REPORT NUMBER

3. PUBLICATION DATE

October 1989

ITLE AND SUBTITLE

DEVELOPMENT OF A COMPUTER-CONTROLLED HOT-DEFORMATION APPARATUS AT NIST

IUTHOR(S)

Yi-Wen Cheng, Yair Rosentha1, Harry I. McHenry

- ERFORMING ORGANIZATION (IF JOINT OR OTHER THAN NIST, SEE INSTRUCTIONS)

J.S. DEPARTMENT OF COMMERCE

IATIONAL INSTITUTE OF STANDARDS AND TECHNOLOGY

IAITHERSBUR G, MD 20899

7. CONTRACT/GRANT NUMBER

8. TYPE OF REPORT AND PERIOD COVERED

SPONSORING ORGANIZATION NAME AND COMPLETE ADDRESS (STREET, CITY, STATE, ZIP)

DOCUMENT DESCRIBES A COMPUTER PROGRAM; SF-185, FIPS SOFTWARE SUMMARY, IS ATTACHED.

ABSTRACT (A 200-WORD OR LESS FACTUAL SUMMARY OF MOST SIGNIFICANT INFORMATION. IF DOCUMENT INCLUDES A SIGNIFICANT BIBLIOGRAPHY OR ITERATURE SURVEY, MENTION IT HERE.)

his report describes a computer-controlled hot-deformation apparatus suitable for hermomechanical-processing (TMP) simulation of forging and steel plates. The apparatus as designed and built at the National Institute of Standards and Technology, and has the ollowing main features: a servohydraulic load frame with a $250 \mathrm{kN}$ capacity in tension or ompression; a variable-actuator traveling speed up to $55 \mathrm{~mm}^{-\mathrm{s}^{-1}}$; a multiple-strike apability with controllable displacements and strain rates; a maximum heating rate of $50^{\circ} \mathrm{C}-\mathrm{s}^{-1}$ with a $10 \mathrm{~kW}$ induction heater (for a cylindrical steel specimen 9 m in diameter nd $18 \mathrm{~mm}$ in height); a maximum cooling rate of $25^{\circ} \mathrm{C}-\mathrm{s}^{-1}$ with helium-gas cooling; and acuum to $1.33 \times 10^{-3} \mathrm{~Pa}\left(1 \times 10^{-5}\right.$ Torr) within 25 min. Source codes of the computer rograms that perform system control, data acquisition, and data analysis are included in his report. The apparatus has been used to perform the direct-quenching simulation of he ASTM A710 plate steel, and forging simulation of the directly cooled microalloyed ISI 1522 and 1141 steels. Results of these studies are presented.

\section{KEY WORDS (6 TO 12 ENTRIES; ALPHABETICAL ORDER; CAPITALIZE ONLY PROPER NAMES; AND SEPARATE KEY WORDS BY SEMICOLONS)}

omputer control; continuous-cooling transformation; controlled rolling; direct quenching; orging; high-strength low-alloy steels; hot-deformation apparatus; microalloyed steels; hysical simulation; thermomechanical processing. 


